University of Louisville

ThinkIR: The University of Louisville's Institutional Repository

$5-2012$

\title{
Complexities of culture : understanding the identity of female veterans transitioning from military to college.
}

Natesha L. Smith

University of Louisville

Follow this and additional works at: https://ir.library.louisville.edu/etd

\section{Recommended Citation}

Smith, Natesha L., "Complexities of culture : understanding the identity of female veterans transitioning from military to college." (2012). Electronic Theses and Dissertations. Paper 1353.

https://doi.org/10.18297/etd/1353

This Doctoral Dissertation is brought to you for free and open access by ThinkIR: The University of Louisville's Institutional Repository. It has been accepted for inclusion in Electronic Theses and Dissertations by an authorized administrator of ThinkIR: The University of Louisville's Institutional Repository. This title appears here courtesy of the author, who has retained all other copyrights. For more information, please contact thinkir@louisville.edu. 
COMPLEXITIES OF CULTURE: UNDERSTANDING THE IDENTITY OF

FEMALE VETERANS TRANSITIONING FROM MILITARY TO COLLEGE

\title{
By
}

Natesha L. Smith

B.A., University of Southern Mississippi, 2003

M.A., Asbury Theological Seminary, 2008

\author{
A Dissertation \\ Submitted to the Faculty of the \\ College of Education of the University of Louisville \\ in Partial Fulfillment of the Requirements \\ for the Degree of
}

\author{
Doctor of Philosophy \\ Department of Educational and Counseling Psychology \\ University of Louisville \\ Louisville, KY
}

May 2012 


\author{
By \\ Natesha L. Smith \\ B.A., University of Southern Mississippi, 2003 \\ M.A., Asbury Theological Seminary, 2008
}

A Dissertation Approved on

April 24, 2012

by the following Dissertation Committee

Dissertation Chair, Dr. Michael J. Cuyjet

Methodologist, Dr. Kristin Wilson

Dr. Bridgette Pregliasco

Dr. Meera Alagaraja 


\section{DEDICATION}

This book is dedicated to my family,

Mr. Lloyd C. Smith and Mrs. Lillie J. Smith (parents)

and Dr. Latonia S. Smith (sister).

Thank you for continual support and encouragement throughout this process. 


\section{ACKNOWLEDGEMENTS}

I would like to thank my mentor Dr. Kristin B. Wilson, whose encouragement helped me to find my voice as a qualitative researcher. I would also like to thank Dr. Michael J. Cuyjet for his commitment to my educational experiences; your support has allowed me an opportunity to grow into the type of practitioner-scholar I envisioned for myself. Thank you to Dr. Pregliasco and Dr. Alagaraja for their contribution to my dissertation research process.

With the financial support from the College of Education and Human Development's Research and Faculty Development Committee and the National Association of Student Personnel Administrator's Research Foundation, I was able to extend my research efforts beyond the University of Louisville community; for that, I am sincerely grateful. Many thanks to my friends and peers (Ginny, Angela, Andrea, Terri, Shawn, and Jonathan) for their encouragement throughout the dissertation journey. Most importantly, thank you to the female veterans who so willingly shared their stories with me during this process. 


\title{
ABSTRACT \\ COMPLEXITIES OF CULTURE: UNDERSTANDING THE IDENTITY OF FEMALE VETERANS TRANSITIONING FROM MILITARY TO COLLEGE
}

\author{
Natesha L. Smith
}

April 24, 2012

Through an exploration of identity and enculturation experiences, this narrative inquiry dissertation investigated how female veteran students make meaning of their experiences and renegotiate their understandings of identity after transitioning from the military into the higher education environment. Eighteen female veteran students participated in data collection efforts, which included two interviews, discussion of military artifacts, and journaling. Five of the eighteen individual narratives are presented at length in the study to illustrate the diversity found amongst the study population. Findings for the five were synthesized into individual narratives and poetic representations of identity.

Emerging across the stories of the eighteen participants are shared narratives of renegotiating identity, regaining control, social justice advocacy, and engagement. They are presented and described by using detailed excerpts from the participants' journals and interview transcripts. The discussion of renegotiated identity describes the process by which the female veteran students have started to recreate understandings of their identity after exiting from the dominant role of active duty service-member. Framing the shared 
narratives in a discussion of regaining control and social justice advocacy, provides a way to understand the need of the students to reclaim their sense of ownership over their understandings of self and continued experiences. The shared narrative of engagement explores the commitment of female veterans to higher education.

This dissertation is divided into six chapters. Chapters One and Two highlight the significance of my personal narrative to the subject of this study and situate the narratives of female veterans in current literature respectively. Chapter Three discusses the rationale for approaching the female veteran students' experiences and understandings of identity through a narrative inquiry lens; which provides an opportunity to look beyond the dominant discourse of veteran students to consider the voice of the silenced female veteran. Chapter Four focuses on the individual narratives and acknowledges the female veteran students' reflections on the perceived differences and changes to identity experienced after transitioning from military to college life. Chapter Five fully discusses the shared narratives of identity, regaining control, becoming social justice advocates, and engagement. Implications for both the military and higher education communities are discussed in Chapter Six. 


\section{TABLE OF CONTENTS}

Acknowledgements $\quad$ iv

Abstract $\quad$ v

Prologue $\quad 1$

$\begin{array}{ll}\text { Chapter One: Significance and Purpose } & 7\end{array}$

Personal Military Identity Development $\quad 7$

Personal Significance $\quad 11$

$\begin{array}{ll}\text { Scholarly Significance } & 13\end{array}$

Research Questions $\quad 15$

Definition of Terms $\quad 15$

Entering Assumption $\quad 17$

Chapter Two: Situating the Proposed Research in Current Literature 18

Encultured Lens Theory $\quad 20$

Women and Identity Development $\quad 24$

Women and Military Sociology $\quad 29$

Being Adrift and Making Sense of the Experience $\quad 35$

$\begin{array}{ll}\text { Adult Education } & 40\end{array}$

Female Veteran Student in Context: A Summary $\quad 48$

Chapter Three: Narrative Inquiry, Hearing the Storied Lives 49

Positionality $\quad 49$

Paradigm Assumptions $\quad 51$

Other Qualitative Design Considerations $\quad 53$

Moving Toward Analysis $\quad 53$

Strategies for Establishing Trustworthiness $\quad 72$

Establishing the Requirements for Poetic Representation

$\begin{array}{ll}\text { Ethical Considerations } & 76\end{array}$

$\begin{array}{ll}\text { Audience and Dissertation Format } & 77\end{array}$

Goals of the Dissertation $\quad 79$

$\begin{array}{ll}\text { Chapter Four: Identities } & 80\end{array}$

$\begin{array}{lr}\text { Tanumen } & 81\end{array}$

$\begin{array}{ll}\text { Abriana } & 101\end{array}$

$\begin{array}{ll}\text { Dasha } & 124\end{array}$

$\begin{array}{ll}\text { Alyese } & 144\end{array}$

$\begin{array}{ll}\text { Lily } & 160\end{array}$

Chapter Five: Shared Narratives and Student Engagement $\quad 181$

$\begin{array}{ll}\text { Shared Identity Dialogue } & 181\end{array}$ 
Regaining Control

Becoming Warriors of Advocacy

Engagement in Higher Education

Chapter Six: Implications and Future Research

Military Enculturation Implications

Higher Education Enculturation Implications

Recommendations for Continued Research

Epilogue

225

References

228

Appendices

248

Curriculum Vitae

262 


\section{PROLOGUE: RESEARCHING THE PERSONAL}

Portraitures are written descriptions or analyses of individuals and/or events. Also considered to be a methodology, portraitures are frequently used in qualitative studies to connect the aesthetic with social science research (Dixson, Chapman, \& Hill, 2005). Researchers using this approach draw from written (e.g. poetry), visual (e.g. photographs), and audio (e.g. music) mediums to aid in constructing the narratives of research participants (Dixson et. al, 2005; Riessman, 2008).

In the following portraitures, I share moments from my own experience of identity crisis as a way to provide context for this present study and to bring to the forefront my positionality as a female veteran in relation to my research on female veterans. By providing snapshots of my remembered experiences, I am identifying myself as narrator (i.e. researcher) and participant in the experience of transitioning from the military to college. As I interacted with the women who participated in this research project, the context of my position in the reconstruction of their individual stories became more significant. My narrative portraitures are living reflections of my continual transitions, from officer to graduate student to researcher. The following self-portraitures also serve as an illustration of how artistic forms of writing can be used in the narrative inquiry research process and how I plan to use it within my dissertation research. The three asterisks signify the end of a portraiture. 


\section{Self-Portraiture: Officer to Graduate Student}

After completing one semester of graduate work, the excitement and novelty of this experience has worn off. I casually glance around the classroom of my peers; feeling the full weight of the disconnect between myself and those around me. Although I would never admit it to anyone, I now believe that I did not make the right choice in agreeing to be discharged. Considering how my health was failing, it was easy for my commander and healthcare providers to get me to agree that signing the paperwork was in my best interest.

Somewhere in my mind, I know that I experienced negatives in the military; but I cannot seem to focus in on those at the moment. All I remember is the comfort of my uniform, a clear understanding of what was expected of me as an officer, and a true sense of who I was within the context of the military community. I was a warrior and a leader; I felt strong and capable. However, no one looks at me like that anymore. I feel invisible. It almost seems as if all of my training and experiences are hidden beneath this feminine exterior. The other students in the class only see me as a Black female. No one knows that I am a soldier, an officer. Without my uniform and rank, I feel naked and vulnerable.

In this room, my mind understands the notion of what it means to be a student again; but, I cannot reconcile that role with my identity. I feel stripped of who I had become within the Army. This new title of student leaves me feeling as if I have nothing to contribute. I knew how to blend in with the system of the military, but I am not sure of who I am supposed to be in the world of higher education. There seems to be no order to 
the system of higher education, no guiding purpose or clear expectations for the student. This feels like chaos.

The feeling of being adrift is frequently described by veterans who are transitioning out of the military (Ackerman, DiRamio, \& Garza-Mitchell, 2008; Branker, 2009; Strickley, 2009). However, unlike their male counterparts, female veterans may often find themselves redefining or reassuming a traditional female/gendered identity that aligns more closely with the expectations of the civilian world (Baechtold \& De Sawal, 2009; Herbert, 1998). Shifting from a military "masculine" identity to the role of student and civilian woman may cause great uncertainty; female veterans may be unsure of whether to redefine their identity or reassume a previous identity held before their experiences in the military.

I took comfort in the military "masculine" identity of being a soldier, an officer. There was no confusion about the expected behaviors or norms. I could easily transition between units and move up in rank and responsibilities without second guessing how I should respond. When I transitioned into the role of graduate student, I could not find a sense of cohesion or expectations. So, I chose to guard against what I perceived to be failing by focusing on my coursework and fulfilling my assignments. I ignored my questions of uncertainty and moved forward with my coursework, not attempting to connect with those around me. 


\section{Self-Portraiture: Graduate Student to Researcher}

Prior to leaving my first graduate program at Asbury Theological Seminary, I

began to make some sense of what it meant to be a student. I believed that is was about academic freedom and finding my intellectual voice. However, in deciding to pursue doctoral work, I was again thrown into what I perceived to be a chaotic system of expectations. The following self-portraiture captures my stance on transitioning from student to researcher.

I, an aspiring writer of authentic research

Feel trapped

By a rigid structure

Of traditions and academic assumptions

So...I

Choose to ground myself in

Christian, Black, veteran, heterosexual, female

Identities

I choose to live in context

To breathe in and out experiences

Of storied lives

$I$ commit $m y$ self and $m y$ research to

Moving within and beyond

Traditional academic epistemologies

$I$ commit myself and $m y$ research

To fully capturing and revealing

The living moments

Of those $I$ encounter

The organizational cultures of the military and higher education systems play an important role in the experiences of female veterans. The basic assumptions and espoused values of each culture can potentially influence how we make meaning of our experiences within each organization. Experiences of marginality within the military and higher education community share a common thread of muting the voices of women and 
positioning the experiences of men as standard (Bem, 1993; Glazer-Raymo, Townsend, \& Ropers-Huliman, 2000; Heilbrun, 1988; Herbert, 1998; Kirsch, Maor, Massey, NickosonMassey, \& Sheridan-Rabideau, 2003). The major differences between the two are the opportunities available for women to engage and interact within the system.

Because the military has adopted the masculine identity as being central to soldiering, women are "unofficially" required to take on this persona in order to be successful; no current soldiering opportunities within the military culture privilege the voices of women (Cornum, 1996; Silva, 2008; Soeters, Poponete, \& Page, 2006). Despite the shared similarity in experiences of marginality, women in higher education are sometimes presented with opportunities to push the boundaries of their marginalization. For example, they may be presented with an opportunity to engage in scholarly pursuits that privilege the voices of other women (Glazer-Raymo et al., 2000; Kirsch et al., 2003). This subtle difference between the openness in each system, may cause us, as female veterans, to experience the culture of marginality differently when transitioning between the military and college environments.

Although I knew "feminine" identity was not at the core of soldiering, I felt comfortable in the clear expectations of the military. However, as a graduate student trying to become a well grounded researcher, I was unsure of what identity was at the core of being a scholar. My questions of scholarly identity were centered around the epistemological considerations of what it means to be a researcher. This uncertainty persisted until I chose to look internally, instead of only externally, for my scholarly identity. Through this reflection, I have been able to determine for myself what it means 
"to know" and identify what constitutes "truth" within the process of research. Similarly, other female veterans transitioning from a unified organizational culture that identifies what your identity should be will have to determine for themselves what their identity will be within the higher education community.

Throughout the remainder of my dissertation, I will continue to include discussions of my personal narrative as it intersects with the literature and methodology. Chapters One and Two highlight the significance of my personal narrative to the subject of this study and situate the narratives of female veterans in current literature respectively. Chapter Three discusses the rationale for approaching the female veteran students' experiences through a narrative inquiry lens. Chapter Four focuses on the individual narratives and acknowledges the female veteran students' reflections on their perceived changes to identity. Chapter Five fully discusses the shared themes that emerged after a complete analysis of each participant's narrative. Implications for both the military and higher education communities are discussed in Chapter Six. I conclude with an epilogue discussing my final impressions of this study. 


\section{CHAPTER ONE: SIGNIFICANCE AND PURPOSE}

In choosing to conduct a study that explores the female veterans' experiences of transition from military to college, I am actively seeking to participate in their process of determining and understanding their identity. By focusing on female veterans for my research, I am placing emphasis on a student population that has been previously silenced in the literature on veteran students. Alongside student enrollment demographics that place women and nontraditional students as the largest percentage of students attending higher education institutions (Banks, 2010), is an increasing enrollment of military and veteran students (Ackerman et al., 2008; Radford, 2009). This shift in the type of student seen on college campuses reinforces the need to better understand how a detailed experience of culture, through time in service, may significantly affect the identity of female veteran students.

\section{Personal Military Identity Development}

After serving on active duty for three years, my own identity shifted when I separated from the United States Army in 2006. Until that point in my life, I had rested comfortably in my military "masculine" identity (aggressive, dominating), not bothering to grow in other identity areas (i.e. female, Black). Although my mother exposed me to the history associated with my culture as an African American, I was not overly concerned with holding on to that information. At the time, I did not feel a strong 
connection to that history. Additionally, much to my mother's dismay, I also was not interested in adopting her understanding of what it meant to be a woman; which closely aligned with traditional views (e.g. gentle, nurturing). For as much excitement as I held about joining the military, my mother held the same amount of disappointment for my decision. It was and still is her belief that women do not belong in the military. During my first semester of undergraduate study (1999) at the University of Southern Mississippi, I was actively engaged in Reserve Officer Training Corps (ROTC) activities. I participated in physical training, field training exercises, and classroom instruction that emphasized what it meant to be a soldier and leader in the Army. Although I participated in other campus activities as well, my focus from that first semester until I graduated was on my military training. Service members often joke about ROTC and "cadet land" because it is not considered a real military experience. This view is taken because ROTC battalions are made up of contracted and non-contracted cadets. Those individuals who are not under contract usually take military courses to get a better idea of what the military has to offer them. Those who are contracted cadets are held to the standards of soldiers and have already committed to serve on active duty or in the reserves/guard. As a contracted cadet, ROTC was more than an activity, it was the start of my life in the military. I wanted to absorb as much as I could during my training in order to be a better leader for the soldiers who would one day be under my charge.

Between my third and fourth year of undergraduate study (2002), I attended the summer training for cadets at Fort Lewis, Washington. That training was one of the last steps I needed to take in order to become commissioned. The amount of time and energy 
I dedicated to getting ready for National Advanced Leadership Camp (NALC) was more than I had done for anything in my life up until that point. I did not want to simply go there and do enough to meet standards, I wanted to exceed standards. I wanted to prove, to myself and my family, that I belonged in the military. Because of this mindset, I was able to finish in the top 10 percentage of cadets completing NALC for that summer rotation. After that experience, I knew I had made the right choices regarding my decision to join the Army and my willingness to accept the espoused beliefs of what makes an effective Army leader. I had done everything my cadre ever asked of me, and I was successful in my endeavors as a result.

Needless to say, ROTC came first during my undergraduate experience and even superseded the role of academics. However, academics remained important because I needed my degree in order to become a commissioned officer. No one set this priority for me. Instead, I set it based on my experience within the university community. My time in ROTC filled me with challenging and exciting opportunities that I did not find in my academic program. In addition, being a cadet meant being a part of a community that depended on me and valued me as a future leader. I was often engaged in leadership positions that required me to be responsible for the decisions of other cadets. If someone under my charge did something wrong or did not show up for training, I was held personally responsible for their actions. No classroom or campus activity could compete with that sense of duty and responsibility in my mind. On the day of my commissioning I felt humbled and honored because I knew I was joining something greater than myself, an organization for which I held high opinions. 
The important role of the military in shaping my identity only grew after my commissioning as an officer. I had sworn an oath to uphold the standards of the uniform and the words of the Constitution of the United States. My oath was something I took very seriously. I did not want to disgrace the uniform or let down my soldiers by not being a good officer. This meant adhering to protocols and not letting personal opinions and views get in the way of my duty. My focus was no longer internally placed; it was externally fixed on my unit. Although serving in the military creates many opportunities to interact with individuals from diverse backgrounds, we (soldiers) shared a clear sense of expectations resulting from standardized processes across the Army.

As indicated previously, I made no attempts to grow the other dimensions of my identity while serving in the military; my focus was outwardly placed. However, there was no awareness of this misstep until I no longer had the reinforcement of my military identity. I found myself unsure of how to transfer my military "masculine" identity into the civilian world; more specifically into the educational community I was entering, Asbury Theological Seminary (ATS). Although the "masculine" behaviors I internalized in the military are expressed in environments outside the military, they are not necessarily expressed as often by females (Baechtold \& De Sawal, 2009; Herbert, 1998); with the exception of females working in other male dominated areas (e.g. engineering, STEM disciplines) where more masculine behaviors are considered the norm and deemed acceptable (Silva, 2008).

After carefully observing the behaviors of the students in the community, I realized that my aggressive and dominant nature did not have a place at ATS. I could not 
find the "we" (i.e. a unit) to serve as an anchor for my experience. This led to my decision to keep mostly to myself. Unlike my high level of campus engagement during my undergraduate education at USM, I spent most of my time at ATS pushing to get through the program. Being separated from the culture and people of the military left me in a state of moratorium. I did not want to have the experience of college again; I wanted to get through college. It was the first time since leaving home in 1999 , that I did not have the military environment to gravitate towards.

\section{Personal Significance}

Having worked as a graduate intern and graduate assistant in the Office of Military and Veteran Student Services (OMVSS), I have had many opportunities to interact with both male and female military and veteran students. I have heard their stories and I have been privy to their thoughts about sharing these stories with nonmilitary individuals. As part of my responsibilities while working in OMVSS, I would identify students to sit on various panels across campus in order for them to share personal accounts of student life and transition. Typically, these discussions involved the students answering questions from audience members and responding to prompts given by a facilitator. The idea of getting through college and low levels of co-curricular engagement seemed to be a shared theme among most panelists. However, there were also some who identified a desire to fully immerse themselves in "the complete college experience." In addition to my personal experience and those expressed by the majority of student panelists, this sentiment of just "getting through college" has been expressed by other veterans as well (Branker, 2009; DiRamio, Ackerman, \& Mitchell, 2008). This 
shared sentiment amongst veterans led me to question what additional similarities existed between myself and other veterans in college.

The panelists who agreed to reveal their stories to individuals in the campus community also shared an opinion that people were more interested in "studying" them than in "knowing" them. The concept of procedural knowing, introduced by Belenky, Clinchy, Goldberger, and Tarule (1986) is helpful in understanding the difference between knowing and studying the veteran. There are two patterns of knowledge construction found within procedural knowing, separate and connected knowing. "Studying" the veteran is closely related to separate knowing; emphasis is placed on investigating and analyzing his/her current situation or experience. "Knowing" the veteran aligns with connected knowing and involves being aware of the veteran's experiences and the meaning attached to those experiences by developing a relationship with him/her. The distinction between studying and knowing is an important one that is an integral component of my proposed research.

In every veteran experience I have been privileged to hear, I have identified some of my own experiences in the story. However, the lack of gender diversity in the discourse surrounding veterans seemingly caused the conversation to remain centered on overall experiences, without any discussion being given to how experiences might differ between male and female veteran students. The majority of the literature looks at gender identity expression within military organizations, service member identity formation for females, the experience of sexual harassment, or the way women experience combat (Bailey, 2007; Dunivin, 2008; Hicks, 2011; Kovitz, 2000, 2003). Other research in this 
area focuses on identifying specific resources female veterans may need from the community or campus (Baechtold \& De Sawal, 2009; Baker, 2006; Business and Professional Women's Foundation, 2007; Herbert, 1998).

Although this body of research has studied the experiences of female veterans and female service members, I was unable to locate a study that looked at how the identity of female veterans is affected after they have transitioned from the military. In addition, none of the studies cited above are really conducive to a connected knowing of female veterans. Despite some of the studies being qualitative in nature, they do not present the full story of the participant, only anecdotes and related themes. My proposed research is designed "to know" the participants and recount individual stories.

My personal experience, work in OMVSS, and interactions with other female veterans shaped the focus of my research and reinforced the personal significance of this dissertation research to me. While engaging others in their varied accounts of military experience, I recognized that presenting the storied life of female veterans as anything other than "whole" would be a disservice. Simply theming the data robs the individual of their individuality and seems counterproductive to presenting a discussion of identity (Gannon, 2001; Richardson, 2002). My identity, just like the participants, is made up of multiple dimensions and I wanted my research to capture the complexity of that configuration.

\section{Scholarly Significance}

Narrative inquiry, my chosen research methodology, involves understanding experience through researcher/participant collaboration over time "in the midst of living 
and retelling the storied life" (Clandinin \& Connelly, 2000, p. 40). The process of knowing someone through narrative includes engaging in the meanings attached to the happenings in their lives and then understanding how those meanings affect other outcomes and future choices (Craig \& Huber, 2007; Polkinghorne, 2004). As someone who has chosen "to breathe in and out the experiences of storied lives," I am choosing to bind myself to the participants and their narratives. I seek to develop a relationship with each female veteran participant and give voice to her experience by moving beyond a one-sided discussion of experience and engaging in and becoming a part of her life.

The significance of this research to the academic community is situated in an intent to create a "new sense of meaning and significance with respect to the research topic [of female veterans] more than it is to yield a set of knowledge claims that might incrementally add to knowledge in the field" of higher education (Clandinin \& Connelly, 2000 , p. 42). I want the readers of my research to connect with female veterans so that they can easily "imagine their own uses and applications" (Clandinin \& Connelly, 2000, p. 42) when working with this or other similar populations of students.

In joining the ranks of scholars who have a "passion for expressing educational research through artistic lenses" (Dixson et. al, 2005. p. 17), I used a variety of communicative tools to achieve the purpose of my research (Clandinin \& Connelly, 2000; Reissman, 2002, 2008; Richardson, 1992, 1998). By incorporating poetry that I developed from the interviews and interactions with each participant and digital images of artifacts belonging to each participant, I was able to better describe and discuss the narrative exploration of female veterans' understood identity and experiences of 
enculturation. This design allowed me to participate in a connected knowing of female veterans by allowing me to enter into the experience as they were actively shaping their thoughts of identity within the stories of their life.

\section{Research Questions}

This understanding of knowing and my chosen method of narrative inquiry helped me to explore the identity and enculturation experiences of female veterans through an examination of the following questions:

1) How do female veterans describe their understood identity (e.g. gender) after separating from the military?

2) How do female veterans perceive enculturation in the military and higher education communities?

3) How do understandings of enculturation and identity affect female veterans' levels of engagement as students on college campuses?

In this process of exploration, I was able to better understand not only the individual stories of these women, but also the commonalities and differences that exist amongst their experiences. To illustrate the connection between the participants' stories and my story, I used "our," "we," and "us" when discussing the experiences of female veterans in the dissertation.

\section{Definition of Terms}

Context and definition is important to understanding the proposed research and the experiences of female veterans. In order to provide clarity, definitions used to discuss the female veterans' experiences are provided. 
- Female veterans for the context of this study are defined as women who previously served in the military during a time of war and received an honorable discharge from active duty service (U.S. Department of Veteran Affairs, 2007).

- Adult learner is used to describe a student of nontraditional status (Lundberg, 2003).

- Enculturation is defined as the process of internalizing the characteristics and norms of a culture (Bem, 1993).

- Militarization refers to the process of developing a military way of thinking (Meilinger, 2007).

- Identity in this study includes the qualities that constitute one's individuality, whether socially or personally constructed (Stets \& Burke, 2000).

- Masculine military identity refers to an immersion in the military culture, and the development of a more traditional military mind-set; a more masculine view of the military, combat, and war (Kovitz, 2003).

- Engagement is used in this study to describe the process of socially and academically integrating into the college /university community (Kuh, 2003).

- Military friendly is a designator given to institutions that have dedicated programs and services for military affiliated students (Military Friendly Schools Academic Advisory Board, 2011). 


\section{Entering Assumption}

I enter my research with the assumption that all female veterans have a shared narrative of time in service, meaning their lives and identity have been shaped in some way by their military experiences. Although I found limited documentation of this claim in the literature (Bailey, 2007), my assumption is primarily shaped by my many interactions with female veterans who are friends, who I have encountered in OMVSS, and who I have been privileged to meet at female veteran specific activities. Despite this assumption, I remained open as a researcher to those experiences that could stand in contrast to this assumption. 


\section{CHAPTER TWO: SITUATING THE PROPOSED STUDY IN RELATED RESEARCH}

A resulting tension in choosing to undertake a narrative inquiry research approach is to "straddle the line between a necessary openness to phenomena that are as-yet-unknown and theoretical sophistication that, loosely held but firmly integrated intellectually, stands in the wings to illuminate the interviewees' words, readings of the texts, and understandings of the narrative that emerged" (Josselson \& Lieblich, 2003, p. 263). In recognizing this tension, I have chosen to identify theoretical frameworks and relevant literature that enhanced the understanding of the female veterans' stories. I chose to use the theory and literature as an analytic tool to generate conversation between the lived stories of the female veterans and what is currently available in the literature. This allowed me to emphasize the voices of the participants, while also being cognizant of how their voices may align or may not align with what is known in the related academic literature.

My review of literature did not stop after the proposal defense. It was an ongoing process that continued in intensity after the collection of narratives from the female veterans. Therefore, theories and literature deemed sufficient to capture the narratives of female veterans were kept and additional literature was included to better explain other aspects of the participants' narratives. Similar to the concepts described in Knefelkamp, 
Golec, and Wells' (1985) practice-to-theory-to-practice model, I approached this study after having first reflected on my own narrative of transition from the military. From there, I began to investigate theories and literature that might provide context for my experience. Once approval was given for my proposal, I turned to the narratives of other female veterans. Analysis of those narratives determined which previously addressed areas of theory and literature were still relevant to the discussion of the female veterans' experiences.

This study is situated in five primary areas of literature: enculturation, identity development, military sociology (e.g. culture), transition and life mission, and adult education (e.g. student engagement, learning). From these five fields of study, the experience of women in the various roles associated with the transition, from military to college, began to take shape. The first area of relevant literature to be discussed is the feminist perspective of enculturation that provides a socio-historical context for understanding the experiences of female veterans. Secondly, I discussed identity development, which served to provide context for how the women created and reconstructed identity from their experiences. Thirdly, I turned to military sociology to provide a foundation of the experiences and organizational culture influencing the identity formation of women having served on active duty. Fourthly, I placed emphasis on transition and life mission theories as a framework for understanding the disorienting dilemmas and life transitions that took place in the women's lives. The final area of consideration is adult education. This area of the literature is home to the growing body of research focusing on the experiences of military and veteran students; however, the 
number of studies dedicated to the sole experience of the female military and veteran student is still marginal. Therefore, the scope was broadened to include a discussion of experiences had by adult women students in higher education.

\section{Encultured Lens Theory: A Feminist Perspective}

Although there are many schools of feminist thought, they have in common the notion of the self, as it relates to power, voice, and experience (Tisdell, 2000, 2001). Ultimately, feminism encourages women to deconstruct patriarchal narratives, in order to make sense of new ways of learning, knowing, and being within society. In using Bem's (1993) encultured lens theory, I want to emphasize the power of the military institution in informing the understood identity of female veterans; other feminist perspectives are discussed throughout the dissertation when appropriate. This theoretical lens also takes into consideration how each woman in the system internalizes and makes meaning of her experiences. Encultured lens theory analyzes the process of enculturation, selfperception, and self-construction; "how the individual who has internalized the culture's gender lenses self-constructs a gendered personality" (Bem, 1993, p. 4).

Theory components. In developing this theory, Bem (1993) expanded her original work of gender schema to include discussions of androcentrism and gender polarization. Gender schema theory is the process by which individuals become gendered or perform gender in society. Androcentrism is the practice of placing the masculine perspective at the center of one's worldview. Gender polarization sets masculinity at odds with femininity and discusses how society is organized around the distinctions between the 
two. These components overlap in varied aspects of each woman's experience and work together to produce her encultured lens.

Most of the research conducted on Bem's work is related to the development of her gender schema theory. Various aspects of the college environment have been studied to determine its influence on challenging or reinforcing the gender schemas students possess (Evans et al., 2010). In particular, academic choice and student life have shown to be the areas most affected by a student's entering schema. Research has shown that there is still a greater chance for male and female students to pursue academic disciplines that will reinforce their established gender schema (Bank \& Yelon, 2003; Coogen \& Chen, 2006). Within the area of academic choice, women are still underrepresented in the science, technology, engineering, and mathematics fields. Coincidently, men are also underrepresented in fields primarily associated with women, such as nursing and social work ( Bell-Scriber, 2008; Bryant, 2003). Research has also indicated a connection between a student's developed schema and her/his involvement on campus. Interactions with peers routinely serve to reinforce or challenge gender schemas, as well as significantly influence students' decision making while attending college (Kaufman \& Feldman, 2004).

Because individuals are socialized in certain ways around what it means to be male or female, gender is experienced through the lens of culture. The discourse model of masculinity that is prevalent in military organizations encourages female service members to exhibit characteristics that align with the dominant discourse. The institutional programming within this culture privileges the gender role socialization of 
men and not women; therefore, the implied message to women is to be more "manly" or masculine (Bailey, 2007; Baker, 2006). Bem (1993) argues that the power of these messages are so pervasive that it can be difficult to experience one's self if that self is in contrast to the dominate discourse.

Systems of influence. Encultured lens theory is concerned with the socially constructed nature of our identity around systems of power and privilege (Bem, 1993). The identity we, as female veterans, assume while in the military was not totally in our control; it was largely shaped by our contexts and experiences. As we gained experience at challenging our external shaping-forces, we began to understand how these forces have shaped our notion of self (Tisdale, 2000, 2001). While recognizing the external shaping forces, it is important to discuss the similar messages found in the higher education setting.

As discussed in Tinto's (1975) theory of integration, questions of one's commitment to various institutions and systems involves a certain level of integration into the new system. Messages about the norms and values associated with the system are communicated with an expectation of conformity and assimilation. Individuals encountering the system take in these messages and attach meanings that either serve to reinforce or challenge current understandings of self and connections to others. When encountering the military, female veterans' commitment to the system is tested by how much we are willing to internalize from the culture. In transitioning to the higher education setting, this is again tested by our willingness to adopt the values of the new system. Though Tinto (1975) and Bem (1993) discuss the process of making meaning 
from experiences in relation to others and systems, Bem's encultured lens theory provides more opportunity for choice and distancing, choice regarding whether or not to allow external messages to be internalized when entering into a new system and distancing in regards to still operating within the system, but only allowing certain aspects to shape one's view or experience.

In considering my own experiences, I realized that there was no real opportunity for me to challenge how the military was shaping my identity. I did not fully realize the magnitude of the military's influence on my understanding of self until I no longer was a part of the organization. Although my awareness of the military's influence was awakened, my perception about the organization did not change. However, my perception of who I am outside of the military is still changing. There are days when I am affirmed in my identity as scholar and believe I have found a place to exercise my voice, a place where I belong. There are also days when I see someone in uniform and feel lost or overcome with thoughts of "what am I doing in this civilian world."

Bem (1993) stated that external constructs do not merely shape us; they also affect what we see, and how we construct meaning. The encultured lens theory highlights the social and historical context of the female service member, who is immersed in military cultural practices that convey male privilege, masculinity, and male-female differences (Bailey, 2007). Through participation in the enculturation process of the military, we collaborate in the reproduction of this male dominated ideology (this is further discussed in the section on military sociology). While this collaboration may prove beneficial to our experiences within the military, the current structure of higher education permits a more 
flexible expression of identity and attempts to analyze socially reinforced gender differences (Silva, 2008). The experience of enculturation while in the higher education setting may not be as influential on the understood identity of female veterans because they are dealing with the "lost" identity and psychological transition from the military. Therefore, Bem's (1993) encultured lens theory provided an opportunity to better understand the meaning attached to the process of enculturation, within both systems, and resulting self-reconstruction.

\section{Women and Identity Development}

Arguably, the most significant aspect of a woman's identity is based on the concept of gender and gender performance (Liao \& Cai, 1995; Moradi, 2005). Yet, early social scientists only "studied the world of men, as if men constituted the whole of society. This not only rendered women invisible, but also concealed the gender characteristics of men's social locations, activities, and identities" (Jackson \& Scott, 2002, p. 1). Gender characteristics include the dynamic social relations that are institutionalized or built into all social institutions and social practices ( Bem, 1993; Jackson \& Jones, 1998; Jackson \& Scott, 2002; Lorber, 1998).

Women's Ways of Knowing (Belenky et al., 1986) built upon Perry's (1998) work with young men by drawing attention to the missing voices of women in theories of knowing and learning. The book presents a model of epistemological development by describing different views or perspectives by which women come to understand themselves as knowers and the concepts of knowledge and truth. Their work emphasizes a progression from "silence" to "voice" as women become independent, yet connected 
thinkers. Belenky et al. (1986) elaborated on Gilligan's (1982) masculine/feminine distinction in the discussion of knowing. Gilligan's (1982) work identified two moral systems found in most Western cultures, masculinity and femininity. However, despite the existence of these two systems, she argues that females have traditionally been subjected to and judged according to standards in the masculine system. Gilligan (1982) understood the masculine system to be defined through separation and the feminine system to be defined through attachment.

Other research conducted about women's ways of knowing have focused on the manner in which students make meaning of their educational experience to inform their identity (Baxter Magolda, 1990). Baxter Magolda's (1990) research on gender differences in epistemological development is based on the assumption that ways of knowing and the patterns within them are socially constructed, such as what is learned through enculturation experiences in the military or college environment. According to the theory, three questions contribute to the individual's journey toward self-authorship: 1) how do I know; 2) who am I; and 3) how do I want to construct relationships with others? Rather than working as single units, these three questions are connected by the enculturation experiences of the individual. Baxter Magolda's (1990) work placed emphasis on how individual beliefs influence the interpretation of these experiences and supports the separation and connectedness suggested by Belenky et al. (1986).

In order to understand how women create their identity, it is important to recognize the ways that women learn and the circumstances that affect their learning. Connected Knowers, as Belenky and Stanton (2000) describe them, try to understand how the other 
person feels. Therefore, it is important to understand the situation that affects women as learners, or those places (e.g. military, college campus) that organize the social norms and expectations that regulate one's identity. As individuals give meaning to particular places, those places influence and help create an identity. Because identity may be based on our experiences as female veterans and the meaning attached to those experiences, it is best understood as being realized within a particular discursive framework, which changes with our experiences of enculturation.

Martin (2000) has written about the role of higher education in contributing to women's persistent position of inequality within the academy. She noted that although knowledge and curriculum are related, some forms of knowledge are more readily reflected in the curriculum than others; theories and narratives that ignore or misrepresent women are still given easier access. Pierce (1998) argued that the predominant mode of thinking in the educational system (K-16) is a hierarchical one that tends to see differences as deficiencies. The author introduced the terms "exclusionary" and "inclusionary" to characterize masculine and feminine ways of thinking. She stated that the educational process favors the masculine or exclusionary orientation, "which is competitive, thinks in hierarchical (superior/inferior) and dichotomous (either/or) terms" (Pierce, 1998, p. 60). On the other hand, inclusionary thinking is characterized by cooperation. This type of thinking seeks a common ground and connection between ideas.

As students, women learn about the structure of the university to which they must conform. Therefore, the characteristics of the university setting have an impact on the 
type of enculturation experience we, as female veteran students, may have on campus. We are caught between trying to maintain an independent way of being (possibly learned and internalized from the military) and incorporating a relational way of being (perceived expectation from society and possibly internalized). Studies that describe this tension in other groups of women students on college campuses are mostly situated within the maledominated academic disciplines. Most of the research conducted in this area focuses on the perceptions of women in specific fields, such as engineering or technology (Blickenstaff, 2005). Unlike our counterparts, we, as female veteran students, are not breaking into a male dominated discipline. We have instead already been shaped by that experience and are now moving into another androcentric influenced culture, higher education.

The similarities between the groups, us and other female students in maledominated disciplines, comes from the initial entry or indoctrination into the maledominated fields; the point of entry for us is the military and the point of entry for other female students is selection of a major (Blickenstaff, 2005). Of the numerous reasons provided in the literature discussing the tension female students feel in certain disciplines, the most relevant is the discussion of the cultural pressure to conform to traditional gender roles (Blickenstaff, 2005; Ivie, Czujko, \& Stowe, 2002; Tai \& Sadler, 2001). As indicated through the encultured lens theory, society routinely draws distinctions between individuals by gender. Because women and men are conditioned to perform gender in certain ways, values and beliefs about one's gender are reinforced. 
Women challenging the traditional view of what it means to perform the female gender will be met with resistance (Bem, 1993; Blickenstaff, 2005). Therefore, to function in a highly male-dominated field like engineering, women will likely increase their performance of behaviors associated with being male (Ivie et al., 2002). Gilbert (2001) argued that the science disciplines silence the voices of females by prefacing the masculine perspective. Female students seeking to enter these fields are faced with a tradition of preferred qualities in scientists that favor men, such as rationality and objectivity. In opposition to these qualities are those that are more often attributed to women, emotional and subjective (Gilbert, 2001; Tai \& Sadler, 2001). This creates the perception, and arguably the reality, that to be successful is to perform the preferred qualities.

Female service member's identity development. In a study conducted with active, guard, and reserve female service members, Bailey (2007) identified five progressive stages of identity development: civilian identity, inductee identity, masculinization/militarization, synthesis, and duty identity. Progress from one stage to the next depends upon the successful incorporation of the challenges each stage may present to the female service member. During civilian identity, the women are naïve and unaware of the demands or expectations of military service; they may be unaware of the sexism and double standards associated with military life. While in inductee identity, the women begin to acknowledge personal conflict between contrasting societal and military roles. This is a period in which the service member is broken down psychologically in order to be renewed according to military ideology. Masculinization/militarization 
identity involves an immersion in the military culture, and the development of a more traditional military mind-set; a more masculine view of the military, combat, and war. Synthesis occurs when there is equilibrium among personal, civilian, feminine, and military values. Duty identity is the result of the integration between the new identity and the job as a service member; there is almost a complete loss of individuality.

Social relationships within the military are supported by internal and external factors of social control (e.g., doctrine, norms) that stabilize relationship patterns and ways of being (Siebold, 2007). Female service members moving through the five stages towards a militarized identity experience a shift from a self to a communal mindset (Meilinger, 2007; Morgan, 2003). All previous definitions of self are stripped away and replaced with a clear notion of what it means to be a military service member. Each woman reaching the third stage and above has been indoctrinated with the history, values, and expectations of the military.

\section{Women and Military Sociology}

"What is it like to be a female soldier? Well, it is making the unintelligible intelligible.

It is going where you don't belong. It is being who you are not supposed to be.

It is creating new meaning." -Manda Hicks

Hicks (2011) published an article describing the experience of female service members on active duty. The poetic representation above provides an introduction to the relationship between women and military sociology. Her prose highlights the preferred identity within the military as being "other than female." The ideas that women entering service are going "where [we] don't belong" or "being who [we] are not supposed to be" 
indicates that the military is a masculine place, where the service member identity is aligned with being male.

The promise of manhood through military service and combat remains a critical symbolic incentive (Kaplan, 2003). Therefore, female service members symbolically embody a contradiction for the individual and the military as an institution, as well as for people who think about soldiering. The military does not differ from the civilian world in its marginalization of particular groups (e.g. women), but it institutionalizes and amplifies the socially prevalent attitudes and stereotypes (Cohn, 2000; Kovitz, 2000; 2003).

For instance, the military often punishes an entire group for the under performance of an individual service member. Allowing, maintaining, and encouraging this type of group punishment fosters intolerance to differences and non-group conformity. This process may also enhance gender polarization (Bem, 1993) because individuals within the military readily draw upon stereotypes in their conceptualization and decision-making processes (Davies, 1996; Davis \& McKee, 2004; Deaux, 1995). For women specifically, military group discipline represents an organizational practice that can negatively prime the workplace, and enhance differences and stereotypes between female and male service members.

Soldiering is conceptualized ideologically as opposite to female and being feminine (Cohn, 2000; Hicks, 2011). The stereotypes of femininity are associated with mothering, weakness, passivity, and submission. In contrast, the stereotypes of masculinity are associated with physical strength, aggressiveness, and agency (Cohn, 2000; Hersh, 2003). Femininity within the military is highly feared because neither 
individual service members, nor the military, can afford to be perceived as weak by their enemies (Cohn, 2000; Kovitz, 2000; 2003). Females that exhibit the stereotypical characteristics of femininity are treated differently (shown low levels of respect) and considered inferior (incompetent) service members by their subordinates and superiors (Hersh, 2003).

I can easily remember not wanting to be thought of as too feminine (weak) by others in my unit. Although I was a woman, I was a soldier first; this was an especially important distinction to make as a commanding officer. Being an officer meant leading from the front. Therefore, I had to physically and intellectually outperform the majority of those in my unit, which primarily comprised men. Any perceived weakness would be exploited by my superiors and my subordinates. If I did not know the answer to something or at least how to get the answer, the perception of my abilities to lead was denigrated. I watched other female lieutenants deal with this very issue. I heard their soldiers speak ill of them as "women" leaders. I did not want to be thought of as a "woman" leader. I wanted to be a leader, which to me meant checking overt aspects of my femininity at the door when I put on my uniform.

Experiences of military sexual trauma. Military culture has the potential to foster an atmosphere where sexual harassment is condoned and encouraged because people tend to embellish differences between gender and exaggerate within gender similarities (Soeters et al., 2006; Van Rooy, Van Overwalle, Vanhoomissen, Labiouse, \& French, 2003). Although literature is available that discusses unwanted sexual conduct within the military (i.e. military sexual trauma), the definitions used to describe this conduct are 
diverse and include rape, sexual assault, and/or sexual harassment (Baechtold \& De Sawal, 2009). Women who experience unwanted sexual conduct often experience feelings of loneliness and isolation. As a result, these women are likely to downplay their experience or fail to report the inappropriate conduct to superiors (Van Rooy et al., 2003). These women often believe their experiences would not be understood by family and peers. Among those who experienced unwanted sexual conduct in the military, incidents of alcohol abuse, anxiety, and anger were higher than among those who did not experience any military sexual trauma (Baechtold \& De Sawal, 2009). Additionally, some who reported experiencing military sexual trauma adopted a more masculine military identity to safeguard and protect themselves from future incidents (Skinner, Kressin, Frayne, Tripp, Hankin, \& Miller, 2000).

Organizational culture. Although the same set of military rules, regulations, and practices apply to both male and female service members, the military world is organized (and experienced) as a gendered place (Gouliquer, 2011). Deal and Kennedy (2000) succinctly defined organizational culture as: a widely shared philosophy of management beliefs and practices important to those in the organization, where heroes, stories, rituals, and ceremonies become integral to the organizational climate. Within the organization, those who best embody the group's purpose and values usually attain the highest status and are most selected as comrades for group and even non-group activities (Siebold, 2007).

The social integration of service members within the larger military system (e.g., the Army) is referred to as institutional bonding. The institution provides a general sense 
of purpose and meaningfulness that is linked to the larger society and culture. This institutional level bonding sets the general conditions under which service members live and function. Service members are provided structures for pay and benefits, training progression, career patterns, and general standards of behavior. Institutional bonding occurs to the extent that there is a dependable exchange between the service members and the institution; service member effort, loyalty, and performance are traded for a sense of elevated purpose, compensation, and socially approved support for values and roles (Siebold, 2007). Women in the military respond in varying degrees to this notion of institutional bonding (Bailey, 2007). Depending on the conflict that arose in the inductee stage into the military, there may be resistance to fully internalizing military ideology. The women who fail to fully integrate into the military structure are usually washed out; they choose not to reenlist or are discharged for an inability to move up in rank (Gouliquer, 2011; Santovec, 2007).

As previously mentioned in my military identity development, my success as an ROTC cadet reinforced my view that adhering to the norms modeled and described by my cadre was in my best interest as a leader in the military. If following the norms meant success, I reasoned that any behaviors in opposition to those norms would mean failure. While on active duty, I did not witness anything to counter this view. I saw how the highest ranking officers were usually infantry soldiers; arguably the most masculine military job specialty and also an area off limits to women. I became envious of the training opportunities men received, such as Ranger or Special Forces. These were all things that were highly valued in the Army and I was uncertain of how to be my best 
without having access to these opportunities. Although I felt transformed (bonded) when I put on my uniform, more powerful and courageous because I was a soldier, I began to feel uncertain about what success looked like for female soldiers.

Militarization of women. In addressing the issue of militarization, as raised by Enloe (2000), it would be useful to present a rationale for why women choose to become and why it may be necessary for them to become militarized when joining the Armed Forces. As an undergraduate student at USM, I spent most of my time learning the military system and weaving it into the core of my identity. I was one of those cadets who willingly adopted all ideals associated with being a part of the military culture.

Considered a "tomboy" for most of my early life, I found the culture of the military to be a welcoming embrace to the parts of myself not deemed feminine enough in my social circles; I cherished the affirmation. Similar to my story, other women often join the service because it provides a challenge, gives them a greater sense of purpose, and allows them to tap into the "tomboy" side of themselves (Gouliquer, 2011).

Whether one is male or female, a primary organizational goal of the military is to create service members out of ordinary citizens. However, given the historical and contemporary reality, soldiering is symbolically synonymous with being male, and a means to confirm manhood and masculinity (Kovitz, 2003). The unconscious basic assumptions which truly define the nature of the military culture can best be characterized as being a "masculine-warrior." As an institution comprised primarily of men, its culture is shaped by men, with accompanying masculine norms, values, and lifestyles (Gouliquer, 2011). Socialization within the system reinforces the masculine 
norms and values of the underlying military culture (Dunivin, 2008). Therefore, the military typically recruits and rewards those individuals who embody or will embrace the combat, masculine-warrior ideology.

Kanter (1977) argued that women who enter male-dominated organizations are more visible to others due to their uniqueness, more likely to be viewed as different from the dominant gender group, and more likely to be stereotyped within the workplace if they choose not to conform. For those of us experiencing transition and identity reconstruction, the culture of the military has been the governing body; our experience within the system produced meanings and reinforced assumptions which enabled us to be successful during our time in service (Garrick \& Solomon, 2001). A transition from the military to college terminates that existing life structure, and creates the possibility of, or permits space for, a new understanding of self to be developed.

\section{Being Adrift and Making Sense of the Experience}

Life experienced in any organization is complex, not to mention life experienced in total institutional systems (systems that govern every aspect of your life) such as the military (Siebold, 2007). When individuals within a system encounter disorienting dilemmas, they can become confused about the appropriate way to respond or adapt to the situation (Mezirow, 2000). The movement between the military organization and the higher education organization, may serve as a disorienting dilemma for female veterans.

To understand the meaning of the transition process and transition tension female veterans may face when moving from one role (e.g. service member) to another (e.g. student), I used role-exit theory, transition theory, life mission, and life course theory. The 
female veteran participant's ability to cope with and adjust to transition depends on her perceived assets and liabilities, which can be understood through her encultured lens and an exploration of the experiences faced in her previous role of service member (Breese \& O’Toole, 1995; Schlossberg, 1981; 1995).

Role exit and transition. Ebaugh (1988) discussed the issues of creating a new role (e.g. student identity), while still adapting to an ex-role (e.g. soldier). Emphasis is placed on the processes of "becoming an ex" and the issues associated with confronting transformation to a new identity. The process of adjustment requires an exploration of the experiences and issues faced in the ex-role. Reflection is identified as aiding in the learning process and meaning making experience. It is through this process that reintegration and reorientation are believed to occur.

This manifests as we, female veterans, learn or reconstruct the new identity as a result of the transition to and within the higher education community. Cote and Levine (2000) maintained that identity problems seem to emerge when there are insufficient restraints on behavior and experience. Without adequate structure and guidance (such as what may occur during role-exiting), we may become confused or lose our sense of place in society. According to Creamer, Duggin, and Kidd (1999), entering or reentering college, as an adult woman student, often coincides with and is triggered by a personal life crisis or major life transition. When women make career transitions, identity shifts are revised or negotiated, and relational processes affect the outcome and meaning attached to the transition (Motulsky, 2005). 
The transition theory developed by Schlossberg (1981) is one way of understanding how we, as female veterans, may adapt to transition into college. The theory facilitates an understanding of adults in transition and coping strategies for better management of the transition process. Transition is understood to be any event, or non-event that results in changed relationships, routines, assumptions, and roles (Schlossberg, 1981). For us, this is the permanent movement of roles from the military into the civilian sector; a shift in a confirmed and reinforced identity into a redefining of our understood identity after roleexiting. To understand the meaning of the transition, the context, type, and impact must be analyzed through interpersonal exchanges and interactions.

Central to this theory is the influence of four factors affecting an individual's ability to cope: situation, self, support, and strategies. Situation refers to the context surrounding the identified transition. Self includes a consideration of the personal and demographic characteristics and psychological resources of the individual experiencing the transition. Support refers to the social network available to the individual and strategies is focused on the coping responses of the individual in transition. In addition to these influencing factors, the theory considers the perceived assets and liabilities as a way to explain why people experience transitions differently. An asset may be a previous experience of a similar transition, while a liability may be an inadequate support system (Schlossberg, 1981).

Charting the course. The life course theoretical orientation considers age, historical time frames, and developmental trajectories to gain insight into an individual's life (Elder, Johnson, \& Crosnoe, 2003). This theory seeks to gain insight into how 
aspects, such as individual decision-making, are influenced by the "sequence of stages or status-configurations and transitions in life which are culturally and institutionally framed from birth to death" (Heinz \& Kruger, 2001, p. 33). Typical stages or transitions include progression through systems of education/training, movement into and out of employment opportunities, and entering/exiting interpersonal relationships. When an adult woman student makes the decision to return to school, she is making a commitment to change her life to the extent that incorporating the role of being a student requires. This inclusion of the student role requires the adult woman student to learn more about herself, the other (institutional context), and new ways of relating within the system (Carrington, Scott, \& Wasserman, 2004).

To fully examine this heightened sense of understanding and relating, life mission analysis can be used to provide an understanding of the individual assumptions held about purpose and motivations for an individual's actions (Kroth \& Boverie, 2000). As female veterans begin to replace the beliefs that are no longer relevant or useful in the new role of student, they are freed from the constraints of their previous identity and the new external environment of the college community. The women are then able to choose whether or not they want to internalize the new enculturation experiences of the higher education setting.

The essence of Mezirow's (1978) disorienting dilemma and Jarvis's $(1987,1993)$ disjuncture requires individuals to unfreeze their meaning perspectives by engaging in critical reflection, and to look at the meaning of their own existence as being more than the person others have made them; they are free to then live up to their own expectations 
(Daloz, 1986; Kroth \& Boverie, 2000). Major developmental and transition theorists contend that change, points of crisis, or turning points push people towards growth (Bridges, 1980; Folkman \& Moskowitz, 2004; Hudson, 1991; Lazarus \& Folkman, 1984; Schlossberg, Goodman, \& Waters, 1995). Effectively moving through these moments is described as "letting go of aspects of the self, letting go of former roles, and learning new roles" (Goodman, Schlossberg, \& Anderson, 2006, p. 21), with emphasis placed on the response of the individual. Creamer et al. (1999) identified that women often turn to education as a way to catapult themselves forward after experiencing points of crisis or change.

Meaning making. While recognizing how disorienting dilemmas and transitions serve as a catalyst for transformative learning in the female veterans' lives, Kegan's Constructivist-Developmental theory (1994) provides additional insight into the process of meaning making. This theory consists of five orders of consciousness that evolve in complexity as the individual progresses through each order. The model is grounded in subject-object theory, where the subject constructs meaning and the object is the prior way of making meaning. The subject is able to make meaning by interacting within an environment; the pace at which individuals move through the five orders is influenced by the environment. Central to understanding Kegan's theory (1994) is the discussion of transformation, a change in the way an individual knows something. This usually occurs by engaging in critical reflection before making decisions. Although an individual's most complex stage is used more frequently, they do have an ability to utilize lower orders of consciousness to construct meaning. 
The first and second order consciousnesses are characterized by perceptions and durable categories. Kegan (1994) placed children in the first order because their reality is defined and understood by what they see. As their perceptions evolve, they move to second order. In the second level of consciousness, people are able to construct meaning around their own and others' inherent qualities. The third order, which is where most traditional-aged college students are placed, is characterized by the construction of meaning through relationships (Baxter Magolda, 1999). At this level, the subject's interests remain subordinate in favor of group cohesion. The fourth order is characterized by an ability of the subject to engage in self-authorship or more authentic expressions of identity. This individual is able to construct meaning and identity internally instead of defining self based on other's perceptions or viewpoints. The fifth order is characterized by an individual's ability to recognize the contextually (e.g. historical, cultural) constructed nature of one's own world and approach to meaning-making (Kegan, 1994).

\section{Adult Education}

When an adult learner has made the decision to attend college this is likely the culmination of much thought and deliberation. Because attending college requires time, money, access, ability, and desire, these students tend to be results-oriented and may drop out if their education does not lead to those results. One of the most defining differences between the adult learner and traditional age student is the presence of other competing life roles and the addition of work, financial, and parenting responsibilities (Kasworm, 2003; Kinzie, Hayek, Palmer, Jacob, \& Cummings, 2004; Spanard, 1990). These other 
responsibilities along with the costs (e.g. personal, financial) of attending college may be the reason behind their results-oriented approach to education.

Typically, adult learners do not live on campus. They participate more in the community than campus life, and they have stronger ties to career culture than to academic culture (Merriam, Caffarella, \& Baumgartner, 2007; Park \& Choi, 2007). Additionally, these students usually seek timely educational opportunities directly related to their perceived needs and appropriate for their career goals (Merriam et al., 2007). According to models of adult persistence, adult learners enroll in higher education institutions having already established a social network of family and friends to provide support during their educational process (Bean \& Metzner, 1985; MacKinnon-Slaney, 1994).

Finding the woman's place. Although women make up the majority of college students and adult learners, they still experience marginalization in the higher education system (Banks, 2010; Merriam \& Grace, 2011; Spencer, 2006). This is evidenced through the master-narrative of campuses that deemphasize the diverse knowledge and experiences that women learners, especially adult learners, bring to the learning environment (Hayes \& Smith, 1994; Nanton, 2009; Wolf, 2009). Unfortunately, the literature in the field of adult education is guilty of perpetuating this master-narrative by reinforcing an androcentric view of the college going experience (Bem, 1993; Hayes \& Smith, 1994; Nanton, 2009). This is evidenced in research being conducted by men, with predominately male participants, that result in the development of theories and models 
frequently used when working with both men and women (Evans, Forney, Guido, Patton, \& Renn, 2010; Glazer-Raymo et al., 2010).

The professionalization of the field of adult education has also been problematic. Women were heavily involved as educators and as learners in the days when the field of adult education was first conceived as a profession (Nanton, 2009; Thompson, 1996). As the field became more professionalized, a narrowing of what constituted significant adult education and who qualified as adult educators began to surface (Hugo, 1990). Men again were able to decide what was important in adult education; they interpreted the history of adult education and developed theories of adult persistence from a male perspective (Hugo, 1990; Merriam \& Grace, 2011; Stalker, 1996, 1998).

Models of engagement and participation. A widely held belief in the literature on student engagement, for both adult and traditional age students, is that those students who integrate into or engage with the university community are thought to have a more productive and rewarding educational experience (Astin, 1977, 1985; Kuh, 2003; Merriam et al., 2007; Pascarella \& Terenzini, 1991; Spady, 1971; Tinto, 1975; 1993). The distinction between these two broad groups rests in the type of engagement experiences described in the literature. For adult learners, the focus is on engagement in the classroom with faculty/instructors and peers. The emphasis for traditional age students is on engagement across the institution through experiences of social and academic integration. Although several studies have tried to identify factors affecting adult students' decisions to engage the college environment and persist, no consensus has been reached in the literature for which factors have definite influences on these decisions (Merriam et 
al., 2007). For my study, I have chosen to focus my discussion of adult engagement around Bean and Metzner's (1985) model of nontraditional student attrition. This model was derived, in part, from Tinto's (1975) work on student persistence and geared towards the adult learner. In particular, Bean and Metzner (1985) expanded on Tinto's understanding of how the students interaction with the institutional environment influences their decision to persist.

Tinto's $(1975 ; 1993)$ model of integration describes successful academic and social integration as being the determining factor in a student's persistence behavior. Consideration is given to the attributes, skills, abilities, commitments, and value orientations of entering students. Whereas, Bean and Metzner's (1985) model of attrition places less emphasis on the integration of the student into the system. They argue that persistence behavior is more likely determined by interactions between academic, environmental, and psychological variables.

Bean and Metzner (1985) identified four themes relevant to the adult learner population's collegial experience: a) academic performance; b) intent to leave; c) background and defining variables; and d) environmental variables. Students with poor academic performance as indicated through their GPA were identified as dropping out at higher rates. Intent to leave or commitment to the institution is affected by academic and psychological variables. Background and defining variables can include a discussion of educational goals and motivations for attending college. Environmental variables include the role of finances, hours of employment, and family responsibilities on the decision of 
adult students in the higher education setting (Bean \& Metzner, 1985; Stahl \& Pavel, 1992).

Within the model, emphasis is placed on how adult students' college experiences are affected by external environment factors. Although this model has been criticized for being difficult to assess/evaluate, the heterogenous description of the nontraditional student provides more opportunity for usage with a diverse student population (Jun, 2005). Because female veterans have not been adequately studied in the context of higher education (Baechtold \& De Sawal, 2009), I believe it is important to sensitize myself to adult persistence theories that are not too restrictive or rigidly structured; leading to emphasis being placed on this model.

The role-exiting we experience as female veterans from our identity as a service member confounds other relevant background and defining variables. Also, considerations of work and/or family responsibilities weigh heavily on our ability to engage and persist (Business and Professional Women Foundation, 2007). These variables may work in tandem with or against our academic performance and intent. Therefore, Bean and Metzner's model provided a variety of conversation points for discussing the female veterans' experiences of education.

Understanding engagement for women. The conversation of adult student persistence also involves a critical look at levels of student engagement. Lundberg (2003) identifies the importance of adult students engaging in educationally related peer discussions, regardless of the environmental context (on campus with student peers or off-campus with community peers). Their level of engagement in these discussions is 
identified as a strong predictor of learning and commitment to education. However, much of the research done on adult learners is not gender specific. The gender specific research that has been conducted indicates that life roles and commitments play a huge part in preventing adult women students from being engaged in their education (Santovec, 2007).

Coincidently, commitments such as family and work can also serve as key motivators for keeping women on the path to finishing their education (Chartrand, Camp, \& McFadden, 1992; Dill \& Henley, 1998; Sciarra \& Whitson, 2007). If adult women students do not feel support from the campus community, there is disengagement from the institution (Bradley \& Graham, 2000; Santovec, 2007). This disengagement may or may not affect their goal attainment of a higher education degree (Santovec, 2007). To further exacerbate the disconnect between adult women students and the campus community, often these students maintain a primary residence away from college or university grounds (Glazer-Raymo et al., 2010).

In both of my experiences of graduate education, first at Asbury Theological Seminary and now at the University of Louisville (UofL), I feel/felt disconnected from my peers and the institution. While attending Asbury (in Wilmore, KY), I lived in an apartment located about 20 miles away in Lexington. The physical distance of my home from the institution created a relational distance with those in the campus community. In an attempt to bridge the gap in my connection to the community, I moved closer to the campus. This shift in location did not change my perceived disconnect from the environment. Similarly, my first semester at UofL was shaped by physical distance from 
the campus; I lived in Danville KY, which translates into an hour commute to UofL's campus. However, this time, I was unconcerned about the disconnect because, while living in Danville, I was focused on an internal motivation to earn my doctorate.

Understanding engagement for veteran students. Student veterans have been identified in the research as being predominantly male and more likely than their peers to be older, enrolled part-time, first-generation students, transfer students, and distance learners (Ackerman et al., 2009; National Survey of Student Engagement, 2010; Radford, 2009; Rumann \& Hamrick, 2009). In addition, a recent report from the National Survey of Student Engagement (NSSE) (2010) indicates that veteran students were less engaged in the college community, but were still satisfied with their overall educational experiences. The 2010 NSSE report marked the first time that veteran students were specifically recognized in the engagement study.

Although information contained in this report and other research may prove to be true for both male and female veteran students, the female's voice is silenced by the description of the veteran student usually offered in the literature. Contrary to the dominance of the veteran student characteristics usually used to provide rationale for engagement activities, women in the military are less likely to be married, marry less frequently (in particular, those over the age of 25), and remain childless more frequently than similar non-veterans (Baechtold \& De Sawal, 2009; Cooney, Wechsler-Segal, Segal, \& Falk, 2003). Therefore, considerations of family and other external variables may or may not contribute to the reasoning behind the lower levels of engagement for this particular group of veteran students (i.e. female). 
Context for female veteran student engagement. In conducting a study on the college integration experiences of other female veterans, I was able to identify two shared narratives that emerged from the interviews: narrative of resistance and narrative of commitment (Author, under review). The shared narrative of resistance indicated a lack of congruence with the widely accepted notion in adult education literature (i.e. nontraditional students or adult learner) of the expectation or desire of the student to actively engage in interactions with faculty members or instructors (Lundberg, 2003; Merriam et al., 2007). However, compliance with this concept appears to be a result of necessity; a need to achieve good grades and progress through the course. Because the female veterans interviewed did not identify as students first, there was a hesitation to interact with faculty members outside of note-taking and attending class. These students were present on the campus to achieve a goal which did not always translate into building a connection with faculty and peers.

The shared narrative of commitment highlighted the impact of external variables (e.g. community involvement), outside of the institution, on the likelihood of persistence for the women interviewed. This shift in power from the institution to the external variable points toward a natural progression of the women to commit to processes that further the accomplishment of predetermined agendas. Although this is not necessarily a bad thing (degree attainment), it can be a potential problem for higher education systems that have students committed to receiving a degree, but not necessarily a degree from that institution. I was able to conclude that the female veterans participating in my study were engaged within their academic units as a way to further their personal goals. 


\section{Female Veteran Student in Context: A Summary}

Most articles related to the discussion of military and veteran students seem to follow this checklist of components to include: discussion of benefits, comparison to "older" students, discussion of deployment, etc. However, a discussion about the difference of experience within the military between male and female veterans is usually left unchecked. My goal is not to make light of these areas for discussion, but instead to emphasize the silence present in the dialogue related to the challenges faced by a particular subgroup within the greater veteran student population, female veterans. Social conditioning, biological differences, or, more likely, a complex interaction of the two are all probable explanations for the reasons that women and men do not always experience phenomena the same way. They are also probable explanations for why women do not always conceptualize knowledge and view reality in the same way (Madden, 2007). Service in the military has been an important life experience for millions of men and women (Soeters et al., 2006). However, the meaning and effect of military service for the individual service member has been highly variable. Therefore, it is important to give voice to the experiences of the female veterans.

The female veterans' experiences represent a vast array of thoughts, feelings, and activities mediated through the lenses of each individual woman's branch of service, rank, years in service, military occupation, race, class, sexual orientation, ethnicity, religion, age, physical condition, and state of mind. I was able to capture this array of experience by establishing a relationship with each of my participants and then by using every communicative tool available to share their story. 


\section{CHAPTER THREE: NARRATIVE INQUIRY, HEARING THE STORIED LIVES}

Although I am aware my approach to research and engaging others is firmly rooted in the qualitative research tradition, I was initially unsure of which design would best align with my research goals. In designing a study that explores the identity of female veterans transitioning from military to college, I wanted to embrace my scholarly identity by honoring the voices of those I encountered. Additionally, I was concerned with being able to discuss and present each female veteran's story in a way that was meaningful and accurately captured her experience. In this section, I describe my positionality and process for authentically engaging the research.

\section{Positionality}

Two years ago, I would have been ill-equipped to research this topic. At that time, I had not yet dealt with the changes in my own life regarding my transition from the military to college. To understand the significance of addressing positionality, is to recognize that I first had to find my own voice as a female veteran before I could showcase the voices of other female veterans (Piirto, 2002; Richardson, 1992). As researcher and primary research instrument, my relationship to this particular study is relevant and needs to be explored. My identity comprises multiple dimensions (Christian, female, veteran, African American, middle class, heterosexual, educated, disabled) that influence how I interact with and interpret the world around me. I do not maintain that I 
am objectively approaching my research; however, I do maintain my credibility as a researcher. By reporting my personal and professional connections with the research, I have remained transparent and underscored the authenticity of my research (Patton, 2002).

Insider/outsider perspective. My time in service and status as a female veteran is a uniting force that connected me to my participants. However, "there [were] no automatic guarantees that [I would] be accepted and that building trust [would] be easy" (Johnson-Bailey, 1999, p. 669). The insider perspective of the military culture I maintain, as a result of being female and having experienced this particular transition, did not necessarily position me at a greater advantage than that of an outsider who might be male and/or has never served in the military. The benefit of my connection was most evident in the "silent understandings, culture bound phrases that did not need interpretation, and non-verbalized answers...laced throughout the dialogue" (JohnsonBailey, 1999, p. 669). While this understanding allowed for a faster descent to intimate conversations between myself and each participant, I recognized that unlike someone with an outsider perspective, I had to be more intentional throughout the process to ask for clarification about these nuances and not let my assumptions be the driving force behind the interpretations.

Reducing the volume. Given my personal experience and passion for this research subject, I continued to maintain an awareness about my role as researcher. With this role came responsibilities to the greater academic community and to my research participants. My responsibility to the academic community is to be transparent in this 
research process. By providing enough detail about my approach and positionality, I am opening myself up to be critiqued and evaluated at each stage. My responsibility to my participants is to tell their story. Instead of my personal story being situated as the focus in the discussions of shared and individual narratives, I used anecdotes from the participants' stories to illustrate the relevant points of connection to the research questions and literature. Additionally, each individual narrative was shared with the participant to ensure that I retold the story in a way that was true to her perceived experiences. Being constantly aware of my responsibility as researcher, in addition to the strategies identified in the coming section addressing trustworthiness, decreased the presence of my voice in the telling of the participants' narratives.

\section{Paradigm Assumptions}

A basic assumption of qualitative research is that the world is understood and experienced from multiple perspectives. Exploring the subjective nature of these understandings and experiences can be done through meaningful interactions with others, thick descriptions, and a sharing of interpretations (Berger \& Luckmann, 1967; Patton, 2002). Although there are various philosophical and theoretical perspectives influencing the approaches to qualitative research, Schwandt (2000) identifies three epistemological approaches which serve as the best framework for the discussion of methods in my research: interpretivism, hermeneutics, and social constructionism.

Interpretivism is concerned with the meanings attributed to individual and other's actions; emphasis is placed on the meaningful nature of interactions with others. The underlying assumption is that reality is constructed intersubjectively through the 
meanings and understandings developed socially and experientially. Therefore, it is difficult for an individual to separate her/himself from what she/he knows (Patton, 2002; Rossman \& Rallis, 1998).

The relationship between myself and each female veteran participant is connected to how we (researcher and participant) understand the world, ourselves, and others in the world. Because my world cannot be separated from my knowledge of it, as researcher, my values are inherent in all phases of the research process. The "truth" of the research is negotiated through the interactions and dialogue with each female veteran participant.

Because theoretical perspectives "emerged from a particular context to address specific concerns," hermeneutics challenges the notion of any interpretation being "absolutely correct or true" (Patton, 2002, p. 114). This philosophy required me, as the researcher, to reveal myself in relation to my research and provide context for my chosen approaches. Emphasis is placed on interpretation, the intended communicated messages of each participant, and the historical and cultural context from which the participant's meanings are derived (Patton, 2002).

Social constructionism addresses the ability of individuals to construct and interpret reality; human perception is shaped by cultural constructs (Patton, 2002; Lincoln \& Guba, 1990). Therefore, what people perceive as real, is real in its consequences and meaning to that individual. This paradigm does not accept the notion of an objective assessment of any proposition. Emphasis is placed on the way an individual's culture shapes his/her worldview; immersion in a culture reinforces how to be more like or a part of the culture (Berger \& Luckmann, 1967). 


\section{Other Qualitative Design Considerations}

Two additional qualitative methods of inquiry, heuristic inquiry and phenomenology were considered but rejected for this study. Both types of inquiry seek to understand human experience in context-specific settings. Traditional of naturalistic inquiry methods, each inquiry type recognizes the researcher as instrument (to varying degrees), with consideration given to the value of the experiences and perspectives of the researcher (Patton, 2002).

Phenomenology was rejected because it focuses on a specific aspect of the lived experience rather than on providing a context for the participants to share their individual stories. With this study, I want to explore the female veterans' stories of identity reconstruction, not just the experience of transition. Heuristic inquiry was rejected because it situates the lived experience of the researcher at the center of the research. Although I am going though a similar experience of transition and identity reconstruction, I do not want my experience to come before that of the female veteran participants. The motivation behind my research is a desire to empower the voices of other female veterans by giving them a forum for sharing their lived stories. Therefore, narrative inquiry is a better fit for sharing a more complete picture of their experiences and for pushing to the forefront the experiences of others.

\section{Moving Toward Analysis}

Lived experiences, meaning attributes, and cultural context are the collective foundation of narratives. These stories represent the construction of self-hood and give life to the transition experiences of female veterans. Through formation of the service 
member identity and student identity, in whatever capacity, these women embody the understanding of how identity is a living organism-a continual, evolving aspect of one's self. In addition to identity, systemic and environmental influences mark the meaning of enculturation I seek to learn about during this research process.

Conceptual framework. Situating the narrative within a feminist perspective of encultured lens theory illuminated the social and structural roots of gendered experiences, while recognizing the environmental factors shaping the lives and identity of the female veterans (Bem, 1993; Reissman, 2008). In particular, this framework provided a way to connect the micro process of self-verification that occurred prior and post military service to the macro process of depersonalization that occurred while the female is serving in the military (Baechtold \& De Sawal, 2009; Stets \& Burke, 2000). Self-verification is a clearly articulated personal identity and self-focused mindset that is derived from the individual's feelings and beliefs about him/herself. Depersonalization is the adoption of a group mindset to negotiate life and is typically drawn from the norms, values, and needs of the group to which the individual belongs (Stets \& Burke, 2000).

Because encultured lens theory recognizes how androcentrism, gender schema, and gender polarization have an effect on the way each woman understands herself, this established intersection helped me to better understand how we, as female veterans, start to view ourselves after transitioning from the military. Identity and experiences of transition exist in relation to one another; the type of transition and meaning attached to the military and higher education systems affected the female veterans' abilities to move beyond their previous group based identity in the military. Situating the meaning of the 
transition experience within an encultured lens underscored the importance of the system (i.e. military or higher education) in informing the identity of the female veterans (Stets \& Burke, 2000).

Because this type of conceptual framework links two levels of analysis, structural and individual, it partners well with the research topic (i.e. female veterans) and chosen methodology (i.e. narrative inquiry). The feminist relational knowing embodied in narratives brought to light tensions found between the veteran and civilian identities further exacerbated by enculturation experiences. The encultured lens theory also provided a framework for understanding how issues of dominance and submission affect identity reconstruction (Bem, 1993; Rubin \& Rubin, 2005).

Methodology. Traditional social scientific research methods and theories have often excluded or marginalized women's experiences (Patton, 2002; Rubin \& Rubin, 2005). Therefore, my goal as a feminist inquirer is to empower the women of this study and to reconstruct how researchers have come to know women's experiences. I used narrative inquiry to capture the varied perspectives of female veterans as they reconstruct their identity. Influenced by both Reissman's and Clandinin and Connelly's view of narrative, I have come to understand narrative as "a series of stories...framed in and through interaction" (Reissman, 2002, p. 698) and the narrative inquiry process as a collaborative effort between the researcher and participant that requires the researcher to enter into the storied life of the participant (Clandinin and Connelly, 2000).

The narrative inquiry approach is frequently used in studies that focus on identity formation or reconstruction because it allows the participant to "make sense of 
themselves and the society in which they live" (Clandinin \& Connelly, 2000; Denzin \& Lincoln, 2000; Riessman, 2002, p. 705; Stryker \& Serpe, 1982). This method created an opportunity for me to enter into the experience of the female veteran participants as they were actively shaping their thoughts of identity within the story of their life. It is because of these concepts, I used this method to explore the identity and enculturation experiences of female veterans through an examination of the three research questions.

Additionally, this approach to research complements the three epistemologies described in the paradigm section and provide insight into the appropriateness of narrative inquiry for achieving the goals of this study. A social constructionism epistemology emphasizes the hold culture has on influencing the female's storied life, while a hermeneutical perspective informs narrative inquiry by emphasizing the historical and cultural context of the female veterans' experiences. At the heart of narrative inquiry is interpretivism and how $\mathrm{I}$, as the researcher, reconstructed the storied lives of the research participants.

To better understand how female veterans renegotiated their identities after transitioning from military to college, I examined their individual stories and became aware of meanings attached to their stories (Clandinin \& Connelly, 2000; Riessman, 1993). This made narrative inquiry a particularly valuable approach to understanding this student population. In addition, narrative inquiry allowed the duality of the woman's identity (i.e. veteran and student) to be present in the research by presenting a holistic view of her experience. Sharing the female veterans' stories firmly placed their voice at 
the center of the research, acknowledged their presence on campus, and affirmed the importance of their experiences (Clandinin \& Connelly, 2000; Riessman, 2008).

In its fullest sense, narrative inquiry requires going beyond the use of narrative as a rhetorical structure to an analytic examination of the underlying insights and assumptions that the story illustrates (Chase, 2005; van Manen, 2003). Narrative inquiry involves working with consciously told stories and recognizing that these rest on deeper stories of which an individual is often unaware. Participants construct stories that support an interpretation of themselves, excluding experiences and events that undermine the identities they currently claim (Chase, 2005; Craig \& Huber, 2007). Objective truth is unimportant because narrative inquiry goes beyond the specific stories to explore the assumptions inherent in the shaping of those stories and how those stories drive future decisions and actions of the individual (Clandinin \& Connelly, 2000; Huber et al., 2006). No matter how fictionalized, all stories rest on and illustrate the story structures a person holds. As such, these stories provide a window into each person's beliefs and experiences. The reconstructed story reveals "cultural and social patterns through the lens of individual experiences" (Patton, 2002, p. 115). By using this methodology and alternative formats for presenting data, I was able to show how the female veteran (i.e. participant narrative) and female veterans (i.e. shared narratives) constructed identities through experiences of enculturation. Because the narrative method and inquiry process are intertwined with the conceptual framework (i.e. encultured lens theory) and other theoretical literature, the participants storied lives of transition were clearly revealed through the interpretation and presentation of data. 
Participant selection. The primary consideration in recruiting participants was to recruit female veterans with varying military and college experiences. Therefore, I recruited participants from three military friendly public universities in proximity to military installations, with a significant number of enrolled female veterans. To identify potential participants, an announcement was sent out by student affairs staff at each institution that work directly with the female veteran student population. I initiated contact with each designated staff member and provided them with a copy of my University of Louisville's Institutional Review Board (IRB) approval letter once acceptance of my application had been granted.

An invitation letter to participate in the study was drafted and included with my IRB application packet (Appendix A). This letter outlined the requirements of participation and described the incentive available to participants ( $\$ 30$ gift card). In addition to the invitation letter, an informed consent letter was also submitted with my IRB application packet. Female veterans agreeing to participate received an electronic copy of the consent letter (Appendix B). All costs associated with my research were funded by grants received from the National Association of Student Personnel Administrator's Research Foundation grant $(\$ 6000)$ and the College of Education's Research and Faculty Development grant $(\$ 3000)$.

Sites. Originally I selected three institutions, University of Louisville, Old Dominion University, and the University of South Florida, due to the growing trend of military veterans seeking enrollment at colleges/universities close to their last duty assignment and the publicity military friendly institutions are receiving within the veteran 
community (Radford, 2009; Rumann \& Hamrick, 2009). However, the University of South Florida declined participation in the study and has been replaced by the University of Central Florida. Identification of these specific institutions involved four phases: 1) locating the states with the highest number of active military and veteran populations; 2) cross-checking the top 25 military friendly schools against the states with the largest percentage of these populations; 3 ) cross-checking the top 25 military friendly schools for their proximity to military installations; and 4) identifying the schools with the highest number of self-identified female veterans. The same selection process was applied to identifying the replacement institution, University of Central Florida.

During the initial selection process, several institutions were identified within the states having the highest percentage of military and veteran populations. To further narrow the list, the institutions were checked for their proximity to specific military installations and number of enrolled female veterans. Old Dominion was selected for its proximity to Marine and Air Force installations and female veteran enrollment of approximately 250 students. The University of Central Florida was identified for its proximity to Coast Guard and Navy duty stations and current female veteran student enrollment of 250. The University of Louisville was selected for its proximity to an Army base and current female veteran student enrollment of 200 . The large number of female veterans on each campus ensured an adequate sample of participants representative of the various branches of service and demographic diversity found within the military system.

Sample. Typically, sample size in qualitative studies is guided by the concept of saturation (Patton, 2002; Yin, 2011). Because I used thematic analysis to discuss 
recurring themes (i.e. shared narratives) from the stories of the women interviewed, I needed to have a sample size large enough for themes to naturally occur (Freeman, 2007; Patton, 2002). I chose a criterion sampling process to identify the women for this study (Patton, 2002). Four selection criteria were used: current college enrollment, a minimum completion of one year in higher education, complete separation from any form of military service (excluding Inactive Ready Reserve), and active duty service experience.

While physical separation from the military occurs within a limited period, research indicates the psychological transition can take place over an extended timeframe (Business and Professional Women Foundation, 2007; Cook \& Kim, 2009; U.S. Department of Veteran Affairs, 2007). Female veterans having completed one year of coursework will more likely be settling into their newly integrated identities and are unlikely to be as sensitive to the experience of transition (Bailey, 2007). Complete separation from the military will ensure that aspects of their identity are not being directly reinforced by the military system.

The culture of the military comprises strong values that are heavily incorporated into each veteran's experience. Part of the training for new service members involves depersonalization and de-individuation, movement from a self to a communal mindset (Morgan, 2003). Engagement in active duty service further emphasizes how service members are singularly focused on military objectives over individual objectives. Although reservists and National Guard members are initially indoctrinated into this culture, their experience of service differs because of the emphasis placed on achieving balance in competing life missions (i.e. military mindset v. self mindset) (Baker 2006; 
Bauman, 2009). Female veterans with active duty experience will have fully developed this militarized identity and will be adjusting to a shift in identity expression and cultural experiences that are not as apparent in reservists and guard members (Bailey, 2007; Meilinger, 2007).

Altogether I recruited 20 participants, with two individuals being unable to complete all requirements. Eighteen female veterans committed to journaling, shared artifacts, and completed two interviews. As the women came forward and identified their interest in participating in this study, I called and discussed with each the requirements of participation. In addition, I shared with them my experiences and journey to this subject as a dissertation topic.

Basic demographic data for each of the eighteen is included in Table 1. 


\begin{tabular}{|l|l|l|l|l|l|l|l|l|l|}
\hline Pseudonym & Age & \multicolumn{1}{|c|}{ Ethnicity } & Marital Status & Children & \multicolumn{1}{|c|}{ Branch } & $\begin{array}{c}\text { Enlisted, Officer, } \\
\text { or Warrant }\end{array}$ & $\begin{array}{l}\text { Years of } \\
\text { Service }\end{array}$ & \multicolumn{1}{|c|}{$\begin{array}{l}\text { Classification } \\
\text { Major or } \\
\text { Program }\end{array}$} \\
\hline Tanumen & 35 & Caucasian & Married & 0 & Army & Officer & 6 & $\begin{array}{l}\text { Graduate } \\
\text { Student }\end{array}$ & Nursing \\
\hline Obriana & 29 & Caucasian & Divorced & 1 & Air Force & Enlisted & 4 & $\begin{array}{l}\text { Graduate } \\
\text { Student }\end{array}$ & Social Work \\
\hline Orpah & 42 & Caucasian & Divorced & 5 & Air Force & Officer & 5 & $\begin{array}{l}\text { Graduate } \\
\text { Student }\end{array}$ & Nursing \\
\hline Lily & 24 & Caucasian & Married & 0 & Marine Corps & Enlisted & 4 & $\begin{array}{l}\text { Graduate } \\
\text { Student }\end{array}$ & Counseling \\
\hline Isabella & 25 & Caucasian & Married & 0 & Air Force & Enlisted & 3 & Junior & $\begin{array}{l}\text { Ocean and } \\
\text { Earth } \\
\text { Science }\end{array}$ \\
\hline Hermione & 35 & Caucasian & Married & 1 & Navy & Enlisted & 8 & Senior & Education \\
\hline Kate & 36 & Caucasian & Married & 0 & Air Force & Enlisted & 12 & Senior & Psychology \\
\hline Dasha & 54 & Caucasian & Married & 0 & Navy & Officer & 29 & $\begin{array}{l}\text { Graduate } \\
\text { Student }\end{array}$ & $\begin{array}{l}\text { International } \\
\text { Studies }\end{array}$ \\
\hline
\end{tabular}

Table 1.1 a Demographic Data of Participants 


\begin{tabular}{|l|l|l|l|l|l|l|l|l|l|}
\hline Pseudonym & Age & Ethnicity & Marital Status & Children & Branch & $\begin{array}{l}\text { Enlisted, Officer, } \\
\text { or Warrant }\end{array}$ & $\begin{array}{l}\text { Years of } \\
\text { Service }\end{array}$ & Classification & Major or Program \\
\hline Annie & 26 & Caucasian & Married & 0 & Navy & Enlisted & 4 & Junior & Human Services \\
\hline Penelope & 26 & Caucasian & Married & 0 & Navy & Enlisted & 5 & Junior & Dental Hygiene \\
\hline Alyese & 46 & $\begin{array}{l}\text { African } \\
\text { American }\end{array}$ & Divorced & 2 & Air Force & Enlisted & 24 & Senior & Sociology \\
\hline Jennifer & 28 & Caucasian & Single & 0 & Navy & Enlisted & 8 & Sophomore & $\begin{array}{l}\text { English } \\
\text { Linguistics }\end{array}$ \\
\hline Lala & 29 & Caucasian & Married & 2 & Navy & Enlisted & 4 & Senior & $\begin{array}{l}\text { Professional } \\
\text { Writing }\end{array}$ \\
\hline Katniss & 32 & White & Divorced & 2 & Navy & Enlisted & 7 & Junior & Psychology \\
\hline Sylvia & 29 & Hispanic & Married & 3 & Air Force & Enlisted & 6 & $\begin{array}{l}\text { Graduate } \\
\text { Student }\end{array}$ & $\begin{array}{l}\text { Applied } \\
\text { Learning and } \\
\text { Instruction }\end{array}$ \\
\hline Sophia & 42 & Black & Married & 2 & Army & Enlisted & 20 & Senior & $\begin{array}{l}\text { Workforce } \\
\text { Leadership }\end{array}$ \\
\hline
\end{tabular}

Table 1.1b Demographic Data of Participants 
Pseudonyms are used in the table to represent the female veterans and are used throughout the remainder of the study when referring to their experiences. The design of the questionnaire provided each woman with an opportunity to identify their race and ethnicity independent of a structured list, which accounts for the different responses seen in the table. I designed the questionnaire in this manner to gain additional insight into how the women see themselves.

Despite their differences, the women share a common identity of having served in the Armed Forces and all agree that their time spent in service was a pivotal point that altered or reemphasized the direction of their life. In addition, there was an unanimous response of appreciation from the women for my focus and dedication to the topic of female veterans. As I continued to hear the gratitude, I began to feel even more pressure to make sure the stories told would be an accurate reflection of each of their experiences. To that end, the participant's response and reaction to her own narrative is included in the analysis.

Data collection and story reconstruction. Through each phase of data collection (i.e. interviews, artifacts, field texts), I communicated a posture of understanding and acceptance to the participant that underscored how her story is uniquely her own. Narrative inquiry required me to build a relationship with the participant as I joined her in co-constructing her narrative (Bruner, 2004; Clandinin \& Murphy, 2007); living in the midst of stories in the field was not an easy undertaking. Ongoing conversations with participants involved settling into the temporal unfolding of their lives (Carr, 1986; Clandinin \& Murphy, 2007); as such, it was important that I have an opportunity to build 
rapport, establish trust, and remain empathetic to the storied lives of each participant. Two rounds of interviews, along with email correspondence and phone conversations provided me with a better foundation for building the relationships.

Reviewing artifacts (e.g. photographs, award citations) and the meanings attributed to them provided me with an alternative way to learn more about each participant. Field texts, which included my personal notes and the individual thoughts of each participant, allowed me to capture additional behaviors or other details that occurred during my interactions with each female veteran. A combination of all three of these data collection strategies provided a more complete picture of the female veteran participant's experiences and identity.

Interviewing in narrative inquiry. Life and oral history interview formats are frequently used in narrative inquiry studies (Clandinin \& Connelly, 2000; Riessman, 1993; Riessman, 2008). Particularly, these interviews created an environment in which each female veteran was able to reconstruct her story in her own words without excessive prompting from me, as the researcher. Oral history interviews include the narratives of individuals who have experienced a specific past event. This type of interview comprises annals and chronicles that shape and narrate the individual's story. Annals refer to dates of memories, events, etc. and chronicles refer to the timing of these memories and events (Clandinin \& Connelly, 2000). Life history interviews are autobiographical as well and they trace the influence of cultural patterns on the storied life of the individual. These interviews are structured around each stage of the participant's life and included main questions designed to focus on the stages of the participant's life (Rubin \& Rubin, 2005). 
Although I am concerned with how a specific event (i.e. transition from military to college) has an effect on the life of the participant, a more holistic narrative description was needed to understand the meaning enculturation experiences have on the women's understood identity. Due to the conversational nature of life and oral history interviews, I was able to co-participate in the kind of dialogue that revealed thick, detailed description. In addition, this type of interview seemed to allow more flexibility for my interpretations in the analysis of the interview text (Rubin \& Rubin, 2005), which was an essential component to the incorporation of poetic representation (Richardson, 1993, 1998; Smith, 1987).

Because female veterans' stories of transition have not been told, I wanted to present them with the opportunity to freely express themselves without regard to rigid structure or sterile question/answer sessions. I believe this produced a more valid and meaningful account of their experiences (Richardson, 2002). I engaged each participant in two rounds of interviews. Although the focus of each interview was somewhat directed by the participant, I was able to draw out stories that related to understanding her identity and enculturation experiences within the military, her transition to college, and her identity, enculturation, and engagement experiences in the higher education setting. During both interviews, I was also able to draw out portions of her story relating to life mission and life course.

Theoretical consideration and reflection on my experiences of transition between the two cultures of the military and higher education helped me to develop main questions to solicit the life history of the female veterans (Appendix C). Although I 
recognized my personal experience was not representative of the story of all the women in my study, I used it as a starting point to approach the conversations with these women. These questions have been subjected to the scrutiny of three female veteran peers not participating in the research. Each interview session was recorded and I hired transcribers to be more efficient with my time.

Artifacts, field notes, and journals. I collected additional data through artifacts (e.g. photographs) and field texts (e.g. participant journals, field notes). "Other forms [of communication] precede words in human development and continue to communicate meaning through the life course" (Riessman, 2008, p. 141). Therefore, it was relevant to include additional ways of getting to know the participant in my research process. Reviewing artifacts with each female veteran enabled me to see as the participant saw, and feel what the participant felt; providing me with a more in-depth look into her identity. Depending on the nature of the artifact, I included a digital reproduction in the dissertation; along with commentary about the context and relevance of the artifact to the participant's story. Issues of confidentiality surrounding the collection of digital images was addressed in the IRB application.

The use of field notes allowed me to further analyze any inconsistencies and/or consistencies observed during the course of my interactions with each participant (Clandinin \& Connelly, 2000; Yin, 2011). I also asked each participant to keep a journal to account for any reflections during the interviewing process (Riessman, 2008; Yin, 2011). Each female veteran was given the option of writing down or blogging about their thoughts and feelings associated with the research experience starting after the first 
interview and ending one week after the conclusion of all participant interviews. All the participants chose the online blogging option; sample journal prompts were provided in the welcome message of the blog (Appendix C). The online blog was set to private and access was limited to the participants of the study.

Data analysis. I combined narrative analysis methods with my conceptual frameworks to analyze all collected data. Transition and enculturation were analyzed via narrative representation and thematic analysis (Bloom, 1998; Clandinin \& Connelly, 2000; Craig \& Huber, 2007; Riessman, 2002, 2008). Data from the life history interviews, field notes, journals, and artifacts were re-presented in the form of narratives for five participants and brief portraitures for thirteen participants. These created stories are considered narrative representation and each will describe the life story of the female veteran participant in light of her experiences of enculturation and transition (Clandinin \& Connelly, 2000). Thematic analyses, a process of encoding qualitative information, aids in describing key aspects of the individual narrative and the shared narratives. After the reconstruction of each female veteran's story, I used thematic analysis to identify the shared themes evident across each woman's story.

Story construction. When I began the process of writing the individual narratives, I realized I had to make a decision about not only how to format and present the stories, but also I had to decide how many of them to present in full length. As I thought through this process, I considered the significance of this study in terms of "knowing" female veterans. I knew I could not present all eighteen narratives if I really intended the reader to get to know participants on a more meaningful level. To select the individual narratives 
to present, I first considered the entirety of each woman's story and removed those that seemed more like case studies from consideration. For example, in my interviews with Isabella, we discussed transition, enculturation, and identity. However, her story is more aligned with recovering from the death of a child than it is about separation and identity renegotiation after life in the military. For the other narratives similar in nature, it seemed counterintuitive to the narrative inquiry process to limit them to the structure imposed by the research questions of this study.

Next, I considered how well each narrative represented diversity (e.g. race/ ethnicity, rank, years of service). One narrative was automatically selected based on my desire to show a diverse group of female veterans, Lily (she was the only Marine Corps participant). Finally, I focused on the level of detail and description provided in each of the narratives. After considering all of these elements, I was finally able to narrow from 18 to 5 participants to discuss at length in Chapter Four. There is one selected from the Army, Marine Corps, Navy, and two from the Air Force. I was unable to recruit any participants from the Coast Guard for the study.

After deciding on which narratives, I shifted my focus to determining how to present the stories. I decided on the following plot line: movement to military, military enculturation experiences, movement to education, higher education enculturation experiences, and articulating the self. I identified this plot line because it presented the best unfolding of each narrative, while also providing structure for connecting the narratives to the research questions. Because each narrative is unique, I used subheadings 
to highlight relevant aspects of each woman's narrative under each main section of the plot line.

Poetic representation. Identity was analyzed via poetic representation, which is described as a way to capture and present an experience or aspect of a participant in a succinct, powerful, and emotionally poignant way (Richardson, 1993, 1998, 2002). The process of developing the poem involved capturing the participant's identity at the time of the interviews and then arranging and reshaping language from transcripts and field texts into poetic form (Glesne, 1999; Richardson, 1992). I began by using thematic analysis to review all available data and to "sort out words, phrases, sentences, passages, [and images]" that emphasized the salient aspects of the participant's identity (Glesne, 1997, pp. 205-207, as cited in Prendergast, 2009).

By rereading data and repetitively listening to segments of the recorded interviews, I was able to pay careful attention to repeated phrases, speaker pauses, and silences in the data (Brady, 2009; Prendergast, 2009). The process of creating the poetry also involved writing in my poetry journal, setting the journal aside, and revisiting the previously written pieces and revising. Throughout the process, I continued to review poetic forms in order to best determine the most appropriate rhythm and structure for each female veteran's poetic representation. After sending out examples of poetry to peers, I determined that a more narrative form of blank verse would be used for the longer individual narratives.

Data displays. A summary and analysis of the individual narratives will be presented in Chapter Four, followed by a discussion and poetic representation of her 
identity. Direct quotes from the interview transcripts and digital images will be interspersed when appropriate to capture the organic nature of the woman's identity (hooks, 1997; Heilbrun, 1988; Poindexter, 2002). At this period in her lived experience, each female veteran has started internalizing the meaning of the transition and enculturation experiences. This process of internalization informed her identity and revealed itself in the most salient aspects of her presenting identity. The dramatic presentation of poetry raises the critical awareness or social consciousness of the reader in relation to the female veteran participant's presenting identity. For this reason, artsbased practices such as poetry are frequently used in discussions of privilege, power, and identity formation (Cahnmann, 2003; Dixson et al., 2005; Gannon, 2001). This artistic form of representation emphasizes the contextual nature of knowledge and the created meaning attached to individual stories (Craig \& Huber, 2007; Glesne, 1999; Hicks, 2011; Ward, 2011).

In the research literature discussing poetic representation, aspects such as "pushing at the edge of tradition" and "gaining legitimacy" have been associated with the right of researchers to use this form in their qualitative works (Chase, 2005; Dixson et al., 2005; Hicks, 2011). The discussion surrounding poetic representation is similar to the discussion surrounding the "right" of women and femininity in the military. Arguments against each of these areas are prevalent and reinforce a narrow understanding of belonging and acceptance.

Because I sought entry into the lived experiences of other female veterans, I wanted to produce a more dynamic representation of the complexities comprising human 
living. To bind data representations into rigid molds would have been a misrepresentation of these women's experiences. By inviting readers to view how I made sense of these women's identity through poetry, the narrative is elevated to a more abstract level that allows the reader to enter into meaning making with the story of the participant. Each poetic representation complements the complexity evident in this meaning making exercise of reconstructing story.

The effect of using poetic representation results in a relationship between the researcher (poet), poetic representation, and reader that is unique to each reader (Richardson, 1993; Ward, 2011). Engaging in the experience of each poem requires the reader to acknowledge their personal narratives and scholarly knowledge in the interpretation of the poem. Because of the difference in people's experiences and knowledge, it is unlikely they will arrive at the same interpretation of the poem as other readers. This is expected, encouraged, and works to achieve the goal of the poem in inciting multiple meanings. An example of poetic representation in scholarly writing is provided in Appendix D. I also used a thematic matrix (Appendix E) to illustrate how each individual participant connected to the identified shared narratives.

\section{Strategies for Establishing Trustworthiness}

Issues of quality and credibility of qualitative research intersects with audience and intended inquiry purposes. Therefore, it is important to acknowledge that philosophical underpinnings or theoretical orientations generated different criteria for judging quality and credibility (Patton, 2002). Narrative inquiry acknowledges that individual experiences are open to interpretation and context. Considering this inquiry 
process is open to the possibility of individual experiences assuming different meanings for different individuals, Clandinin and Connelly (2000) urge researchers not to squeeze this methodology into criteria "created for other forms of research [e.g. objectivity, generalizability] (p. 184). Therefore, a composite criteria strategy of evocative and social constructionist criteria allowed me to utilize the most theoretically sensitive criteria to safeguard the integrity of this particular study.

Evocative criteria is associated with artistic based research inquiries and is embedded in lived experiences, such as those evident in narratives. Emphasis is placed on the research maintaining authenticity and an aesthetic quality. Research using this criteria is designed to be provocative and connect with the audience ( Clandinin \& Connelly, 2000; Patton, 2002). Social constructionist criteria acknowledges subjectivity and is associated with capturing and respecting multiple perspectives. To establish credibility and trustworthiness in my research, I used various triangulation methods (social constructionist criteria) and reported wakefulness (evocative criteria) (Clandinin \& Connelly, 2000; Patton, 2002; Yin, 2011).

Triangulation. Triangulation is the incorporation of various techniques to study the phenomenon of interest. Exclusively relying on one technique, whether data, analyst, or theory, may distort the research picture and provide an incomplete reality of the female veterans' experiences (Hicks, 2011; Patton, 2002). The purpose of methods triangulation is not simply to reveal inconsistencies in the data, but it is also an attempt to uncover complexities (Patton, 2002). To address issues of data source triangulation, I used interviews, participant journals, artifacts, and field notes. In addition, the use of multiple 
theoretical frameworks to understand identity and reflexive processes (i.e. peer viewing, thick description, researcher journal) served to address concerns of theory and analyst triangulation respectively.

Wakefulness. Clandinin and Connelly (2000) suggest wakefulness, an evocative criterion, as a framework for engaging in and judging the quality of narrative inquiry. Wakefulness can be described as maintaining a reflective stance, an awareness of self, and an awareness of what others think or say about the inquiry process, while ensuring the authenticity of each participant's story. Wakefulness is also encouraged to guard against reducing a narrative to a simplified text in order to illustrate a theory. At the core of this evocative criterion is an emphasis on the artistic aspects of qualitative inquiry that allow the researcher to give power to the voice of the individual by privileging all components of the participant (e.g. emotions, thought processes).

By maintaining wakefulness, I remained aware of the need to be critical of the research text and was challenged to embrace its complexity (Clandinin \& Connelly, 2000). Though already mentioned as a way to practice analyst triangulation, I embodied a wakeful mindset through the use of my researcher journal. In this reflective process, I captured full descriptions of my experience during the research process and the reactions of others to my research. I have provided relevant entries from my reflective journal and field notes in each individual narrative to demonstrate my approach to maintaining wakefulness throughout this study. My intent is to share my reflections as the researcher. By providing the reader with a snapshot of my initial reactions and emotions, I have invited you to witness how I interpreted and processed meaning from the interviews and 
from the female veterans' narratives. Excerpts from my field notes are being used to introduce each individual narrative. Excerpts from my journal entries are included in the body of the narratives. Both the entries and notes are italicized.

This idea of remaining wakeful is also an important stance for the reader to maintain. By being wakeful to the narrative process and my view as a narrative researcher, I had the opportunity to highlight the shifting, personal, and social nature of each female veteran's narrative. This requires the reader to challenge the dominant ideology of a phenomena being fixed and unchanging throughout the research process and challenges each reader to consider the value of relational knowing, truth as communal, and lived experience.

\section{Establishing the Requirements for Poetic Representation}

The aim of poetic representation is resonance, understanding, multiple meanings, dimensionality, and collaboration (Cahnmann, 2001; Sorsoli \& Tolman, 2008). Although this aim promotes a sense of discovery and showing that connects the reader to the known, there are evaluative measures that can be used to critique poetic representation: (a) substantive contribution to understanding the participant; (b) aesthetic merit; (c) reflexivity; (d) resonance; and (e) time in field (Glesne, 1997; Richardson, 2000). Through careful study of my field notes, participant's journal, interview transcripts, poetic techniques, and aesthetic, I was able to produce poetry that captured my interpretation of each female veteran's identity. I also kept track of poetic techniques, poetic representation drafts, and recognized themes relating to each participant in a designated poetry journal. 
Substantive contribution to understanding the participant is described as the connection between the focus of the poem and the goal of the study. Aesthetic merit (e.g. form, rhythm) refers to how the poem is structured and presented within the context of the study. Reflexivity required me to be aware of myself in the research process and to make clear the steps of progression from transcript and notes to poetic representation. Resonance is described as the affect of the poem on the emotions and intellect of the reader. Time in field is focused on the quality of the established relationship between me and each participant.

Just as important as what is included in the poetic representation is what is missing. Each developed poem was sent to the respective participant in order to collect her thoughts and reactions to my perception of her identity. Any comments given were included in the final discussion. This was done to clearly distinguish between my thoughts as researcher and the thoughts of the participant (Jones, 1997; Piirto, 2002).

\section{Ethical Considerations}

The ethical considerations in narrative inquiries are commonly situated in relational responsibilities that would be negotiated between myself and the participants (Clandinin \& Connelly, 2000; Huber, Clandinin, \& Huber, 2006). This responsibility shapes the need to negotiate research texts that respectfully represent participants' lived and told stories. Negotiating research texts creates a space where participants' narrative authority is honored. Issues of anonymity and confidentiality take on added importance as the complexity of lives are made visible in research texts. Therefore, I used strategies such as fictionalizing (i.e. pseudonyms) and blurring identities (use of digital images that do not 
reveal the identification of the individual). Additionally, procedures for ensuring confidentiality are described in the Statement of Informed Consent each participant received via email after agreeing to participate in the study. All research procedures were in compliance with the legal and procedural aspects of the University of Louisville's research on human subjects policy.

Another area of consideration that often arises in narrative studies is the question of ownership (Josselson \& Lieblich, 2003; Patton, 2002; Reissman, 2008). Who own's the story of the participant, the researcher or the individual participant? If the female veteran is given a pseudonym, does that mean an aspect of her voice has been silenced and the story is no longer really her story? Additionally, if my name is listed as author of the dissertation, does that mean the narratives belong to me? These are all questions I have considered throughout this process. Although most texts discussing narrative studies describe this as a question of ownership, Clandinin and Connelly (2000) suggested that a more accurate discussion is one of relational responsibility. As trust developed in my relationship with the female veteran participants, I remained wakeful to how the research text was read, and exercised caution in how I represented each participant.

\section{Audience and Dissertation Format}

The five chapter format appears to be more representative of the rigid structure of the positivist paradigm found in traditional quantitative research than the fluidity of shared experience and meaning making within some qualitative research designs. Instead of adhering to the five chapter format, I identified two possible formatting structures for my dissertation; one included eight chapters, prologue, and epilogue and the other 
included seven chapters, prologue, and epilogue. The primary difference between formats had to do with the order of content. After a discussion of the two proposed dissertation structures with my committee members, the first proposed structure was selected with modifications. Instead of eight, the dissertation includes only six chapters. Chapters Five (shared narratives) and Six (levels of engagement) were combined and the prologue was not designated as the first chapter.

The order of the chapters and chapter titles were driven by the themes of the narrative process and were designed to evoke an understanding of the experience. To further build the connection between story and reader, I have used first person narrative. This writing style gives research a more human voice (Clandinin \& Connelly, 2000; Meloy, 2001; Woodring, 1981). Also, using the first person narrative in constructing the dissertation allowed me to show my connection to the participants while still situating them at the center of the experience.

Identifying the intended audience is an important component to determining how to structure and format research (Meloy, 2001; Patton, 2002; Woodring, 1981). Although my dissertation was written to fulfill the requirements for my degree, the content has a lot more meaning. I have written and shared the untold stories of women veterans; their story is my story. They are as much my audience as any academician reviewing my work. I have also written this for educators working daily with this population; therefore, presentation is everything. Vigor, interest, and style will draw in a much larger audience and must be maintained in order to keep the reader connected to the experiences of the female veterans (Meloy, 2001). Similar to the works of Josselson (Revising Herself: The 
Story of Women's Identity from College to Midlife) and Gilligan (In a Different Voice), I wanted to format my research so that it significantly contributed to the conversations of women (particularly female veterans).

\section{Goals of the Dissertation}

As a narrative researcher and doctoral candidate, I was not only concerned with clearly representing each female veteran participant's experience in this study, but also maintaining the integrity, authenticity, and invitational quality of my dissertation research. In choosing to conduct a narrative inquiry and pursue an alternative design format, my subjectivity as a researcher was made evident. By taking the stories that participants shared with me and pulling them into the boundaries of a dissertation study, I presented the participants' shared meanings and also imposed meanings on their lived experience through the interpretation and analysis of interactions. The amount of time needed to continue forward in narrative inquiry required close collaboration with my participants and a recognition by the reader that the process of narrative inquiry illuminated me as much as my participants. I now invite each reader to partake in the pilgrimage of each female veteran participant as she moves between the military and higher education landscapes. 


\section{CHAPTER FOUR: IDENTITY}

For this chapter, I have selected five of the eighteen narratives to describe more fully: Tanumen, Abriana, Dasha, Alyese, and Lily. Tanumen was the first participant interviewed for the study and she also was the one participant whose narrative most resembled my own. Therefore, I remained hypersensitive about projecting my experiences onto her narrative. Her story focused primarily on returning to the role of student as a way to reclaim aspects of her identity and to align her understood life mission with her career goals. Abriana's narrative focused on how she was able to use her time in the military to heal and recover from previous disorienting dilemmas. She perceives her identity as being transitional and evolving. Dasha spent the most time on active duty and was the one that seemed to be the least affected by her military service. She joined the military having already developed a clear understanding of her identity and was able to maintain that same understanding throughout her 29 years of service. Alyese spent the majority of her time on active duty internalizing the culture of the military and felt that she was losing more and more of herself with each passing year. Her narrative focuses on an evolving understanding of her identity. Lily is one of the few participants who experienced both sexual harassment and sexual assault while serving on active duty. Her narrative focuses on reclaiming her identity and moving beyond feelings of isolation. 
To present these five stories, I am using the following plot line: movement towards the military, military enculturation experiences, movement towards education, higher education enculturation experiences, and articulating the self. I selected this plot line because it provides a natural unfolding of the individual narratives, while also ensuring that I have connected each woman's experience with the first two research questions:

1) How do female veterans describe their understood identity (e.g. gender) after separating from the military?

2) How do female veterans perceive enculturation in the military and higher education communities?

Military Enculturation Experiences and Higher Education Enculturation Experiences speak directly to the enculturation experiences each woman has had in the respective systems. Movement towards the Military and Movement towards Education are included as was to begin each narrative and move the storyline along in a more organized way. Articulating the Self focuses on the female veteran's understanding of her identity.

\section{Tanumen}

Setting. Tanumen's interview was the first one scheduled with any of the participants. I first met her in a crowded and noisy Starbucks on a Thursday afternoon. I arrived about thirty minutes early hoping to calm my nerves before her arrival. With each opening of the door, I eagerly looked to see if it would be Tanumen. Finally, she arrived at our scheduled interview time and I stood to signal my position in the coffeehouse. She walked over and we exchanged greetings while taking our seats. Unlike my excited nerves, Tanumen appeared calm and ready to engage in conversation. I went over the 
consent form and answered her questions about the process. Then, we began to discuss her identity and experiences.

Movement to military. Tanumen's decision to join Army ROTC while attending Johns Hopkins University was motivated by a need for educational assistance. During her first year of undergraduate study, her father lost his job and ROTC seemed like a good option. Although the military was not a foreign idea, her father attended West Point Military Academy and her brother was a non-commissioned officer (NCO), Tanumen never considered the Army as a possibility prior to her financial troubles at school. She received the scholarship and started ROTC in her second year.

Doubt about her decision to commission as an officer surfaced during the fall semester of her senior year. Tanumen was presented with an opportunity to study abroad in Thailand and her eyes were opened to the world and all the ways in which she could be of service to others. Thailand was her first encounter with human trafficking and the devastation caused to young women who found themselves sold into modern day slavery. She was so moved by this experience that she began to weave the role of advocate for these women into her life's mission. This exposure led Tanumen to consider the ways she could get out of her commitment to the Army and pursue her interests as an advocate for women. Upon returning from the semester abroad, she spoke with her ROTC Battalion Commander about her options. He, in turn, called her father.

It was the absolute only time in my life my dad told me he was disappointed. My dad had a talk with me and then I changed my mind. I was like, "Okay, I won't 
further this. I guess I will stay in and do what I have to do." It was more about fulfilling an obligation.

As Tanumen recounted this portion of her narrative, it was evident that she still felt a strong emotional response to the situation. Although she stated that she was not really sure why she was getting teary-eyed, it seemed as if the thought of disappointing her father was not something she took lightly. It also indicated the heaviness of her decision to fulfill her obligation to the military despite her overwhelming desire to do otherwise.

In addition to the desire to help other young women similar to the ones she encountered in Thailand, Tanumen was also fearful of how she would fit in with the culture of the military.

I was scared of how I was gonna fit in and what I was gonna do. I also felt like it was kind of a trap, like, "I'm stuck and I won't have anything else I can do. For four years, I'm obligated to this." I think that was scary. On the one hand, I was like, "Okay, well, I don't have to look for a job." Whereas, all my peers were, but on the other hand I was like, "This is scary." Just feeling like there was so little control.

Giving up control seemed to be at the root of most of the anguish Tanumen felt about joining the military. Although she does not regret her decision to commit, she indicated that at that point in her life, she had different goals for herself.

Military enculturation experiences. Tanumen was commissioned as an officer in 1999 and served for six years on active duty. She was identified as a Military Intelligence officer, but branch-detailed to the Chemical Corps for her first few years of service. In the 
following excerpt from her transcripts, she recounts an incident that occurred at the Officer Basic Course (OBC) prior to moving to her first duty assignment.

We had a female captain that lined all the females up and she walked down and told us all about how our hair wasn't appropriate and you shouldn't do this and that, and this and that, and she gave us all the speech. "You've got a decision to make right now, before you go to the first unit. Either you're gonna be the pushover or you're gonna be the bitch. You decide what you wanna be." And that was like our sending off to the Army experience. I think I started being more of the pushover, but then when I started to have young soldiers it became apparent that for me to be successful, I had to be a little firmer than I think I would've wanted to be. Definitely, being a young girl with a lot of young boys and them thinking it's a mission to get the Lieutenant to date them, or for them to push the line and say inappropriate things just to see where the Lieutenant's gonna draw the line. I just think those are things that men don't have to deal with. I had some complications with things like that.

Realizing that her experiences in the military would fall along a gendered line caused Tanumen to really consider how she wanted to approach her career in the military. Oh, I think I became much more of a snap-judgement kind of person. I started to see soldiers more in terms of the way that the Army sees you as successful. Are you good at PT? Are you good at shooting? Are you good at these things that really, as a person - these are not things that people's worth should be wholly judged on. But that was how I started to view things. 
Her understanding of what it meant to be a good soldier changed and she internalized the cultural norms of the military. However, after an interaction with a female unit Commander, she made a conscious decision to push against the overwhelming pressure to internalize the culture of the military.

When I got the Eighth Army staff [position], we had a lieutenant colonel, a female that was like the raciest, raunchiest mouth woman that I'd ever seen, and I just — and I looked at her and I was like, "This is just not who I want to be." She was very successful and she did very well in the Army. She was a very nice person, but she definitely had become who she had to become to fit in that world. And I was like, okay... That was, I think, a good experience for me to say, "Okay, who am I gonna be at this point? I don't wanna be that person."

Instead of following in the footsteps of this commander, she adopted a persona that allowed her to move within the system of the military.

After the advanced course, I went into an Army-level position on the $G$ [generals] staff. It was a little bit easier for me to be - not to feel so much pressure to have to be firm and a little bit more of the mentor role. I think I was a little more mature, too, and not feeling so overwhelmed. I think I felt, as a platoon leader, so overwhelmed all the time with just feeling like I had to protect myself so that I could be functioning. Once that kind of pressure was off, I think I was able to be more of the officer I would've wanted to be.

The kind of officer Tanumen wanted to become was someone who actively engaged in advocacy efforts and stood up for the rights of others. At this point in her career, she was 
able to incorporate her understood life mission of advocating for the rights of young women involved in human trafficking with her career in the military. She served on a task force, chaired by the chaplain, to strategize ways to prevent soldiers from going and hanging out in the "juicy bars" during off-duty hours. The "juicy bars" are bars or clubs in South Korea that house young women who have been sold through human trafficking.

Although Tanumen initially thought her work would produce a decrease in soldier's attendance at the juicy bars, she soon perceived that the task force was pulled together without any real intent of action. The military has policies that prohibit service members from entering certain establishments and her command developed a task force, but none of these worked to reduce the problem. She became dissatisfied with the culture of the military and the willingness of the system to allow those types of establishments to continue existing so close to military bases. Her frustration was not directed at individual soldiers, but instead at the military.

Feelings of worth. During our interviews, Tanumen also discussed feeling undervalued as an officer because she did not always fit the stereotype of what it means to be successful in the Army.

I felt, honestly, that this Colonel really didn't give me a lot of — didn't really value me as a staff member until I got a 300 on my PT test. And then suddenly I was a really good officer and he wanted me to do all these things for him. But I was doing the same stuff staff-wise....So there were definitely things that - I think he was sexist. I don't think he treated the males the same way. I don't think it took them to get a 300 on their PT test for him to think that they were valuable. 
Interestingly enough, Tanumen still places significant value on the physical performance she exhibited in the military. One of the artifacts she shared with me during our second interview was her German Armed Forces proficiency badge (Image 1.1). Although she has somewhat rebelled against the military's idea of physical fitness, she perceives the badge as being an example of what she was able to earn while serving in the military; the acceptance of her peers and superiors.

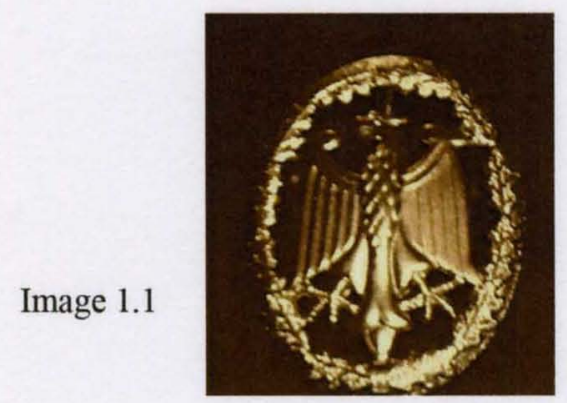

A source of contradiction in her life was her views on other female soldiers.

I think when I was in the military I really struggled with females who wouldn't be tough. I think that I found that frustrating. The females that were just very masculine - they weren't masculine, but really embraced that culture, I don't think I felt frustrated, I just think I felt more of an aversion, like I just don't wanna be that. But I guess I felt like that was a way to be successful. Upon reflection now, I think I probably should've been more compassionate to the females that were not really stepping up to the plate, because I think the expectation for them to was so low. I think the Army they also really teach you there's one method to motivate, and I now see that different methods motivate different people, and I wish I had more patience to kind of discover that and find ways. 
While discussing whether or not she felt comfortable sharing her frustrations about the military with her superiors, she stated

Our squadron commander was a female. She had come in. I kinda talked to her somewhat about it a couple times, just about like how you fit in, in a man's world. She very much was like, "You just adapt to them." "I told her, "This is the series of experiences I've had." She pretty much commented like, "Don't cry. Get over it. Move on. This is the way it is. You're not gonna change it." She's kinda mean. She was like, "I thought you'd cry about this." Or something like that. And I was just like, okay. And she had taken over from a guy who had told my best friend that she had to - he said to her... What did he say? Basically, "As a female officer, you need to make cookies for your soldiers if you want to be successful. [laughter] I was so struck by the absurdity of the commander's suggestion that I almost got completely sidetracked on her retelling of this experience. His suggestion was a first. I knew of soldiers who would frequently suggest making them brownies or cookies. But I have never heard of a commander giving his/her lieutenant such advice. I think if I had been in that situation, I would have laughed in his face. Then, I would have gotten upset over the absurdity of the suggestion. However, this does fit with the double standard I have witnessed when commanders give advice to female versus male officers.

Although it is clear Tanumen had some struggles with the culture of the military, she reflects on her time in service as being a point of growth and self-discovery. 
It is, really, and it's so unique. Other people will never get that chance to do something like that, and so I think it certainly... I valued it, and I think it taught me to grow. I grew a lot. But thinking about it now, I'm like, I don't know if I always made the best decisions. I was thinking as a 22-year-old. [laughs] But, anyway, no one died, so...

Even though she clearly values her experience in the military and the continued benefits of service (e.g. Post $9 / 11$ GI Bill), Tanumen regards her time in the Army as a personal part of her life story that she does not want to readily share with others.

Yeah, I definitely do. I don't tell a lot of people about a lot of the things. Some of it people are not ready to hear, and some of it is that there are so many misperceptions about soldiers, just the things that are sensationalized, like Abu Ghraib and different things. I do think that is the exception. I think there are so many great people. And I think there's something that people outside the military may not understand, that the military really is an opportunity for a lot of people to get out of some really bad places. You can't expect someone who's come from a very traumatic background and come into the Army, then everything's just... They're still processing and dealing with a lot of stuff, and then we're throwing on trauma by deploying them three or four times. I think I have compassion for the systems that these things happen in, so I feel protective because I think there are so many great individuals. I think there's a lot of room for systems to improve, a lot of room for education and change in policy, but I don't like other people to feel like soldiers are bad, or that people are bad in the Army, or that 
they're just all out to hurt each other and be violent, because I don't think that's true.

Movement to education. Tanumen's decision to enter graduate school was not a matter of if, but rather, a matter of when. She had no thoughts of making a twenty year career out of the military, even though she ended up staying two years past her service obligation. Tanumen was motivated by a belief that her gifts lay elsewhere, outside of the military environment. She was looking for an entrance into a more obvious helping profession, such as counseling or nursing.

Initially, she was unsure of which program of study to pursue and considered several professions related to health and wellness. However, she decided on nursing after carefully reflecting on which career would be "flexible enough to move with her husband" and which career would best capture all of her health-related interests. Along with the flexibility of nursing as a career option, Tanumen was also able to reconcile her passion for public health and working with young women with the career of nursing as well. She wanted to be able "to do health outreach, educate and empower, [and] increase self-advocacy" efforts among women.

It's kind of like combining all the things I really liked. I like the medicine, I like the wellness stuff, and I like coaching, counseling and educating. That's nursing. Higher education enculturation experiences. Although she was finally in the place that she had envisioned for herself (i.e. graduate school), Tanumen still felt frustrated by her surroundings. 
Some of it, I felt like it was a question of integrity almost. I can take these exams. I know how to take these exams and be very successful, but is that good enough? Is that appropriate? Am I gonna feel good about myself saying that's a degree I earned and this is the field I should be in? So I think that was just such a different academic experience for me. Maybe some of it was just having ten years and being in the military and realizing that there are bigger consequences to things.

The previous quote describes her reaction to the structure of the undergraduate nursing program. Tanumen views the structure of the program as encouraging negative behavior from the students.

My theory is — and this is why I think I felt frustrated in nursing school — that kids are now taught to the test. I would see over and over in my nursing program that people would want to know, "What's going to be on the test?" Not, "Why you make these decisions when you're doing this as a nurse?" I just would see this so much in school and I would be thinking, "Do you guys realize this is going to be a real-world application at some point?" It didn't seem like that. You've gotta know what to do and when to do it. Anyway, I think that was very different and very frustrating for me.

Seemingly, her desire to not be viewed as one of those types of students led to her ending up on the other end of extremes by pushing herself too much. She felt overwhelmed during her first semester of graduate school. Now, she realizes that she must take a different approach to her academic pursuits. 
I gave myself a little bit of a break in the fall and said, "Okay, I don't have to get all A's. I don't have to do all of the reading, to the detail of note-taking and reviewing that I was doing. I gave myself a break. I let myself do a little skimming, a little more like just... I don't know, not to the detail that I had been doing. I think it was necessary.

At this point in her academic journey, Tanumen feels challenged as a student and at peace with where she is in her life. She has been able to find her way back to higher education and fulfill a long held dream of pursuing a graduate degree. More importantly, she has found a career path that seems to complement her skills, while also combining all of her health, wellness, and advocacy interests.

I finally found this place where I feel like this is where I belong. You can be completely organized and obsessive about things being in the right place and things - But still care and be a nice person.

Articulating the self. When asked to describe her identity, Tanumen stated that her identity was in transition and that it was a struggle to define herself because she had not yet arrived in her career as a health researcher. This led to further discussion of how she interprets the influence of roles in understanding her identity.

"Anchor"

Being adrift and floating

Feeling overwhelmed

By swells of uncertainty

She searches for a stabilizing force

Trying on multiple roles

That fit, but aren't quite right

She dances from one to the other

Seeking a moment of clarity 
Recalling what others have said

Their perceptions of reality

She struggles to see herself

In the midst of their definitions

Easily overshadowed

The small voice in her mind

Repeats a refrain of...student

But after leaving the military

She would feel weird

Being over 30 and in school

Years pass, the voice grows louder

Calling to mind desires

To reconcile mission with reality

She dreams of her becoming

Of fulfilling previous ambitions

She tentatively moves toward student

The only constant voice

No longer overshadowed by

External pressures of being

Tanumen's transition out of the military occurred during the same time she was transitioning into the role of military spouse. Only later, after three years of separation from the military, did she transition into the role of student. The decision to get married to an active duty officer meant that she had to renegotiate her previous thoughts of education and career choices.

And then he had to go to his advanced course, so it was just hard to figure out what I was gonna do until he got settled into a place. So we moved three times in one year, and then finally [laughs] we were in Michigan, and I started kinda looking at more practical realities of being an Army spouse. 
For Tanumen, those practical realities meant taking into consideration how whatever career she choose would travel from duty assignment to duty assignment whenever her husband changed duty locations.

Role of spouse. Although being a military spouse has an effect on her career and educational goals, Tanumen did not seem ready to completely embrace that as a part of her identity. She remarked that the "Army wife identity really isn't very present for [her] because [she doesn't] have a lot of Army connections right now." For much of their married life, she and her husband have been disconnected from the typical experiences associated with being a military spouse. Typical experiences usually include an officer's spouse being in charge of the unit's Family Readiness Group, frequent engagement in socials at a superior's house, and aiding the spouses of the soldiers under the officer's command. The typical experience seems to portray the image of the military spouse whose life revolves around that of the service member.

I don't mean I've been an Army wife like the typical Army wife, but my husband's career has been kind of the leading factor. This is where we moved because of his career. This is why we do all the things we do. These are the things we build up for is for his career. So in that sense I guess I feel like an Army wife, but I do think I've been fortunate to kind of still make my own way within that. So I don't know.

I am struck by how we, as military members negatively view the spouses. I have never given much thought to whether I view military wives or husbands differently. They both have been in my periphery and ashamedly, I don't typically 
think very highly of them. I find that my opinion stems from how they (these spouses) seem so quick to say they know what it means to be a Soldier. For some reason, that is likely a study in itself, their empathy doesn't sit well with me. Although Tanumen has been a spouse longer than she served on active duty, she still distinguishes herself and uses distancing language to discuss her role as military spouse in comparison to the "typical military spouse." Her interpretation of Army wife is that she is someone who does not have goals and aspirations beyond that of her husband's career.

I think in the recent years he and I have recognized my need for my own path and goals to be realized, but we really struggle because in a year and a half he'll have to go on internship and I'm not going to be done with my program and so what does that mean for us. Do I drop my program or take a year off and come back and hope he can get stationed back at Knox or maybe even Fort Campbell? I could probably come up here a couple days a week. I don't know... We debate and debate, but then we're like well, we're going to have to make the decision, but I will likely need at least one more year of course work and then time for a dissertation to be done. So I don't know how to fit that in...

Role of student. A role that Tanumen has interpreted to be significant to her understanding of self is the role of student. She has placed this role in a dominating position within her life. It is clear that fulfilling this role anchors her in a way and gives her a sense of purpose. The pursuit of a graduate degree is her way of saying no to the aspects of her life that she does not want to incorporate into her identity by allowing her to focus more fully on who she can become through her time as a student. 
Tanumen's life has been through a series of transitions since separating from the Army. She has gone through several job changes and has really tried to figure out what she wants to do with her life and career. While discussing her life and career goals, the concept of mission was introduced, along with how she sees her mission in relation to her identity.

So I partially think part of my purpose is to combat human trafficking, only because it's something I'm very passionate about. I see that not everybody does feel that way, so I feel like that must be there for a reason. Yeah, I don't know how it is all specifically going to look like, but I just think that I've been given these talents and given these opportunities to develop certain skills that I think I need to embrace and develop further and put to use for the good of other people.

Tanumen freely discussed the roles of student and wife. However, considering the nature of the study, I found it interesting that the role of veteran did not initially come up in our discussion. When asked how her status as a veteran fit into her understanding of self, Tanumen responded:

That would be an identity to have, huh? Maybe yes, no, maybe... I guess so. You know I don't and I think a big reason is I didn't deploy and that's not a really reasonable thing. It's not that people who don't deploy...but it's just when I hear people talk about veterans I think that's the image they have is people have gone to Iraq and Afghanistan and I didn't. So I don't tell people very often that I was in the military because it then leads to the question of ' $\mathrm{Did}$ you deploy? Where did you go?' I think some of it is also that I just didn't do a full career. 
I found myself easily relating to most of what Tanumen shared with me during our interviews. I, too, struggle with identifying myself as a veteran, but it is a very real part of my identity. The struggle is the association with the word itself. I did not deploy, so at times I don't truly feel like a veteran. But it seems more absurd to consider myself as an Army officer still or to call myself a separated service member. I call myself a veteran because it is the only option left that makes sense, even though I feel like a fraud at times for using it.

She also added that her previous exposure to older male veterans also served as a deterrent of sorts from identifying herself as a veteran.

...I have a major fear of being one of those crazy people stuck in the Army past. You see these old men that gather at McDonald's and they talk about their...you know? So I may be overly the other way. Unless someone really asks me what did you do before you came to this point in life, I usually don't offer that information.

Notwithstanding the fear of being associated with the stigma of "those crazy people stuck in the Army past," Tanumen shared experiences of how people reacted to the news of her time in service that might also have contributed to her reluctance.

I think when you tell people you were in the Army they just have this preconceived notion of you're mean or tough. Then sometimes people say 'Oh, I totally can't imagine you being in the Army.' It's like well, what does that mean?... What am I not that you think people in the Army are. Usually it's not meant to be offensive, but I'm like they think I was like Private Benjamin. 
It would seem that these experiences have served as another deterrent for sharing her Army experiences with others. Although she recognized "the general population's image is very different than what it actually is," she did not seem to want to offer herself up as a way to counter those views.

Throughout both interviews, Tanumen shared examples of how she "brings the Army into everything [she does] in terms of being a student and being a nurse and everything." She approaches her life and the situations she encounters from the standpoint of "How could this be done better? How can we problem solve this?" These are lessons that she considers invaluable from her time on active duty.

Analysis and summary. Throughout Tanumen's narrative, she expressed a belief that her life had been put on pause, first because of the military and second because of marriage. Although her reaction to both of these perceived pauses is different, her opinion of how they interrupted her life are clear. She did not expressly articulate that pursuing a doctoral degree was part of her life mission, but her actions and the verbiage used to described her experiences outside of higher education indicate the significance of the graduate degree to her understanding of self. Not only was Tanumen unable to fulfill her life mission of advocating for women sold into human trafficking, she also was unable to fulfill her mission of pursuing higher education while serving in the military. This led to an incongruence between her understanding of self and the military system.

More than just the pursuit of a graduate degree, Tanumen was looking to transition into what she considered to be a meaningful engagement of her skills and passions, to feel self-actualized through her work. Her perception is that she has found 
that in the field of nursing. This new career field also presents her with an opportunity to align her internal desires with the role of Army wife. An expressed fear, although she does not call it a fear, is that she will be perceived as "just" an Army wife, a role that she does not perceive to be meaningful. In our discussions, she does not use any language that describes the work or role of military spouse in a positive way. Because she does not associate any positives with that role, it is understandable that she would want to distance herself from it as a comerstone of her identity. Yet, she recognizes what being a military spouse means for future life decisions.

Her choice to marry someone on active duty will likely result in a feeling of incongruence in the future unless she is able to associate positive attributes to the role of spouse. I say this because there may be times when she is unable to secure work in her career field because of a military assignment that her husband has received; military assignments are required work locations given to service members on active duty. A more immediate possible concern is that she may have to again put her life on pause depending on the decision she and her husband make regarding his residency. Although Tanumen has begun to renegotiate aspects of her identity after serving in the military, she is still moving towards developing a better understanding of herself and who she is becoming.

There are two aspects of her identity that did not expressly come up during our interviews, race and gender. Although I found myself asking her about the role of "veteran" in her understanding of self, I did not ask her about these other areas. On the demographic questionnaire, Tanumen identified herself as Asian and Caucasian. It is important to note that participants were allowed to write in their race instead of selecting 
an identity from a predetermined list. It was not until the interviews that she disclosed more detail about her ethnic background. She informed me that her mother was Korean, but never did she identify herself as being part Korean, nor did she express an understanding of how her race/ethnicity informed her worldview or was incorporated into her identity. I expected more about her ethnic background to be discussed when she told me about her assignment in South Korea, especially considering her mother grew up near Seoul. However, Tanumen did not mention anything about connecting with family members or friends of her mother.

From our interactions, it seems as if Tanumen has yet to attach meaning to the significance of race her life. I wonder if part of the reason is that a Korean identity was not embraced or emphasized in her home while growing up. The literature discussing intermarriage and assimilation into a "white" identity may help to explain Tanumen's narrative. According to a study completed by Zhou and Xiong (2007) "most children of Asian parents hold firm to the ideology of assimilation and aspire to achieving parity with the society's dominant group" (p. 1119).

Another silence was the role of gender in the discussion of her identity. The work of Belenky et. al (1986) emphasizes a progression from "silence" to "voice," as women become more independent and connected thinkers. Tanumen's narrative shows an awareness that gender is relevant to her experiences in the military through the use of gendered language when describing much of her experiences. However, when the conversation shifted to focus on her experiences in higher education, I heard no such language being used. Because she was able to see distinctive gendered experiences in the 
military environment, she may have isolated her perception of how gender affects her life to that situation as well. Her interpretation of the transition away from that environment would mean she no longer needed to view herself through that lens.

Although I am unsure how Tanumen's understandings of race/ethnicity will evolve, I do believe that she will begin to reevaluate the role of gender in her life as she continues to renegotiate her identity and incorporate her life mission into her understandings of self. Her identity still appears to be mostly situated in understanding herself through the perceptions of others, but she is moving towards an understanding of herself that is not externally grounded. Engaging in higher education has served as a way for Tanumen to regain control of her life, to remove it from pause, and explore new ways of being.

\section{Abriana}

Setting. My second interview with Abriana took place on an unseasonably warm February afternoon. I made plans to go running after the interview; so, I was casually dressed. I'm not sure if it was because this was our second meeting or if it had something to do with my attire, but the feel of the interview was a lot more relaxed than the first one. We decided to sit outside of the coffee shop to take advantage of the slightly warmer breeze. Although there were no stalls in the flow of the conversation, we were frequently interrupted by cargo trains passing by on the tracks across the street from our table. During those times in the interview, we engaged in conversation that allowed me to share more about my background and our common experiences. Although this interview was 
the more relaxed of the two, I was able to learn quite a bit about Abriana's narrative from both of our sessions.

Movement towards the military. Traumatic experiences colored Abriana's childhood and an inability to positively adjust to life's circumstances initially lead her down a path of self-destruction.

I grew up with a single mom, my dad was an alcoholic and an addictive gambler, and he definitely put women in front of me. My mom was diabetic on top [of that]; so she was a sick single mother and didn't make a lot of money. I think I got that picture of knowing what it is like to be on that bad side of things. Especially as a child, you don't have any control over that whatsoever so knowing what it is to be on the bad side of things and seeing how awful things can go. When I was a teenager I tried to commit suicide, I took a bunch of pills and that started the substance abuse issues.

My mom passed away when I was 17 . With that, my mom was a single mother and she suffered from severe depression as well. My dad wasn't really around, and it was just a lot for me at that age to deal with. My mom was sick, not only health wise but mentally. I was an only child, the only one in that situation and a lot of that came on me. I was definitely a lot of times in the parent role, I had to hold a lot of secrets in. Secrets are nasty, they tear you up inside. I don't know how much and to what extent but my mom was involved with drugs. For me it was just way too much to deal with and I didn't understand life yet at that point. All that I could see was that I was trapped in the pain. I didn't understand at that 
point that you grow up one day and there is so much more. That was all I could see, I had tunnel vision, I didn't understand life yet.

Yeah, it was very chaotic. That is probably the best way to explain my life because growing up it was always so chaotic. In a lot of ways the military was my way to get out of it. My mom passed, my dad didn't have any money and I needed money for education. I had seen so much shit that I didn't want to be there; I didn't want to be that. I think it drove me in the complete opposite direction because there was no way I was ever going there.

I was impressed with Abriana's willingness to share these tragic moments from her life and her ability to reflect on them with such candor and control of emotion. Although Abriana had yet to face the depression and anxiety of her youth, she was able to move her life in a more positive direction by joining the military. The Air Force was an escape from her current life's situation and it provided her with an opportunity to access education in the future.

It was a huge turning point. I don't think I would've even went in the military had my mom not passed away because I was this very rebellious teen. I was just wild and when my mom passed away. I just remembered her message was very "think positive." Positive brings positive, negative brings negative, and that she really just wanted me to do well in life and get my education.

Educational aspirations. Obtaining a college degree was one of Abriana's primary motivator's for joining the military. However, she was unable to aggressively pursue her education while on active duty. 
I guess it would've been nice, but I just got kind of caught with a long tour right off the bat and I never had any plans to really stay in the military, so that's just kind of the way it worked out.

Most of her time on active duty was spent on deployment rotations. This was due in part to the timing of when she went on active duty (October 2001), and in part to her military occupation.

So it was a really scary period to go in and then being through training and everyone kind of harped on my career field. They're like, "If you're Security Forces, just don't even unpack your bags. Just be ready to go," and that really scared me, but it was more just the being scared of the unknown.

Of course I deployed a lot. I got really lucky to deploy once to Guam for disaster relief and that was great. I went to Saudi and kind of did some clean up there. I went to Yemen and I went to Iraq. And that was pretty much it as far as deployments. I was just always training. It's just one of those career fields you're always training.

Deployments weren't that bad. I got pretty lucky. I didn't go to Iraq until the very end of my term or whatever so...But, I came home and I'm safe and everything worked out.

Military specialty. Being assigned the occupational code of security forces was a great source of pride for Abriana and her family.

I have a lot of legal people in my family so it was kind of natural for me to go in and be a cop. I almost did that just to make my grandfather proud and say I did it. 
So I think I have a lot of experience with, maybe, male dominated career fields, but never military experience. I think everyone - they were proud of me.

I definitely carry around that pride with me, I am not a veteran that goes around telling the war stories, I am very reserved and quiet about it but I am very proud that I am a veteran. Even though I didn't know it at the time, it gave me a lot of self confidence.

As her confidence in her abilities increased, she began to understand her capacity to adjust to life's changes in healthy and positive ways.

Military enculturation experiences. Upon reflection of her time on active duty service, Abriana realized how naive she was to the culture of the military at the beginning of her career. She found herself engaging in a militarized version of the first year experience, similar to what many college students face with the first tastes of freedom college life brings.

I was just incredibly immature at that time. I'd never had anybody yell at me and I was still kind of a wild child in a way. I had to kind of settle into myself and not be so wild because there is a lot of partying and stuff.

Especially - I don't know if for everybody, but for cops particularly, they say they party the hardest. It was kind of like making a lot of the immature [decisions], drinking way too much — that's probably not the best thing to be doing. And just learning - I learned a lot [about] how to compose myself, to take things more seriously and be more professional about things. 
As she settled into the role of airman, Abriana began to refocus on her reasons for joining the military. Although she fulfilled her military responsibilities, her mind was constantly aware of the desire to separate from the military and pursue higher education.

Never. I was never that person and I knew that. I think it - with me getting deployed so much, and I knew the direction I was going in - it made it even more like, this isn't what I wanna do. It just wasn't a good fit for me. It was a good learning experience, a good place to grow from, but it just wasn't me and I don't think I would've been happy [staying in]; so I had to make the decision that was best for me.

Becoming an air"man". Although recognizing her incompatibility with the Air Force culture, Abriana still had to learn how to navigate the military system. She believed the best way to do this was to accept all elements of the culture.

Yeah, I was Security Forces... in the Air Force but that was probably one of the toughest career fields you could be in, especially for a woman. It was just a "put your boots on and get over it kind of thing, we don't want to hear about it." I won't say all because I had a really good experience with one of my supervisors, but in general, if you would have went to an authority figure and had an issue or whatever that was life oriented, it was just like, "Whatever. Get over it and go do what the hell you need to do."

There was such a fear with us because if you needed any type of help, you knew that you could possibly lose your weapon. If you lost your weapon, you weren't out there working and you are really labeled and looked at as "the person." They 
didn't have to know what was going on, it was just like, "That is the one." So you didn't come open in that way. I have dealt with a lot, when I was in the military, like I said with the grief issues; I never had really dealt with that. [And] I was in a really bad long distance relationship, oh my God, and that just bore on me.

Abriana considers herself to be a private person; therefore, she easily internalized the culture of suppression and/or repression that is often evident in service members and did not seek help for her mental health concerns. With the adoption of this persona, Abriana felt better prepared to withstand whatever the Air Force brought her way.

Remaining motivated. Although she was successful in her career by military standards, Abriana was still aware that she did not feel like she fit well within the military system. However, she was able to stay motivated because she recognized that her "piece [in life] was much broader and [the military] was not [her] dream."

It didn't fit with my personality. Everything's so structured and kind of uptight. I'm kind of more go with the flow and - how can I say this? They can be kind of abrasive and mean at times and I'm not that person. I'm very good hearted. I want the best for everybody even if I don't know you. You know what I mean? That kind of thing. I don't know if that was kind of because of the career field I was in.

I think, too, that I didn't always see people get treated the best and I didn't like that. So, for me, it was kind of like I wanted to go to the other side of that and make sure people got treated right. 
Recognizing the injustices in the military had an opposite affect on me, I found myself wanting to stay in so that I could contribute to the positive and provide my soldiers with an example of an officer who is concerned about the individual in relation to the organization.

Even without having the proper terminology for it at the time, Abriana was able to recognize the social injustices at play within the military system.

It was the whole - I always called it the "good ole boys" system. It just drove me crazy because it just didn't sit right with me. It was kind of like, if you were a guy and whatever, you fit that mold, you were going this way. And if you didn't fit that mold you had all this adversity just to get to the next place. That kind of frustrated me. I didn't like that. I didn't approve of that.

For me - I don't know, I can't speak for everyone's experience, but for me in Alaska it was like kind of if you were into hunting. If you - you know, I hate to say it, but if you were white. Just kind of male, macho, very - I don't know how to explain it.

Yeah, the machismo. It's very, yeah, and it was almost like they were very privileged; thought they were better than people and they could get away with that. I just didn't think that was right. I would see people get treated differently. I don't know how it is now - with gay rights and all the policies with that how much it's changed, but I had a lot of female friends that were lesbians and just to see how they had to fit into a world that wasn't really meant for them. 
That affected me a lot, too. I just - I guess I did see a lot. To me, now being a social worker - a lot of social injustice, things that just wouldn't fly — that for me and my personality, I would sound the alarm to and be like, "This isn't right," and you can't do that in the military. So it just didn't fit for me.

No time to say goodbye. The fast-paced world of Security Forces in the Air Force helped to quickly move along Abriana's four year commitment. During her last year of service, she found herself facing a deployment to Iraq that had her returning stateside with about a month left in her service contract.

It was crazy. I didn't even have a full month. It really was kind of frustrating because I didn't feel like I got everything I needed when I got out. It was just like bam, bam, bam, bam, see you later. I was just like, "Jeez, thanks."

I felt like I needed [more] time to decompress from being in Iraq. I needed time to really kind of settle my affairs, say goodbye to my friends. You need that time, that was a huge part of your life and you're saying bye and it's kind of over. So I needed that time to process it on a personal level, in that way. It was just kind of like I got back - I think I had three weeks — everything was an appointment. It just felt very impersonal and rushed.

No longer a part of the system that helped her to grow into a more mature woman, she found it extremely difficult to deal with the compounded effects of separating from the military and readjusting to life after a deployment.

I think it was just shock, really. It took me so long to kind of get what I would call normal. I was still always in that very tense, fast paced thing. You know how 
they talk about the cashier at Wal-Mart — you're like, "Come on. Come on. Come on.” I couldn't stop. I'm like, “Come on, people. Let's move it. Let's go." You know what I mean?

It took me a really long time to kind of part from that piece of me. Of always being - I was very high strung and — so it took me a really long time to settle into myself. I remember being kind of lonely when I got out because you get so used to - I mean even though you say whatever and you fight and whatever might happen, you're like a family in the military. You always have people around you; even when you don't want people around you. You've got people around you.

You get so used to that. So it was just very - kind of lonely. It was just a huge adjustment going from the fast paced, always having people around me, always having a sense of direction, and what's coming next to just...where do I go from here? What do I do?

Movement towards education. Abriana initially took a year off after separating from the military to figure out life and what direction to take her education in regarding a career. At the time of her transition, she was involved in divorce proceedings and dealing with the loss of a relationship that had spanned her entire time of active duty service. During that year of transition, she began to adjust to life outside of the military and formalized a plan of action to move her forward.

Well, I think just for me, just finally coming home. Coming home and getting adjusted back to being around my family and going to school. As soon as I came 
home that was my mission. School, school, school, and I think that was, for me, incredible. That's what helped because then again, it was like, "Okay, you do this and you're gonna graduate at this time." It was getting back into that structure and having something more than just myself.

The need to be a part of a greater system prompted Abriana to look into careers in traditional helping professions.

When I came home I started out at [name of community college]. So I did probably about three years there, kind of took my time. And I came here fall 2009 and originally had signed up for psychology, so I was kinda on track to do counseling and psychology and go towards that direction. And I had an advisor kinda suggest social work and I was just like, "No way, no how." And I happened to be at my job - I work at Bed Bath \& Beyond — and the dean of social work came through my line. So it was kind of one of those - just one of those things that happen. He was getting his barbecue supplies and I didn't know he was the dean. He had a $t$-shirt on and I was just kinda like, "Do you know anything about the social work program? I heard they don't get paid." I said every stereotypical thing. I had no idea, no knowledge, and he kinda laughed me off. He's like, "Yeah, I'm the dean. Let me tell you about it." And I was like, "Okay." And he just kinda sold me on the program.

And I knew from the very beginning that I wanted to work with veterans, providing some type of counseling. So I basically just went home, did my research, found out I could almost do the same thing with a social work degree 
and I could get it in a shorter period of time. That's just kinda the way it went on that...and I love social work.

From a chance encounter with the dean of a social work department, Abriana was able to identify a career path that has connected her with an academic community that serves as a source of support and encouragement in her educational journey.

Especially the jump from [name of community college] to [name of university], that was when I really appreciated becoming a part of the social work program because you feel like you are part of something.

It is really close knit, I think for a lot of people when you go for a degree like that, you learn so much about yourself.

I don't know I just heart the bachelor's program.

As encouraging as the bachelor's social work program was for Abriana, she has had some difficulty adjusting to higher education in general and the social work graduate program in particular.

I haven't had that connection as much in the master's. I think it is just the environment. You know, one thing that I think is kind of hard to part with is, in the military you know that you can trust the person beside you and here in college and in the real world, that's just not there at all.

Higher education enculturation experiences. While attending school, Abriana has experienced several losses that have brought her time in the military back to the foreground and motivated her to really pursue advocacy work for veterans. 
Then I just recently had an experience — and he was really my best friend. We lived together. We were roommates. He's a Staff Sergeant in the military, was going through a divorce and some kind of a custody battle, and he just recently committed suicide.

So that's been kind of tough. It's brought my connection to the military back. So it's just been kind of tough losing the people that [I] felt like [I was] so close to. That's been kind of difficult. I was talking to him a lot and I knew he was depressed and I kept saying, "You need to go get help." Because if he was a cop - he was actually a flight chief - he can't just go on base and get help. He would've been stripped from everything. So I kept talking to him and saying, "Just go off base. Just pay out of your pocket. It's not gonna cost that much, just go that route and no one has to know."

I didn't know that it was that bad. I didn't - I guess because - and it taught me a lesson that way too because professionally, anytime someone tells me they're depressed my next question out of my mouth, "Well, do you feel suicidal? Are you having any suicidal thoughts?" From him being a friend, I didn't go that direction. It was like, “Oh, I know you. I know you would never...” You know what I mean?

So it was really hard knowing that he was in that place and he didn't feel like he could get the help that he needed and that that happened. That was difficult, but like I said, it kind of reinforced, this is why I wanna work with veterans because the reason that I go toward working with veterans is because I feel like, in the 
military, you don't have those opportunities when you have mental health issues and it's not until you get out that you really deal with those things. So that's why I'd rather work with veterans than active duty.

Although part of her initial reaction to the news was to wonder if she had done enough or said enough, Abriana did not take responsibility for the actions of her friend. Instead she has chosen to see this incident as another motivation for completing her degree.

That's another reason I really wanna work with veterans and I think that's kind of how I do want to look out for my brothers and sisters [in] how we say that we look out for each other. I don't want anybody telling one of my veterans, you can't have this. I'm gonna be like, "No, no. Excuse me, this veteran needs this and this is why."

She recognizes a need to promote mental health care among veterans and wants to serve as an advocate for those individuals who are in need. The experience of losing a fellow veteran to suicide has reminded her of the deficiencies in the mental health care provided to veterans and active duty personnel. She described the fear service members frequently experience of being removed from assignments if too much is revealed during a therapeutic session. Abriana believes this fear leads to a decrease in the number of military personnel willing to seek assistance. She also discussed how the apprehension associated with seeking mental health assistance does not disappear when the service member leaves active duty.

Abriana has made it to a point in her life where she is willing to seek care for the anxiety and depression issues she has dealt with in the past. The move towards seeking 
mental health assistance is a direct reflection of her participation in the social work program.

You are tested and you are challenged in a lot of ways. They are really, really supportive. I have had issues with depression and anxiety since, I don't know, I think I have always had it. I have always been very nervous about getting help, I think a lot of that is because I had some substance abuse issues when I was younger...

I was at [name of internship location]. That was really trying for me because I was dealing with a lot of people with cancer and end of life issues sometimes, and on top of that I was still doing grief work. I have my own grief issues, I feel more comfortable with them today in the present but when I started doing grief groups I felt mine creep back on me. It was one of those internships where it was really trying, it tested you in a lot of ways and it was overwhelming for me. I did very well there but it was trying and it pulled at me emotionally.

It was a journey and it was things like that happening where I would just build up and stupid stuff would happen. Basically, my cup would run over. Through reflection papers, learning how important it is to get that therapy and really digging into those issues, that was the place where I got challenged so many times and I got pulled emotionally. I never did therapy [before] and I think part of that was the military. I didn't feel comfortable asking for help, not even just emotional issues, but just in general. To talk to a manager or someone in a superior level, I just felt so uncomfortable asking for help and to be open about things. Everything 
in the military was so cut, dry, and authoritative. It just took me a while to get into that and understand that this is the way that the real world is, not everything is like it is in the military.

Through her time in the social work program, Abriana has felt freed of certain restrictions placed on her in the military. She now feels like a more authentic version of herself and embraces those opportunities that allow her to share more of herself with others.

It's just a lot more relaxed. I feel like I can be myself where in the military I was always kind of, do I say this? Do I do that? I always felt like I had to kind of censor myself. I didn't feel like I could completely be myself unless I was around my airmen, people that were my peers, where you just be yourself.

...the great thing about being in school, even in my internship, I don't know if it is just the area that I work in, people are just so understanding. They really promote self care. I could call my practicum supervisor up and be like, "This is going on..." and he's like, "That is cool, do what you need to do and I will see you tomorrow." It is just totally different, it is so much easier to approach people and let people know where you are at. I never had that in the military at all.

I think just getting closer. Like you were talking about with my purpose and life mission, I felt myself getting closer to that. It is what I want to do with my life, it is one thing to go and do the work, like, oh great, I passed my psych class or whatever. Then when you really get into doing what you want to do for your life, I think that is what, for me, changed. 
As she continues to move forward in her academic program, Abriana is motivated by the alignment of her purpose and life mission, identity, and intended career.

\section{Articulating the self.}

"Evolving Identity"

She was scarred by setbacks experienced early in life Often walking into situations with no defined expectations Letting things happen as they are meant to happen Yet preparing for both positive and negative occurrences

Joining the military seemed like the best way To become a part of something greater than herself To prepare for the possible future of pursuing higher education To provide a service for her country

In the military she learned about responsibility, strength, and courage The responsibility of completing the mission, no matter the personal cost The strength to suppress authentic expressions of herself The courage to continue as an airman despite the injustices

Recognizing that her ability to deal with the military Meant that she could take on anything and anyone She understands herself in a way that few people experience She has evolved into a mother, a student, and a veteran Eagerly awaiting her transformation into career professional

Abriana has reached the end of her twenties and finds herself moving toward a career in social work. Although currently a graduate student, she spent most of her twenties between time on active duty in the Air Force and finishing up her bachelor's degree. At this stage in her journey, she can clearly see how her life has been transformed by her past and current experiences.

Fulfilling her purpose and mission. Guided by how she currently understands her life's mission, her outlook is positive and she is excited about the next few stages of her life. 
I just wanna - it's great to get paid every day, but at the same time, I wanna get paid for doing something good, doing something that is helpful to other people. I think by helping others you give back to yourself. I want a more rewarding fulfilling experience - that I've helped, that I've gone beyond and above. It's easy to go through life and not - just worry about yourself. I guess when I say fulfilling it's just really about helping others and working toward the greater good.

For me it is just that I want to help people. I really want to help people that are afraid or uncomfortable to ask for help. I think a lot of the reason that I went that direction is because I have always been able to help people feel really comfortable. People know that I am not judging them so I guess I come across as non-judgmental. I always was that person that people would come and talk to and I always liked to put my hand out and help people.

I would like to work with people that need the help but maybe need the extra step or push to go to that place. I think I just try to keep doing the right thing and that is where I go with it. I try to do what is right in my heart; I try to do what is right in my soul and just hope that the pieces will come together.

Being of use to others and exploiting the innate skills she possesses, are at the cornerstone of how Abriana understands her purpose. She is driven by a need to help other individuals move beyond their current circumstances. This need arises from previous experiences of difficulty at various life stages and a need to do what she believes to be right and meaningful. 
I can see the depths of how bad it can go in a bad situation and I don't want that for anybody, I don't want people to suffer. For me, in a lot of ways, it is more spiritual and hard work even though sometimes I take it to [a] more technical aspect of it. I think God places everyone and gives them the skills and it is important to do God's will in work in whatever way you can. I also think it is a ripple effect, you help people and it changes a lot of people's lives and they help people.

I guess just really my purpose is to get out there and really work, hopefully, for my veterans and make their transition a good experience and help them in any way I can. I'd love to do some outreach. I'd love to do some awareness pieces. I think I have a lot to give in a lot of different ways, as far as in practice, I want to incorporate a lot of holistic care. I really get into art and writing because I am creative. I also think that working out is huge for people with mental illness. Becoming an advocate. Fulfilling her life's mission moves beyond one-on-one interactions. Abriana is also concerned with how to affect change within organizational systems and communities. She is interested in changing policies and in becoming an advocate for social justices issues through her outreach.

I want to do a lot. If I could say I want to change the world, that is true. I am one of those people, I don't want to change it on a drastic level because I am very much more on a community level person and I like working within the community and I want to make change. I am definitely the type of person that a lot of reason I want to work with veterans is because I am not afraid to stand up to 
people. I think that is a lot of the brother sister connection you have with people that are in the military. I know that you try to mess with one of my clients you are going to get your foot up your, do you know what I mean? I don't care. I think there is not enough of that in the VA and it frustrates me that a lot of the people that [are] in the helping profession in the VA are not veterans themselves.

Yeah, empathy and understanding. I think that when it comes to [the] social justice piece, how can you fight for something that you don't understand $100 \%$ ? My purpose is to help people...sound call to issues that I think are really important to the veteran population.

Connecting the self and continuing in service. Professional student, veteran, and mother are all roles that Abriana see as comprising her identity. In the role of student, she is learning about her intended career field and anxiously awaiting the opportunity to practice her trade. As someone who loves "to learn and always [wants to] do more and better [herself]," going to school is the fulfillment of a long held dream. She is excited about what being a student means for her life and what her education will allow her to accomplish in the future.

For Abriana, the role of veteran is woven into every aspect of her life and serves as a foundational element of her life's mission as well. She has identified a desire to use her education as a way to reconnect with the veteran population. By helping them adjust to the transition out of the military, as well as by providing outreach services that promote positive ways to address mental health concerns, she will be able to further her life's mission of helping others to move beyond their experience of difficult circumstances. 
It's just such a huge issue and I feel that as being a veteran myself, that it's kind of my way to continue my service. I appreciate life so much and I understand how much there is to do in life and how much to give and receive.

As much as Abriana relishes her roles of student and veteran, both of these come secondary to that of mother. A constant motivator for her to finish her education and pursue her career goals is knowing that her daughter is watching her example.

But for me being a mother is huge, there is just no way to explain it. It's one of the best things that I have ever done is becoming a mother. I would like to have more children....

Abriana appears to have adjusted to being out of the military and has found a way to use her experiences to propel her along a second career path. She has found a way to connect all aspects of her identity so that she can continue to transition throughout life's stages in a positive and healthy way. Although she recognizes that understanding herself is an evolving process, she is comfortable in her present identity and embraces the beauty of the journey.

So I am learning a lot about myself, about making wiser decisions and not just going by my emotions. I think for a long time I would just fool around in life with these rose colored glasses. I don't know if it was the hippy in me, I don't know. I think I am coming to a much more, in my identity, more structured [place]. I have learned more about myself, and I realize the beauty within. 
Her journey of self-discovery and acceptance has been a long and winding road of both positive and negative experiences. Along each leg of the journey, she has rolled with the punches and consciously chosen to continue moving forward.

Analysis and summary. Most of Abriana's experiences revolve around a pattern of recovery and healing. To recover from her childhood experiences, she sought healing in the military structure. To recover from her experiences of feeling stifled and silenced in the military, she sought healing from higher education and a new career. There are also isolated recovery and healing incidents that occur within the larger context of these patterns (e.g. moving beyond marriage). As a way to show how her life has evolved, Abriana shared her narrative in a way that would highlight these patterns. For every negative experience that presented itself, she discussed what she learned and how she was able to move forward.

She did not discuss the significance of gender or race to her understanding of self. Though she did on occasion use gendered and racial language during our interviews, it was externally focused to describe someone else's experience or how the system affected others. Closer to the end of our second interview, she briefly mentioned a connection between herself and the perceived injustices witnessed in the military system. However, that was only to describe her interpretation of why being in the military did not fit with how she understood herself. Because a lot of her experiences since the military have been about healing from experiences before and while on active duty, I believe that the level of introspection required to understand what shapes her worldview will occur at a later point in her life. 
Abriana mentioned several times during our interviews that she has been moving at a fast pace since starting school. I believe that this is driven by an internal need to identify once again as a professional. The pride that she felt while serving in the military is related to how she views military service as being a part of something greater. This same wording is what she used to describe her decision to pursue social work, "being a part of something greater." Her desire is to recapture that feeling of pride and belonging. Because she feels unable to experience those feelings while a student, she feels restricted by her current state. In recognizing the need for the process of learning and becoming a competent professional before starting practice as a social worker, she has been able to remain motivated in her educational pursuits.

Several times throughout her narrative, Abriana mentioned the passing of her mother which indicates the significance of this incident in motivating her future choices and how she understands herself in relation to others. She spoke of having to act as the primary caregiver for her mother and how she had to act in ways that she believed were beyond her maturity level. The passing seemed to be a turning point in her story and served as a catalyst leading to a decision to join the military in order to create an opportunity in which she could grow and learn more about herself, as well as find order from the chaos of her life. Abriana appears to maintain a constant awareness, of how her early years unfolded, as a way to remain motivated and encouraged as she continues moving forward in life. No matter how difficult things may seem, she appears to be determined to keep a positive outlook and contribute positively to the experiences of others. 
Her response to the written narrative was one of gratitude. "It is absolutely beautiful and true to life thank you for hearing my story and seeing the value in my story...it truly means so much." This led me to believe that she perceives her narrative as being an authentic expression of how she currently sees and understands herself.

\section{Dasha}

Setting. My first interview with Dasha was on an early Thursday morning. I usually like to do a reconnaissance prior to traveling to a location for the first time, especially when my appointment is scheduled kind of early. However, I was unable to do that before my interview with Dasha in her home. I got up earlier than I needed to so that I could give myself thirty minutes of wiggle room if I got lost. After getting into my rental car, I pulled out my phone and typed her address into my GPS application. As much I do not like to rely on navigational systems to help me get around, this interview was too important for me to be stubborn. I pulled into her driveway (ahead of schedule), got out, walked to the door, and knocked.

I heard the greetings of her greyhound before she even had an opportunity to open the door. Dasha welcomed me into her home and we settled in for what turned out to be one of the most enjoyable interview experiences of this study. Not only did I learn about her experiences, but I also learned from her years of experience.

Movement towards the military. The most frequent response provided by service members when asked why they joined the military is educational benefits. Others will say they joined to serve their country or for the adventure. Dasha fits nicely into the latter 
group; she primarily joined the military because she viewed it as a way to travel and see the world.

It struck me that I needed to get out and try something else. I was 24 and started looking into things. The Peace Corps did not want advertising majors, imagine that. The Coast Guard was my first choice, but they had met their quota for women.

In addition to the military fulfilling her need for travel, it also presented her with an opportunity to work within a system that provided equal pay for all its members. Having come from the field of advertising, Dasha was keenly aware of the discrimination in pay women faced in the work force.

Back then it was something like .80 cents on the dollar for women's wages doing the same work that a guy would do. There was a ceiling as to how far you could progress. Men were moving further and women were held back a little.

Although she considered other branches of service after being turned away by the Coast Guard, Dasha ended up selecting the Navy and set out to start her new career. It was just to try something different. Their logo was "join the Navy, see the world; it's not just a job; it's an adventure." I took them up on it.

My reason for going in was not really what he was recruiting for. I said that I just wanted to get out and travel and he said, "Why don't you go for business? You have a business degree." I said, "If I want to do business, I will stay in business. I want to drive ships or do a Navy thing." He said, "Well, all right." So, I took the ASVAB. I 
did not even know the difference between an officer and an enlisted just to give you an idea of how far out of the military circle [I was] there in Chicago.

I said, "What will I be doing?" and he said, "You will go to Officer Candidate School."

I said, "So I will be an officer?" and he said, "Yes, you will be an officer." I said, "All right, how long is that?" and he said, "Well, it is three or four months. It is in Newport and you kind of learn what you will be doing." All right, fine. I was sold. I was just picking between services, so he was not doing a really hard sell. Back then, the quotas were so low for women that they just had to open the door and, basically, women came in. It was not a lot of pressure.

Travel and equal pay were not the only reasons Dasha was excited about joining the Navy. She was also interested in gaining access to "...the beaches...and a bigger dating pool." Eagerly anticipating what lay over the horizon, Dasha moved forward and prepared for her commissioning into the United States Navy.

Military enculturation experiences. She fondly recalled how naive she was when first starting out as an officer, sometimes forgetting even the little things associated with the culture. Luckily for her, a few sailors decided to mentor her and helped her along her journey to becoming a career officer.

I had no idea what to expect. However, I had been through Catholic school as a kid and they had nothing on the nuns.

When I went to my first duty station as an Ensign, I worked for a lieutenant commander, an O5. He said, "I am going to straighten you out and teach you how 
to be a good officer. Whatever you make, save a lot of it. Do you have a retirement plan?" [I thought], "I'm 24. I'm just looking for a date!"

There were a couple of other women officers who were stationed there; there were three of them. They all grabbed me and worked with me.

I had a chief and the chief said, "You know, you're my Ensign and I'm going to make you the best officer in the Navy."

Despite being initially unaware of certain cultural nuances associated with Navy, Dasha began to successfully navigate the organization and identify the ways military culture differed from that of her civilian life.

Understanding the culture. Although she found herself being exposed to many dissimilarities of culture, Dasha really enjoyed the experience of being a naval officer. It was a huge adjustment. The whole thing was going from a very hard-core, civilian, liberal background and trying to figure out what all these rules were. I saw a lot of discrimination against women because we were just getting into tenders. They were sending women out to the warships to do training and that whole strange mindset about how "this is a boy's club and women are not welcome." I thought, "What is with this?" [I] grew up in a society where men like women. It was kind of an odd thing. [However], I learned that if you just interact as a person, typically the barriers fall down.

I thought, "Okay, whatever," so I liked it. I really enjoyed it. I immediately felt the teamwork and the camaraderie. We were going out on ships a lot doing the fleet training group missions. I really enjoyed it. 
Dasha credits her rank as being helpful in shaping how she experienced the military. As an officer, she was able to challenge barriers and was provided opportunities to empower other women.

I think it also helped I came in as an officer as you did. Thank goodness, because all those knuckleheads I would have had to have worked for had I been a junior enlisted woman, I'm so glad I skipped over the 80 percent. I still had to work with them but it's different.

I'm not sure if it's the age difference between when I entered (22) and when Dasha entered (24) (in your twenties every year counts regarding maturity) or if it has more to do with the difference in culture between the two branches of service. But at times, Ifelt like I was working for the enlisted soldiers..."the knuckleheads she refers to in her narrative." So, at no time did I feel like I skipped over anything. In my experience, I would get in there and talk to their women. I'd say, "I just want all the women in here." I would go through the whole thing. I would say, "This can work. You just have to make it work. You have to be strong and confident. Everyone deserves to be treated with respect so stand up for it. If you really can't, then come see me, or see the master chief or whoever it is but we're going to resolve it. We're not going to tolerate this [harassment] because we can't change the system unless we change the [culture of the military]"

Even though she tried to bring the women together, she noticed a disconnect between her views and the views of some of the other women. 
Women aren't as good at coming together and helping each other. In the military, there's a little bit of a stigma. When a couple of women are together, the guys are like, "Oh no, what's going on?" Those women, for whatever reason, accommodate that odd sense. They want to be one of the guys. They hang out with the guys. Dasha was not dissuaded from her personal views or her thoughts about life because of who or what she encountered while serving in the military.

It was a career. A way of life, that's a little strong. It was a career, a great career. I really enjoyed it but I came home every night. We did things, we had a life, we continued to do a lot of things. It was one aspect of my life.

The way of life part of it was the moving. I loved it. [Name of husband] and I love to travel and live overseas, and experience different cultures. The Navy facilitated that.

Again, having been raised in the Catholic religion, there's hypocrisy everywhere. I see that with these big hierarchical organizations that they say one thing but they do something else. It's a bit of a lie. It's disappointing, but it's life. I saw that early on. I took that philosophy with the Navy...

After twenty-nine years of active duty service, Dasha decided that she was ready for a different experience in life.

I think the military is a relationship. It is more than just a job. It starts out that way; it is a career. However, it has such a strong identity and culture that you either relate to it or you don't. If you don't, then you leave and it is not an issue. If you do and you are really attracted to all that goes with that package, then it can be hard when 
it ends unless you drag it out to 29 years. Then it is, "Enough already!" Then you do not want one more PT test.

I love the use of relationship to describe one's connection to the military. I have never really thought of it that way; I just knew that is was more than a job. Just like other relationships I have found myself in, I am better prepared to walk away when I am the one in control. However, if I feel like the rug has been pulled out from underneath me, I have questioned and wondered what I did wrong and whether or not I could one day have an opportunity to correct earlier mistakes. I wonder if other female veterans view their time in service similarly.

At 29 years when you can only stay in 30 unless you rank Admiral, I was in a community and we didn't have any Admirals and we weren't going to make Admiral. I knew that Captain was where I was going to be, which was fine. When I came in for four years twenty-some years ago, I never even thought about it. Again, it was 29 years. I knew from when I decided to stay in beyond 20 that it was going to end at any tour where I did not want to go to the next tour. I was ready for it. It was an easy decision. I didn't want to just move to stay in, to go for 30 years because that was never a goal. I wanted to be in for the next job. If they didn't offer a job that I liked, I was going to get out...

She shared her excitement about retiring with her colleagues and was met with question after question about what she was going to do next in life, to which she replied, "I don't know and I don't care." Dasha decided to take time off after retirement and "just kind of chill out." 
I look back at people who are still in the military and I think, "God bless you. I am so over that!"

We got in the car and drove west for a month with no itinerary, unplugged. I said, "I just need to get away from it and calm down." It was really nice. It really was. Dasha and her husband spent about a month sightseeing in the western part of the United States. They drove to New Mexico and "went to the hot air balloon festival and camping." They "got a pass for the national parks [and] went hiking in Zion." She and her husband "went all over" and explored the presidential libraries and memorials throughout the region.

Movement towards education. After her western adventure, Dasha spent time with family and friends. She still had no plans; however, a conversation with a close friend and the chair of the international relations program shifted Dasha's focus towards the pursuit of a doctoral degree.

A girlfriend of mine who is in the Navy now, she's retiring in a few months, we met in Italy. We've stayed in touch. She's getting her $\mathrm{PhD}$ at [name of university] in the same program. When I came back here, I was asking [name of friend] what she was doing so she talked about it. I said, "Well, that really sounds interesting." [Then], I met the director of the program at a social thing. She said, "Come over and talk to me," so I did. I told her my background. She said, "If you're thinking about school, you'd be ideal for the program." That's when I started to think about it. Then I just assumed I was going to do it and did it. It's just one of those things, somebody started talking about it and it's working out. I like it. 
With her previous military experience and educational background, Dasha could have done like most of her retiree counterparts and walked right into contract work for the government or any other position of interest. However, she had no interest in working full-time and she wanted to take advantage of the Post 9/11 GI Bill education benefit while she had time.

It was just that there wasn't anything else. I did not want to go to work. If you just do the decision tree, there was no work. I did that for about six months and then, "All right, this is good for breaks." Then I worked part-time and that was okay; I liked that.

I did not want to work full-time and I always liked school. Really, the GI Bill is such a big deal and such a good thing and it is not going to last. I did not have a $\mathrm{PhD}$, so I decided to go do it. I knew about that program being here that really suited my interests, so it just came together.

Entering into a doctoral program seemed like a natural step for Dasha and fits in nicely with her history of pursuing challenging opportunities and her desire to learn.

Higher education enculturation experiences. After the first few minutes of interacting with her, it was apparent to me that Dasha values education and learning. Though we did not start out initially talking about her higher education experiences, I got the distinct impression that she embraced every opportunity to learn and grow as an individual; whether in a structured classroom setting or through life experiences. Her appreciation for learning is possibly a result of combined efforts, childhood exposure and an internal desire. 
There has always been a very positive atmosphere and support group in our family about school, about education and training, and that it is valuable. It is worth the investment in time and money.

I have been in and out of school my whole life. It is not like I finished college in 1977 and it has been 40 years...I love learning.

Dasha is no stranger to pursuing graduate education. She was able to earn three master's degrees while serving on active duty and is now working on a doctorate in International Relations.

I got one [in Systems Management] at night with USC with tuition assistance. I got one [in Joint Command Control and Communications] at Monterey post-graduate school. The third was in Strategic Affairs and Studies from the War College...and then I had a year as a National Security Fellow at Harvard. I loved that.

Not one to simply let her knowledge lay dormant, Dasha has sought opportunities to incorporate her knowledge into everyday practices. She shared an example of how useful her undergraduate education was while engaging other service members in the military.

The advertising and marketing I have used throughout my entire life. In the military we call it Strategic Communications, but it really teaches you how to persuade people. This has been very helpful in my different leadership posts when I was working for the ambassadors overseas, when I was working with different host nation Navy people talking about our programs and our training and doing different joint operations. You use all those skills, so it really was a very fundamental education which I had no idea I would use so much, but I have. 
Very similar to how she has approached most of her life, Dasha is open to the possibilities that this new degree will offer. Although pursuing a degree does impose some constraints, she is on no one's timeline and finds freedom in progressing through the program at a leisurely pace.

I like to contribute to class. I actually like doing the reading. I remember with a masters, they would say, "Oh my, it's so much reading." It's only a lot of reading if you do it. I'm actually doing it now. I like it. I'm taking subjects that I like to do the reading. The teachers are saying, "You really can't read every word. You got to skim it." I thought, "I don't want to skim it." I've been skimming it for years. I'm reading it. I'm enjoying it. I like learning it.

No, I do not want this to be over soon. I am not in a hurry. I want this to last. I love it.

I like transitions. They are times of change and it marks the completion of something. You can kind of wrap that all up and have that, the bad memories go away, and it is all good memories. Then you are into the next thing. It is about phases of life. If you never have transitions, it is just one long "Groundhog's Day." Because I have done it on my terms I am happy about it and I embrace it. It's great. Dasha's comfort with herself and where she is in life is rooted in her freedom to choose a direction and follow it, without someone else or some system imposing an arbitrary will on her. She is living in the moments of life and loving it.

\section{Articulating the self.}

"She Is"

Curious and free thinking 
She uses internal motivations

To break down barriers

Clearing a path for others in her wake

A nonconformist

She takes on any shape

While remaining unbound

To organizational systems and cultures

Led by a spirit of learning and embracing

Accepting the responsibility that comes with knowledge

Expressing the authority that comes with experience

Finding value in what "is" and "was"

Yet, moving freely she sets her own tempo

Sharing her ideas, while remaining open...but

Following only what she understands to be right

Allowing others to be delayed in their enlightenment

She exists in all of these

Dasha comes across as someone very comfortable with herself, not searching for an identity or appearing to be unsure of herself in any way. Throughout her career, she strived to maintain a balance of military responsibilities, familial roles, and personal desires; not regularly giving priority to one area of her life over another.

I think because of my experience in the Navy, being married and coming home, I was always a wife and a naval officer, and a friend to whomever. There's always been a pretty good balance.

At times when work gets crazy, obviously a little more goes to that. When I go on vacation, it goes toward that. I think I've always been pretty well balanced. I don't think it's changed all that much being a student. 
Being a wife...that's not less important than being the commanding officer of 500 people scattered around the world doing the Navy's work. It's on par with it. I don't feel that's a big part of my ego, what I'm doing...

She has "enjoyed being a woman working in a nontraditional field," and frequently finds herself "pushing barriers back and succeeding, and hoping others [would also] come up." One such barrier is the belief that you have to plan for the next role. She admittedly agrees that it took a little while for her to shake the thought of having to accomplish specific tasks every day. However, she is now comfortable with just "being," without worrying about "becoming" someone.

It was interesting between being in the Navy and being a student, when I wasn't doing either and I just had time. I would get up and think, "What am I going to do today?' It took a while to realize I don't have to have a plan. I don't have to accomplish certain things.

I had this conversation with [name of husband] about six months into it. He said, "I was wondering when you were going to have this feeling." He said he comes home from work and it's like, "I did this, I did this." "You're always accomplishing things. There are people that just wake up and go through a day, and then they go to bed. It's not that it's without value. It's just with less structure."

Instead of focusing on what happens after graduation or even planning a second career path, Dasha is focused on the "now" of her experience as a graduate student. Similarly, her life outside of the classroom takes on the same openness and appreciativeness of the moment. 
The people who would say, "So what are you going to do?" "I'm retiring." "What are you going to do after?" I said, "I don't know yet. I got to wait and see what comes up." They just can't stand it. So many of the guys retired on Friday and start something on Monday.

I talk to them four years later. They say, "So what are you doing?" "I'm going to school." "Really? Full time?" "Two days a week." [They say], "What are you going to do with it?" [I said], "Graduate."

I think people are always working toward something, but it was fun to ride my bike to the library, go to the biography, history, or whatever I tend to like to read [sections], pick out a book, bicycle home, and sit in the room. We have a library. I love to sit in there with the dog and read a book, go out and swim in the pool, have wine with lunch. It's been great, I planted a garden.

No plan, kind of like joining the Navy. Every day is a new day. You wake up, see what's out there, say yes or no, and go onto the next thing.

She spends each day choosing what is the best option and capitalizing on newly presented opportunities. Unlike the other women of my study, her experiences in the military did not alter her outlook or approach to life. "If it looked like [she] could add something to it [or learn something from it], then [she] would do it."

Not succumbing to a militarized identity. As someone entering military service at a later stage in her identity development (age 24), Dasha was able to become a part of the Navy without loosing sight of who she already understood herself to be. 
I've always been very confident and very outgoing. It was a little challenging because it's a very male hierarchical organization. I do okay with structure but I do okay without it, so always being held in a very structured environment and organization, I chafe at that at times.

You know, I always felt I was a little bit of an outsider to the Navy which seems pretty strange with 29 years but I never felt that I completely embraced the culture. It was a job and I enjoyed it. I loved serving my country but I didn't become a Navy person. I'm still who I am and I worked for the Navy.

Although I cannot imagine being a part of a system for 29 years and not becoming more like the system, I am amazed by Dasha's story of serving. She seems to represent those rare women in the military that are so comfortable with themselves, that they don't feel a need to overcompensate or change to fit the structure of the institution. I haven't met many of them.

Although she recognizes the contributions of the military to her life, she declares that her core identity remained unchanged.

I don't know. It's $100 \%$ of my experience so I don't know what it would have been otherwise. I think I've always been a self contained person. I can go into different environments but I don't change much who I am. I had my husband tell me, it was interesting because during my retirement, it was a lot of reflection and stuff, "You're the least military person I know." It's not that I didn't like it but I don't do that. I don't absorb other cultures. I am who I am. I liked it okay. I learned how to enjoy it. I appreciated what it brought to 
the people who really needed it, loved it, and wanted it, that camaraderie and teamwork.

Embracing the action of advocacy. Part of staying true to herself involved challenging injustices that she saw in the Navy. Although she told me that she does not really see herself as being an advocate, but instead views herself as being more "selfserving," her actions as an officer in the Navy tell a different story.

I think coming in the Navy in the timeframe that I did, it was fortunate because it had been opened by some pretty tough women who really had some struggles but there's still a lot of room, because a number of jobs I had, it was the first time a woman had gone into it.

There have been so many battles to get into that job. I've had to find a mentor, typically a guy, who would work it, be my advocate, and get in there. Then it always worked. In each - not each, in most of the jobs, a woman would come behind.

I've never accepted any of that stuff...I'm not conflict adverse. I don't mind challenging things. I can be pretty tenacious.

As Dasha shared how she has challenged barriers in the Navy, it is apparent to me that her actions are the actions of an advocate. She may have initially challenged some barriers because they directly affected her, but she also questioned barriers that had nothing to do with her personal experiences.

You know what, it improves it for everybody, not just them but for everyone you're working with because we bring something different to the workplace. We affect so 
many people. When you're working in the Netherlands at the embassy and my first day, I'm a lieutenant commander, female, working for an O6 Air Force fighter pilot.

We went over to meet the chief of navy for the Royal Netherlands Navy. My boss, the colonel, said, "Well admiral, this is lieutenant commander [participant's name]. She's going to be the blah blah blah." Then he turns to my boss. The admiral says, "So she's a woman and a lieutenant commander. It's typically filled by a commander and a guy."

My colonel didn't miss a beat because he had been there for two years and he knew. He said, "Well admiral, I asked you. I had shown you her resume before she came in. I asked you, 'Did you think she would be able to do the job?'Your answer was, 'Why not?' So we agreed that she should probably be able to do the job. If you have a problem, please talk to her. If you have a problem that she doesn't resolve, come talk to me." The admiral said, "Fine." I remember two years later, at that admiral's retirement, he mentioned - he thanked me in front of everyone there. I thought, "Wow, great, alright." I took that as a challenge. I was selected for commander but I hadn't been promoted yet but whatever. I've always enjoyed that but I think then, their Navy then sees the US Navy as sending a woman into that position, which is an important position. It improves our reputation as an organization, that we have diversity going out to the different jobs. 
It felt nice doing that. As I was looking at that question and thinking about it, I guess I do continue to enjoy breaking down structures and barriers. I've never been one to accept them just blindly. I've always asked why, why not me, why not her, or why not whoever is being excluded. Why don't we have opportunities that are inclusive for all? That's something I'm interested in but it's not very concrete. In relation to her husband. The nature of Dasha's relationship with her husband, has provided her with an opportunity to remain her authentic self. He encouraged her openness and desire to live in the moment, while also being supportive of her military career.

Our common goal was to spend time together and to be married in fact, not just in name, and to travel. The work thing wasn't so big. He said, "Let's go with your career because you can retire in ten years. I got to work 23 more years. This way we can both travel so it works better."

We lived on my salary as a lieutenant commander and commander. It's not that hard but for some people it would be. I had peers where she was working, he was working full time. They were still in debt. We drove the same car for 12 years. We just did things a little differently.

My folks never had money so it wasn't a big stretch for me. It worked out fine. Now I got retirement and he's working. We're going to pay off this house, we're going to both [be] retired soon. It's not that hard but you have to make some decisions on how you have it work with the military and how you prioritize your 
standard of living or your quality of life, which are two different things, who is going to do what, what their role is.

He did the grocery shopping, he did the laundry, he didn't clean the house but we're not too big on that, he did some of the cooking. When I came home at six at night, he'd be starting things up. We always ate together and spent that time.

Now that he's working and I have more time off, I'm doing more of it although he says, "Your full time job is school so I don't expect you to do all this stuff." We talk about that.

I think that's important. When you go into a culture, when you talk about it and express it, it's easier to assimilate or have it fit. When you change cultures, you got to have that discussion with your support to make it really work out.

Dasha and her husband have been able to successfully maintain a 15 year relationship because they have found a way to offer support and encouragement to one another. Although her journey to this place of self-assuredness and comfortability did not start with a decision to join the military, Dasha's time on active duty has been a large part of her adult life and has provided her with many opportunities to reaffirm her understood identity.

Analysis and summary. Frequently repeated content in Dasha's narrative are her length of service, view of the military as a reciprocal relationship, and comfortability with the moments of life. In her reflection over the last 29 years of service, she describes herself as someone who entered the service with thoughts of continuing as long as the Navy presented her with new and exciting opportunities. This attitude directly connects 
these three repeated content areas. By viewing her service contract as a reciprocal relationship in which she would give the Navy her time, while they provided her with adventure, she readily moved from assignment to assignment without regard to how certain assignments would shape her military career. Whether coincidence or a subconscious action of Dasha, she continued to select assignments that allowed her to successfully progress through the ranking structure of the Navy. It was only at the end of her career, that she found herself faced with no opportunity for advancement or exciting new assignment.

During our discussions, she appeared to be unconcerned with the social constructed identities of gender, class, and race/ethnicity. Although she spoke of her experiences from a gendered perspective, she did not explicitly discuss these roles in relation to her understood identity. Dasha's description of her identity seemed to be rooted in someone who is open to "being." She eagerly sought out new experiences without feeling compelled to attach significant meaning to them. If something she experienced was meaningful, then she would be open to that; however, no expectations were placed. While conducting both of Dasha's interviews, I could see how curious she was about me and the content of the research. She frequently asked questions about my background and views of the military, while being careful not to try to control the flow of conversation. Her curiosity during the interview sessions serve as an illustration of the her passion for learning and gaining knowledge. It is apparent that she sees challenges and transitions as opportunities to grow and learn, while still remaining authentic. I would argue that most individuals serving in a position for over twenty-nine years would 
have a more difficult time adjusting to the separation, unless they possessed an outlook similar to Dasha's outlook of embracing transition.

In her feedback about the written narrative, Dasha said, "It's fascinating to see how you have made sense [by] connecting portions of our discussion. I'm impressed with what you have drawn from the interviews." I recognize Dasha's ability to offer substantive feedback and appreciate that I was able to summarize her narrative in a way that impresses. However, I get the impression that she has distanced herself from what I have written and no longer considers the narrative as hers. The use of phrases like "you have made" and "you have drawn" focuses on my interpretation of the narrative. There is no sense that she feels authentically represented in the narrative; or maybe I am being too analytical.

\section{Alyese}

Setting. Although Alyese and I decided to meet in the university library, we did not have a room reserved and found it difficult to identify a location for the interview. We spent about 15 minutes going from floor to floor looking for a place that would allow us to engage in conversation without receiving angry glares from the library patrons wanting a quiet place to study. We were finally able to locate such a location on the third floor. I was a little concerned about how our time together was starting out because of the apparent anxiousness we both felt in trying to identify the ideal interviewing spot. However, I realized as the interview started that the anxiousness felt in walking from floor to floor did not affect her willingness to share her experiences. I was relieved. 
Movement towards the military. Alyese was raised in a very strict household, in which there was a clear divide between the roles of a woman and the roles of a man.

Even in my younger years, I always knew that that was not right. My younger brother could do whatever he wanted and my older brother could do whatever he wanted. But me, I had to make sure that I was home to maintain everything. So I didn't really have an outlet for social life. So I knew in my mind, I was leaving. She originally considered college as a way out of her home environment, but soon found out that her parents had other ideas.

My parents said no, that's not happening. So in my mind, I knew the military was going to be a route. I knew that. But I tried the college thing, because that's what they wanted me to do. And I just couldn't take it.

Not being able to select a college of her own choosing served as the final straw for Alyese and unbeknownst to her parents, she signed up for the military.

And then I told them that I was leaving, pretty much. It was like a family meeting. Not a good one. They told me they didn't want me to go. I didn't really have their blessings. But they let me go and things turned out okay. That's what I wanted to do in my heart.

In her mind, she had finally found freedom and independence.

Originally, I'm going to tell you I wanted the Marines. I was hardcore into Marines. I guess the recruiter when I went there was like, "No, you're not Marines material." I think he did everything in his power not to steer me toward that direction. 
I wondered if Alyese's initial gravitation towards the Marine Corps was her way of maintaining a connection to a strict environment similar to her home life. Although the military lifestyle is strict in general, the Marine Corps is often considered to be on the extreme end of that continuum.

Rejected by the Marine Corps, Alyese began to look at the other branches of service and decided on pursuing a career in the Air Force.

Military enculturation experiences. As ready as Alyese was to leave the structure of her home life, she acknowledges that she was not prepared for what the Air Force had in store.

But, I don't think my emotions were ready. I think once I got there, there was a shock. I tried to do the "under the radar thing" as much as possible. And you kind of cling to a group of girls, like-minded. That's how I kind of got through it. But, I don't think I was ready emotionally. No, definitely not.

Her ability to acclimate to Air Force culture was heavily influenced by her ability to build relationships with other service members. She started out connecting with women, but then her focus changed after she got married.

And it just seemed like the first man that I met was my neighbor, and that's who I ended up marrying. I got pregnant first and we ended up marrying each other.

After getting married and settling into a family unit of her own, she began to really adjust to the military environment.

Understanding the culture. She took note of the standards required for all Airmen and realized that being successful meant she would have to push herself beyond her 
comfort zone. As a self-described "B-type personality, [who is] quiet and laid-back," Alyese knew she had to accept parts of the white, "masculine driven" culture of the Air Force in order to remain a part of the organization.

I would say not color. Not color. My parents never really did that whole color discriminatory thing. But my ex-husband is from Louisiana and he experienced a lot of that [discrimination]. So from his standpoint, he would come home with it, and I would always have to hear it. And I just couldn't understand it. So maybe I went into it [the Air Force] with the attitude of...what would he always call it? He would always say, "You just try to think everybody's so color blind like you.

Everybody's not color blind like you." I think I always blocked it, because I would always say, "But you're not supposed to be that way in the military." Pretty naive of me but, mm-hm. I think when I became an MTL [military training leader], a lot of stuff-things did open my eyes. I did open my eyes to a lot of things....

Just one particular one, [that] I found to be unbalanced was the whole selection of deployments, who got to go where. Because there were some nice deployments, and there were some not so nice deployments. So if you were [part of the] favored few, then you went on the nice deployments. And job positioning. There were some really nice jobs, and there were certain not so nice jobs.

It was not always easy for Alyese to accept the negative aspects of the Air Force. At times, she found herself rebelling against the dominant culture.

Well, there was four of us in a room. One of the girls was Air Force with me, and talk about the girls that over-compensate when they're in the field, we over- 
compensated because we just didn't like it. It was just so dirty and stuff. I'm not usually the type of girl that wears makeup or smells flowery, but I did, during that period of time [a deployment]. Because I just wanted to...I did it for me, because I needed to know, you're not going to grab me and take me down. We also made sure our sections of the room were decorated with decorative scarves we used as curtains. We had rugs and pretty bedspreads.

I've often heard other women in the military say similar things; that the only way they know to exert their feminine identity is to wear "smell goods and make-up." From a psychological standpoint, it makes sense to me. But from a practical standpoint, especially for women in the Army, it doesn't make sense. Why would you bring attention to yourself when you are in the field? The whole point of some missions is to go undetected, to be in stealth mode. How can that possibly happen if the enemy can smell me before they see me? Although some scents are more natural, Victoria's Secret isn't one of them. And that's what I frequently saw women putting on.

Towards the end of her career, Alyese realized that she did not like the person she was becoming and connected it to how she had to adapt to military culture and she also connected it to other life transitions that occurred while in the military.

And that was one of the reasons why - because I never really wanted to put myself in the bubble, and I said I couldn't do it because I'd be selling my soul. I'd always say, "I'm selling my soul. I'm selling my soul." And I couldn't do it [anymore]. 
I went through a lot in the military. I went through a divorce. I was deploying a lot, particularly toward the end. Every other year, I was going somewhere. And I had my son who was either living with my ex-husband or he was living with my parents. So every other year, I would leave him.

Her experiences on active duty began to take their toll.

My mental state was diminishing. Greatly. Because there was a lot of stuff that I just didn't appreciate any more, the injustices of, um, the politics, the favoritism, I didn't appreciate any of that and I just felt like I was fighting a losing battle trying to do certain things and having certain people- I just felt like a kid all the time. You know? I'm a grown woman and I can't do what I want to do. So that kind of messed with my psyche a lot. The real defining point is when I had to go to Afghanistan and there was a list of NCO's, and they went down the list to see who was going to go. One NCO just came back so he was automatically off the list, I understood that. But two of the NCO's were thinking about retiring as soon as that list came down...and they didn't have to go.

Alyese was selected for a six month deployment to Afghanistan, that included two months of scheduled training with the Army, within the last two years of her military career.

Movement toward education. Instead of fully decompressing after her final deployment, she made a decision to retire and began the process of transitioning out of the military. 
I was so, "Got to go, got to go, got to go." I had a time-line because I wanted to make sure my son was in school in August, that I think I would have, looking back now, I think I would have taken my time more, to decompress more. ...From Afghanistan I decompressed more after I got out. So I would have taken more time for that, but my schedule didn't allow for that.

Part of Alyese's motivation for maintaining her tight schedule of transition was because she knew she was unable to continue performing her duties as a service member. After a heated exchange with a chief, who oversaw a training exercise in which she and her troops were involved, she found herself having to leave work for the day and immediately sought mental health assistance through LifeSkills counseling. For the sake of her mental health, she decided to shift her focus towards the pursuit of higher education.

Higher education enculturation experiences. While on active duty, Alyese had been able to complete her associate's degree and believed that should would be ready to start school as a junior.

Well, I always knew that I was going to finish my college degree. You know, when you're in the military you take classes and you pursue a certain level of degree that they want you to pursue. So I did get my associate's degree and I always knew that I would pursue further. And I knew [it would be] after I retired, because for me I couldn't really juggle the whole wife, mother, student, supervisor. 
So my parents have a house here, so I just moved here and live in their house. They actually live in New York. But it was just an empty house. That was it. It was the availability of a home.

After settling into her new home with her son, Alyese began the process of enrolling in school.

I applied to [name of institution] originally and they said I needed to [enroll in a] transfer program. You had to go through the transfer program, which means I had to go to community college, receive an $\mathrm{AA}$, and then transfer over into them, and that's exactly what happened. So my first year, I finished my degree in community college and then I transferred over.

I was upset. I was extremely upset. But then I took a deep breath. It took me a while to exhale, but I just said, "I'll do it."

She finished her second associate's degree and then transferred into a sociology degree program at the local, public four-year institution.

Moving forward. Now in the final semester of her degree program, Alyese is in the process of determining which career fields are of the most interest to her.

When I first came out, I said that I wanted to be a probation officer, but now, I honestly, truly don't know. I am so, waffling because, I had a conversation with some people, who say, "Why do you want to go back to being a cog in the wheel?" And that opened my eyes, because I had already been there, in that kind of a bureaucratic system. And as a probation officer, I'm working harder than I'm getting paid. 
At the beginning I said, "I want to do a job that I actually want to wake up in the morning to, a job where I'm helping. At least I'm trying to help. I want to work in a job for the betterment of kids. Because I believe they are our future. And there has to be people out there who want to invest in the future, and that's one way to do it. That was my thought process originally, now I'm thinking, because I like nice things, I want to be able to just find a job that I would like to wake up in the morning to, plus make, make the money. And I did believe maybe that [I] could go back to logistics. What I was doing before [in the military], supply. So I'm considering something like that and then volunteering [with kids].

An important factor in her decision making process is job security and the possibility of earning retirement benefits similar to what she is currently receiving from the Air Force. Because before [this interview], previously, I really didn't want anything to do with the military, and I think this last conversation that we had really opened my eyes that it's not that bad of an institution. I have been actually applying for jobs overseas, Army bases, Air Force bases, Marine bases. It was therapy for me. It really was. And I don't think anybody else on the outside could've related, or I could've expressed these things to. I felt lighter after. I really did; I felt lighter. The feeling of being lighter after sharing her experiences with me during the interview, underlie her ability to make meaning of her experiences through our conversation and align those meanings with her renegotiated identity outside of the military. Additionally, Alyese was provided an opportunity for continued reflection on the transformations of 
character that have occurred during her process of role-exiting from airman to veteran student (Ebaugh, 1988).

\section{Articulating the self.}

"Evolution"

Gaining strength

Through introspection

Finding that quiet place

A center of power

Laying dormant for years

All this time she never knew

What she wanted, she possessed

Looking first towards family

Their faces reflecting

A girl overshadowed by man

Looking then to the military

A system reflecting no single images

A female overshadowed by men

Nostalgic for the simplicity

Of life back at home

Searching, she found

A wife overshadowed by husband

No longer able to withstand

The pressures of external shaping

She broke, turning inward for strength

The center of power growing

Steadily pushing against

Reflections and overshadowing

Emerging as her voice

Silenced, no longer

As Alyese looks forward to where her life is headed, she is able to see how much

she has changed from when she first started out, as an E-1 in the Air Force, to the present. 
And I have to go back to my parents. Like I said, my parents were controlling, and I married a man that was controlling, and then I was in a controlling environment like the military. So all those things of control, control, control. I just wanted to say "F-you" to everybody who wanted to tell me [something]. And I still have that kind of attitude. "Do not tell me..."

Throughout her career she learned how to blend and tried to maintain that posture until her twenty years were up.

I knew who I was. But at the same time, I had to become... I had to prove myself to the other type-A personalities. See what I'm saying? So I had to really step my game up. I really had to, "Oh, you want to step to me? I'm going to step to you, too." Versus before I would have been like, "Fff! I know who I am." But if you do that, you will get eaten alive. You will get eaten alive. And I was not going to get eaten alive. Because I know who I am, and so I had to become something I wasn't. After moving out of her position as a MTL, Alyese was able to relax her persona a little. However, she again had to revert to a more militarized identity when she found her self deployed to Afghanistan and attached to an Army unit.

Moving beyond roles. Prior to her deployment to Afghanistan, Alyese did not consider herself to be a veteran, even though she had roughly twenty years of service under her belt. Now she feels comfortable embracing that title as part of her identity because she has seen combat; though she does not usually bring it up to others.

I do believe that I am... If I talk about roles, then there are different pieces to me. There are definitely different pieces to me, because when I'm in the role of 
"mother," I try to...just [be] an educator for my son, most definitely, and a good role model.

And as a student, I'm not gonna say I'm the best student out there because right now I'm just - I'm doing good, but I'm not putting that much effort into it. I'm just because maybe it's my last semester and it's just, "Could I just pass?" [laughter] But before it was definitely — as a student, it was definitely to make sure I pass these classes so I don't have to retake anything. So that was very important to me. And then as a friend, just to be there when my friends need me; that's important to me. Just like, in return, I would like for them to be there for me.

Alyese was able to articulate her identity in terms of the roles she fulfills, but foundational to those descriptions is how she has come to view herself independent of those roles.

And then just for me, as far as being Alyese, I would say there's two sides to Alyese. There's the Alyese that's the everyday go to school, mother, worker. And then there's the off-duty Alyese. There's the "Lola." That's my middle name. [laughter] And then that's the vixen maybe, the person who's gonna put on those six-inch heels, with the ponytail down her back and... You know what I'm saying? Just go out and have a good time. There's definitely that. I have learned to appreciate and embrace that side of me, whereas, before, if I would have done that, if I was married or in my parents' house, that would've been a shameful no-no. "Who do you think you are? What are you projecting?" Against them, not me - 
what am I projecting against them? You know? So I know I've embraced that, and I know it's not a bad thing if I wear those heels. [laughter] I can appreciate how Alyese now views herself as being more than the roles she fulfills. At times, I find myself feeling weighed down by the roles in my life. Taking a step back to see that I am more than the expectations (I see those expectations as being tied to the specific roles we fulfill) others have placed on me is a very freeing experience. I believe that it is in this place we truly begin to understand our identities.

Discovering mission and purpose. As Alyese frees herself from specific roles, she has begun to connect her identity with what she perceives as her life mission and purpose. I'd say I've come a long way in establishing - I can actually verbalize this. In previous years, if you'd asked me like five, ten years ago, I wouldn't have known what to say. But now, since sometime before I left the military and now, I try to look inward. Any time there's something going on, I like to see how I affect in a negative or a positive way. So, for me, I'd like to be remembered as somebody that was kind, most definitely. From the call of my heart, I never wanna be considered anything other than kind.

But, I think I'm transitioning more into what I want to do.

...As the woman, as a secondary, and as a child, still trying to find their way, that sometimes gets lost. I know I'm doing well, mentally, socially, financially, I'm okay. [But] being out in the civilian world, I find, because times are hard, and people will see what they see, think what they think, at times people take kindness for 
weakness. But right now I think I'm struggling with, "Do I let that hinder me from still being who I want to be?"' You know, as far as helping people who do need it. Still with the assisting kids and women who lost their way.

She finds herself torn between wanting to serve others and not wanting to be taken advantage of by some who would consider her desire to help as being weak. However, in remembering how she was able to empower her troops, she again finds motivation to continue with what she considers to be her calling.

Becoming. Although Alyese understands how much her life has changed, she recognizes her growth has been a slow and intentional process.

I'm towards the end of it, I do believe. But, my goodness, what did I do? A lot of crying. I'll admit that. I did a lot of crying. I did a lot of soul-searching. Before I left the military, I did cruise-through counseling on my own. Reading books. Just personality books. Self-help books. Talking to other people. Listening to how other people respond to me. Asking them their opinions about me. Absorbing everything and just really spending a lot of time for myself and just really going through everything.

I never really thought about it [before]. Well, it has to be related to the military because when you're in the military, you're a different person, I do believe; you have to be a different person because your life revolves around that system. So I think I just had to shed that. And there were people in my ear telling me, "You need to shed it. You need to let it go. You're no longer there anymore." 
[Now] I can laugh more and smile more. And anything crazy that happens in my life, I just let it go. I really do.

Alyese, in part, credits her current success of moving beyond the transitions of life to a lesson she learned from the military of "always [setting] a goal for yourself and always [trying] to attain that goal [by] planing that goal out." She has been able to incorporate this philosophy into most aspects of her life and it has helped to carry her this far.

Analysis and summary. Alyese's narrative shows a progression of consciousness. She moves from blindly accepting the perceptions others have of her to inwardly focusing on understanding what her experiences mean in relation to her identity. Now included in her meaning construction is the influence of her values rather than titles or roles bestowed by society.

Her narrative also includes a movement towards increased awareness of the social injustices surrounding her in the military. She starts with an explanation of the messages she received as a child growing up and those messages were heavily influenced by the expression of traditional gender role perspectives. Although something in her intuitively identified the expression as being unfair, she did not attempt to transform her understanding. Instead she joined the military and created an environment that allowed her to fulfill the expression of traditional gender roles she experienced while growing up. During the day she pushed against gender stereotypes and in the evening she embraced them in her roles of wife and mother. As we engaged in conversations, I could hear how her understanding of what it means to be a women is evolving, along with the other aspects of her identity. It was not until she fully separated herself from the bonds that 
produced the most controlling messages (i.e. the military and her marriage), was she able to take time for introspection.

Although Alyese identified herself as Jamaican American, she did not discuss how that played a significant role in her understanding of self. It is apparent from the shared narrative that most of her adulthood has been spent denying that race has an important effect on one's worldview and understanding of experience. Much like her evolving understanding of what it means to be a women, I believe that her understanding of what it means to be Jamaican American will evolve as well. She has already discussed how naive she was to the presence of racial injustice in the military. However, now she concedes that some things might be occurring within the system.

Of the five individual narratives, Alyese was the one from which I did not expect to receive feedback about her written narrative. During the second interview, she informed me of her discomfort in reviewing other's perceptions of her. After hearing her narrative, I can understand that hesitation. For much of Alyese's life, she has felt bombarded with external messages pressuring her to become a certain way and it is only recently that she has moved towards relying on internal messages to inform her identity expression. She likely perceives the entrance of someone else's messages of interpretation as an opportunity for them to shatter her understood meaning construction. However, somewhere between the second interview and when I emailed her the narrative, she gained confidence in her ability to withstand external messages; she responded to the content of the email by saying, "Thanks for the experience, I feel you captured my thoughts and feelings very well." 


\section{Lily}

Setting. I met Lily for both of our interviews in a little coffee shop close to the university's campus. I had been eagerly awaiting both interviews because she was the only Marine I was scheduled to meet with for this research. I remember that before the first interview, I wondered what her story would be like. Would it be a stark contrast to what I heard from the other female veterans? Would her experiences be similar to my own? As we began the interview, I realized that my apprehension was completely unwarranted. I recognized the familiarity in her experiences as she recounted her time on active duty as a Marine. She spoke with an ease of spirit as if she had already settled something in her mind. I soon learned that she was settled in the articulation of her narrative. She was no stranger to revealing this part of her life and had told her story on more than one occasion in the classroom setting to help inform others about the experiences of female veterans.

Movement towards the military. Lily grew up in a really small town in Texas. To emphasize how small her town was she informed me the population was around 2500 and there were only 27 people in her graduating class. There was very little diversity and people in her town tended to try to blend in and adhere to mainstream ideas.

Okay, so I grew up really poor. Well below the poverty line, I have three siblings, it was always kind of known in my family, "If you want to go to college, you better join the military because we don't have the money to send you to college." My oldest brother joined the Army, my sister was in the process of joining the Air Force, then my brother (the third one, I'm the youngest) joined the Marine Corps. I 
was a junior, senior in high school, and I went to his graduation in San Diego, and I had already talked to an Air Force recruiter, I was joining the Air Force. And I went to his graduation, and they showed this motivating video like, right before. $\mathrm{He}$ graduates and I mention in the parking lot, we were hugging and everything, and I was like, "Man that was a nice video, I think I'll join the Marine Corps, that will be cool." And he laughed at me and said, "You wouldn't last one fucking day." Literally, as soon as I got home, I met a recruiter and signed up just to prove him wrong. And I got a higher physical test score than him, I got a higher rifle range score than him, and I just did it to prove him wrong. He's like, eleven months older than me, so we're really close. So literally, that is the number one reason. [Also], I got into a lot of trouble in my high school years, I feel like I went to college when I was in high school. So I needed something to change. I needed to get out of this town, get some diversity, get some perspective. That's why I joined. As Lily's military career started out, she wanted be a "a lifer..do twenty-five years...be the first female whatever-whatever." So enthralled was she by the Corps that she decided she was going to be "the face of the female Marine;"the girl on the posters.

Military enculturation experiences. Although Lily's mind about being a "lifer" did not change until after a series of incidents, she began to notice early on the injustices associated with being a female in the Marine Corps.

Yeah, I did anticipate it on some levels, everybody kind of talks about it, [how] it is a man's world. It's a boys club. And everybody, from day one, talks about, "You 
don't want to be that female who tells, you don't want to be that female, you don't want to be that female who reports anything, crying wolf," all those things. You don't want to draw attention to yourself, you're exactly right. And it's like, unsaid, but everybody knows that, everybody knows that. And you pointed out something, the command in general, at least my command - pro report. Always brought in like, three family counselors to give like, sexual harassment, sexual assault briefs, at least once every three months, and we had to sign off. But it was just a check the box, it's not something they would actually practice.

She learned from the military culture that to survive and be successful as a female meant remaining silent about anything that detracted from the image of a Marine.

From day one, even within our boot camp...there was already like, rumors spreading like, "Oh, you don't want to listen to that girl, she'll say you did this," or whatever. So it's really, like, embedded and imprinted in every woman, every female Marine's mind from day one. And it's not like a spoken rule, just unspoken, and everybody knows about it, and don't report, shit happens, kind of like when people say, "You're not a real Marine until you get NJP'd (written up under misconduct)." You're not a female Marine until somebody has physically or emotionally attacked you.

However, her approach to surviving her time in service changed after things became more personal.

In November we had gotten a new first sergeant. First sergeant, single, young, late thirties, early forties, something like that. He'd been in command maybe a 
month before the [Marine Corps] ball. After the ball, we all went to an after-party keep in mind I was under twenty-one. Drank with all of the higher-ups, everybody's barking, Marine Corps ball, rah, rah. At the end of the party, the first sergeant asked me to walk him to his room. So I say, "Okay." [name of friend], which was a friend of mine walked with me. So I walked with the first sergeant. Obviously the first sergeant didn't think I would do that, so I'm walking him to his room. [Name of friend] stops down the hallway to talk on his phone. He was married.

[So] I'm just grabbing his [the first sergeant's] arm, because he's staggering or whatever. And he's talking to me as we walk down the hall and he says, "You know how you got meritoriously promoted to corporal?" I'm like, "Yeah." He says, "That's really great, but if you want to get meritoriously promoted to sergeant, you need to come in my room tonight with me." I was like, "Ha, ha. No thank you. I don't want to earn it like that. I want to earn it the real way." He opened up his door and when he opened up his door, he tried to pull me in. Like, by my arm, he tried to pull me in. Luckily, [name of friend] was just like fifteen feet away and he ran over and shoved...he's a lance corporal at the time. Two lance corporals fighting a first sergeant, it was crazy. Shut him down. And we left and that was it. And I didn't tell anybody. Just left it between [the three of us].

Nobody really talked about it. No, nobody really talked about it. I told my boyfriend at the time, now my husband. He said, "I'm really sorry." He was very supportive. "But you know, you're probably going to cause more drama for 
yourself if you tell anybody." Which he was so right. So right. Six months later six or seven months later, same time but the following year, I start preparing for the Meritorious Sergeant Board. Totally prepared. The sergeant's board is a lot different than the corporal's board. Because [with] the sergeant's board you have to drill, you have to drill a platoon, then you have to do a PFT [physical fitness test], you have to do all these things that you don't have to do for the corporal's board. I PT'd [physically prepared] for like six months to get ready for it. Out there practicing every single day for like six hours with a platoon. Practice, practice, practice. I was so ready. A friend of mine was actually going with me to compete against me. He was kind of chubby, never practiced the drill. Never worked out.

The judgment that Lily used to determine whether the guy was of quality is strictly a militarized standard. She talked about his weight and whether or not he worked out. She presented no alternative for determining whether or not he was deserving of the promotion.

So day of the board, got my uniform, he's got his uniform. I rented the car. Got in the car, we're ready to go, and he's like, "Go by our office real quick. I've got to go print out my MCI." Which MCI's are like [records from the] Marine Corps Institute. You have to do like training - like book type training. You have to do a certain amount of them before you can pick up the next rank. I'm like, "What do you mean, you have to go print it out?" He's like, "Yeah, my..." Whatever MCI it was. "It didn't post online, so I have to go print proof that I did it." I'm like, "Well, 
that MCI's been having problems for over eight months. Because I've been on the phone with MCI, the Marine Corps Institute and it's not a big deal. I finished it six months ago, but it still hasn't posted. It's not a big deal." He's like, "No, if it doesn't show on the computer when they pull your stuff up, you're ineligible to even go up to this board." I'm like, "What do you mean? Who told you that?" He said, "First sergeant told me." I'm like, "What do you mean?" He said, "First sergeant came to my office and said 'Here's a devil dog [nickname for Marine's in that unit] at Marine Corps Institute. Fax your MCI to this guy and he'll put it in the system for you."'

But he [the first sergeant] didn't tell me. Didn't tell me. So I called the first sergeant. I said, "Sitting here talking to [the Marine who was able to go before the board]. Talking about his MCl's. Mine hasn't posted in the system yet, but I have it. I have the paper copy. I can just bring it." He's like, "Nope. Sorry, devil dog." Sorry...devil dog...so I had to literally unpack all my shit out of the van and watch that douche-bag drive away. And he won. Yeah.

While attending [the Marine who was able to go before the board's] promotion party, Lily and her friend discussed how wrongly things turned out for her regarding the board. They began to talk about the incident that happened after the Marine Corps Ball and how it led to the first sergeant leaving her out of the loop.

It gets better, are you ready? The shoehorn officer [Equal Employment Opportunity Officer]- works in our office-overhears. And he comes over and starts asking me about it. I was like, “Yeah well, crap. I wasn't going to tell anyone but you 
overheard me, so..." I tell him everything. And you know, I'm emotional. And I'm like, "Okay, I 'm fine." And [name of friend], which is my boyfriend, soon to be husband's best friend, the married guy, that was there the night that all this went down, was being very supportive, very nice, and says, "Let me walk you home." Because we're like six blocks from my house. "Let me walk you home." And at the time I lived with two male roommates. Loved my roommates. Two guys I'll never forget. They're like my best friends. Anyway, at the time, I lived with them in a three-bedroom house on base. [Name of friend] walks me home. I say, "Good night," kind of pound his shoulder, "This sucks, you know. Good night." Go in my room, go to sleep. Two, three-thirty in the morning I wake up, because my boyfriend at the time was calling, because I didn't call him when I got home. I go to answer the phone and I miss the call, but the light from the phone [is still showing], and I look over and [name of friend] is sitting on my floor. Just staring at me, watching me sleep.

Yeah. My husband's best friend. Sitting on my floor. I'm like, "[name of friend], is that you?" He's like, "Yeah, sh, sh, sh, sh." [He gets up] throws back my blankets, starts touching me. I literally screamed bloody murder and I punch him. He ran out of my house. There was a girl that was visiting one of my roommates that was on the couch, civilian. Saw him run out of my house. [I] reported it, crying, that night. "My husband's best friend. What just happened? He was my support. I don't know what just happened." You know, a whole emotional, cognitive thing. Reported it. As soon as he left. 
Literally, I was just talking about not reporting something that night with him. So if I hadn't just talked about that, I don't think I would have reported it. So, I reported. Police came, arrested him. Took me in for questioning, questioned everything. Questioned the witnesses. My roommates heard me scream, heard a door slam. The girl on the couch saw him leave. You'd think it would be a win-win, right? She learned a hard lesson about what can happen when a female goes against the culture of the Marine Corps and breaks the silence.

Through the whole investigation, I was told "Don't talk to anybody." So I was isolated to high command, while he was talking to everybody in command [saying] "I didn't do it. She's crazy. She's got something against men. I didn't do it." His wife, which was one of my best friends - I wasn't allowed to talk to her. She came to my house crying, several times, "Lily, you've got to talk to me." I'm like, "I can't. Literally, legally, if I talk to you, it can ruin my case." So I didn't talk to anybody or advocate [for] myself within the command. So by the time the actual NJP came, everybody in the command was on his side. Everybody in the command. So I went in, like an idiot, I didn't talk to anybody, didn't advocate [for] myself. I just sat there quietly in my office. He's working like six feet away from me at his desk, for like a month [before the case]. The investigation went on for like a month. One of his golf buddies was actually the gunnery sergeant that was in charge of the investigation.

So we go in to NJP, and I'm thinking...I go into it expecting, this is a pretty serious offense, right? They didn't ask the girl who saw him to come back. They just took 
her written statement. They had him come in. They had his wife come in. They had like four character witnesses come in and then me. You know, I just told my story. I didn't know that he was going to have character witnesses. I didn't have time to like ask somebody to speak on my behalf or anything like that. I go in for them to tell me that they dropped it. No punishment. Nothing. I was like, I just laughed, "Roger that."

Didn't cry. Got my stuff. Left the building. My stupid chief warrant officer and my master sergeant saw me. Came out to the parking lot. I was like, "Literally, if you don't let me go home right now, I will end up saying something that will get me NJP'ed. To you and to you." They were like, "Whatever you say right now, we promise there will be no consequences." "Whatever. I don't give a damn. I just want to leave. I just want to leave. I just want to leave." They would not let me leave for like twenty minutes. I just had to stand in the parking lot and cry in front of my chief warrant officer and my Master Sergeant, both men. Because they were scared I was going to pursue it. Once they figured out that I was okay, then they let me leave.

So I got in the car, went home. Called my husband, boyfriend at the time, told him what happened. And he was as supportive as he could be, but he was like, halfway across the world. And I didn't have anybody else. None of my family flew in for it. I didn't know I was going to lose. I literally expected the exact opposite. So I was completely unprepared. 
Although her boyfriend showed support, Lily's actions towards him after the case belied the truth of her feelings. She felt angry, hurt, isolated, and invalidated; so, she turned towards unhealthy ways of coping.

I've had my own issues with [my husband's response] as well. He's never seen him [since the incident]. But it took me a while. And that's probably a lot of what motivated me. I feel like a lot of why I went crazy at the end stemmed from that one event. And how my husband didn't like, stick up for me. Granted, he was halfway across the world, but he could have like, called him, yelled at him, or wrote him a letter, threatening letter of some sort. Something to like, validate that he believed me. You know what I mean?

I would say thirty days before my EAS [end of service contract], I drank a lot. Substance abuse. I smoked cigarettes back then. Smoked cigarettes a lot. Lot of late nights. Actually cheated on my fiance a few times. Cheated on him left and right.

As Lily was preparing for her separation from the Marine Corps, she felt overwhelmed by the transitions that were about to occur in her life.

Having huge issues with independency, and not going to have any money, freaking out about money. My [husband] was a Staff Sergeant at the time. I knew we were going to have money, but it wasn't going to be mine. And dealing with that, and moving, and everything, like, just kind of went off the wall. And then, finally brought myself back down to Earth. 
They don't really prepare you to get out. They don't prepare you. I mean, you have three days of TAPS class, but what's that? It's three days of information overload with administration-type stuff that you're really not paying attention to anyway. And nobody talks about the social, emotional, cultural things that happen when you get out. I think I just kind of freaked out in preparation of that transition. [But] mentally, I was fine once the transition hit. Because I had the support of my [husband]. That was a huge help. Thankfully [he] didn't break up with me, because I told him everything [about the drinking and cheating]. But he understood...ish happens. And we still got married.

She and her husband have been able to move past their initial rocky start through the support of counseling. From the sessions (individual and couple) and her experiences in the military, she was able to determine her next steps.

Movement towards education. Throughout her military career, Lily pursued higher education with the aid of tuition assistance. She was able to complete her associate's degree before her separation.

I got my associate's in just arts [to make it easier]. I started to go like, criminal justice. And I had this idea that I was going to go to Law School one day. I took one criminal justice class and I took a human growth and development class. Really loved my human growth and development class. Got an A. It was super easy. Loved going and learning. Hated my criminal justice class. So I'm like, "I've got to figure out something, because if I hate Criminal Justice 101, I'm pretty sure that I'm not going to want to go to law school." 
So that's when I really...taking that one class and understanding a little more about it, I guess pointed me in the right direction. But I didn't know if I wanted to do counseling or psychology, like get started on [which] track. Then after I learned more about psychology and people kept telling me, "You're never going to get a job." That's when I decided, "Okay, I'd better go master's."

After applying and being accepted into one institution, her husband's orders changed and she had to identify another school to apply to in a different state. She decided to apply to [name of institution] because they offered the undergraduate and graduate programs she was most interested in pursuing. Lily received her acceptance letter and began preparation for the start of her undergraduate career. With a clear idea of what program to pursue, she developed a plan of study.

Higher education enculturation experiences. Although she loves the program and the classes, she has had some difficulty in adjusting to college life.

[I] couldn't really relate to anybody in your classes. I was twenty-two, so I wasn't that much older than the general population, but I was. It was different. There are so many different things that the military culture puts into you that's so different than the average Joe Schmoe or Suzy Q in class. So like, I didn't fall asleep in class, I wasn't disrespectful, I wasn't throwing things, I wasn't on my phone. It was just culture shock to see people on a cell phone in class. I'm like, "What are you doing? How disrespectful is that?" Talking over the teacher, things like that. I was in culture shock, like, "Why are you doing that?" And the clothes! The clothes! 
Seeing these little girls all over the campus in these shorts that are four inches long.

Yeah, it was hard. The whole culture of college is so much different than the military. No one telling you where to go, where to be, what time to get there, how fast to run on your way there, what to wear. I'm still at classes fifteen to thirty minutes early. I was doing that in undergrad and nobody...everybody was coming in thirty seconds after class started, is when people usually sat down. I didn't understand it.

I just felt like no one could connect to me. It just took a really long time to be friendly, to get a friend. I was like super-social in high school, cheerleader, made really good friends in the Marine Corps. Then I got to college and it was like, as an adult, how do you walk up to somebody and like, "Want to be my friend?" You know, you can't do that. It's weird.

At this stage of her educational career, Lily has formed bonds with several of her peers and frequently works with faculty on various research projects of interest. Additionally, as a way to give back and help others, she has worked with two other student veterans to bring a chapter of the Student Veterans Association to [name of institution's] campus.

\section{Articulating the self.}

"Stolen, But Recovering"

She embraces the culture

Of being "the few and the proud"

Taking comfort in the first place

She has felt like she belonged

By pushing limits of expectations

Constantly challenging herself 
To be distinguished and set apart

Overcoming resistance and barriers

Through individual successes

She externally seeks support

And encouragement of camaraderie

Freely given; until she became a threat

Feeling the power source cut off

The loss of brotherhood

She is separated from the unit

Feeling isolated...and female

Forced to internally seek support

A journey both difficult and challenging

But a familiar motivator

She is recognizing her power

She is coming to her voice

As someone who desires to be an advocate for those transitioning out of the military (especially women), Lily recognizes the influence of military life on one's identity and relation to others.

I was so scared to transition from active duty military to military spouse. I felt like it was degrading and my rank was being taken away from me. Issues of independence and dependency with him [her husband]. How are we going to make any money? Luckily, where we moved - we didn't move on base. And we're not in a highly Marine Corps populated area. So, had we moved to North Carolina, my situation would probably be a lot different. But as far as here, I don't feel like I'm a military spouse. Because I don't have any interactions with other military spouses, I'm not on base. When I go to the commissary, I use my reserve ID, not my dependent ID. My husband carries my dependent ID, I don't even carry the thing. 
When I picture a military spouse, I picture someone with a bow in her hair, and she's got a patriotic apron, and a yellow ribbon on her shirt, and a red dress. With a sign that says, "Welcome home." Something like that, with eight children, a dog and a cat. And she's juggling balls. That would be my picture of the military spouse. That's just the stereotypical picture, but I'm sure that's what the general population thinks as well, like we're uneducated and we have like, red white and blue pom-pons. And that's all we do.

I am hearing this view about military spouses again, but not as often as I would have thought when speaking with former active women, now turned military spouses. I really want to know where this thinking originated. Is the tension that sits between spouse(wife) and female service member a result of how close we are to their husbands? Do they even feel this tension or is it all on the side of the female service member? Come to think of it, I can't remember if I have heard a wife speak this way about a female service member. But that could be a result of not being around many. I think this is an area to be studied.

Although military spouse is not a key aspect of how she understands herself at this point in life, Lily does realize that her identity is evolving and recalls how often she has gone through changes.

My identity shifted I think about 12 or 13 where I became very girly. I didn't want to work anymore in the fields with my dad. I was very lazy and my dad would yell at me all the time because I didn't want to work very hard. I was like whatever. 
Then when my parents divorced it shifted again. I really started to create my own identity when my parents divorced. I tried all sorts of things as far as style, emotions, boys, alcohol, drugs, only once with drugs.

Then at $\mathbf{1 6}$ my mom moved to Florida and my dad moved to Amarillo and I was stuck in small town Texas by myself. So at 16 I literally paid my own rent, had three jobs, my own car, paid for my gas, insurance, food, everything. [And] I became more promiscuous than girly. I was really trying to figure everything out [and I was] like okay, obviously, I can't be on my own and function. What am I going to do now?

I went off to boot camp. Then it shifted to a very masculine identity. I wanted to be just like the boys. Run just as fast as the boys. Shoot just as well as the boys. Spit with the boys. Cuss with the boys. That's what I became for at least the first year and a half of my time in the Marine Corps.

Yeah, it was hard to let go. It was really hard to let go of that feminine piece because I was girly before I went in and then that was stripped away when I went into the Marine Corps. I was glad that [part of] it was stripped away, because I had some really big issues with gender roles and gender expectations. I was so ready to strip all that. I really embraced the masculine identity of the Marine Corps and the Marine Corps mentality. It was almost my saving grace when I got that new persona. I thought I was unstoppable.

Then when I met my husband and had a few girlfriends that were also in the military who were girly, who had lots of clothes, shopping, I kind of morphed 
into... Don't get me wrong, I still wanted to be just as good as the boys and spit with the boys, but I kind of I guess embraced a little bit more of the feminine side of myself [again], becoming more aware of my surroundings, become more aware of my emotions.

Embracing emotions was not something Lily was accustomed to in the early stages of her life. She grew up in a family where "emotions were repressed and suppressed, even with the girls."

After the incident with [my husband's] friend, I reverted back to my behaviors, thoughts and emotions from when I was 17 and [became] really promiscuous and egocentric. I really reverted back to that time in my life. I had picked up another job, so I was working all day and then worked all night at a bar. I started drinking a lot more and smoking cigarettes again. Male attention was something that fueled me during those times. I wasn't super promiscuous, just one person twice.

Not being able to express her emotions in an open and healthy way led to an identity crisis.

Leading up to my nights at the bar, getting the male attention at the bar was what fueled me and in that my identity shifted to where I was lost. I didn't even know who I was. I didn't know who I wanted to be. I didn't know what I wanted to do or who I wanted to marry. I was totally and utterly lost in my identity and my life, everything.

The return of her fiance to the states from Japan served as a stabilizing force in her life. 
Then whenever he came back and we got married and got to Virginia is when I started rebuilding who I am, what I am and what I want to do. He helped me a lot in a lot of those areas, but he also gave me the space I needed to figure things out for myself.

And then I kind of just rebuilt my identity I guess literally starting from nothing. I got back into the church, stopped smoking. My husband and I still recreationally drank on the weekends or whatever, but it was always together.

Then I really came into who I am today as far as identity wise, a good balance I guess. I'm still a super feminist and I hate gender roles and expectations, but I do understand the balance of husband and wife. That's kind of given me that balance that I needed as far as those ideals and then learning and going to school and everything has made me feel more confident and competent. Over the last two years I think my identity is fixated now. Well, not fixated, whole, I guess.

Lily is now more comfortable in her identity and how she has been able to align her actions with her mission and life purpose.

In a most general sense, my purpose is to be happy and to be loved, to love- all those good things.

[And] my mission in life is a little less egocentric; it is to help people similar to myself. I want to help the general population as well, but more specifically I would say my mission is to help female veterans transition and also the sexual assault/ sexual harassment piece of the military, being an advocate or, maybe one day when I'm older, advocating to change policy or do something along those lines as a long- 
term goal.

Through her chosen career path of mental health counseling, she sees how her experiences have prepared her to fulfill her life's mission. She is also motivated by her spiritual identity and believes that she would not be able to really "have anything, love, happiness, fulfillment, anything like that" [outside of her relationship with God]. So in the most basic sense [her relationship with] Christ is the cornerstone of [her] life." Although she recognizes that there are still areas of her life in which she would like to see more growth, she is proud of her newfound awareness of self and looks forward to how her identity will continue to evolve.

Analysis and summary. Throughout the early retelling of her narrative, Lily's identity and understanding of self seem to be in reaction to different changes in her environment and is externally shaped by others' perceptions. She does not actively move herself away from this until after she is married and separated from the military. Seemingly anchored in her relationship with her husband, she has been able to critically reflect on how her life has changed and identify how various systems contributed to those changes. It was apparent from our time spent together during the interviews that she is still processing some of her military experiences and trying to make sense of what they mean in the present.

Her educational experiences have helped to inform her understandings of self as she works to become socialized in the profession of counseling. She is taking her knowledge from the classroom environment and using it to better understand herself and how she relates to others. At this point, she expresses a desire to align the identity of feminist into 
how she understands her identity as wife. Although she used language like "balance" to describe how she perceives her marriage, I interpreted her nonverbal communication to indicate that she still has some uncertainty about this particular area in her life. I attribute this uncertainty to incongruences between her Christian faith and her desire to achieve balance. She spoke of the Christian concept of submission and how she perceives it as being unequal or less than. Lily believes that to be a good wife, she must learn to submit to her husband. This directly contrasts with her understanding of what it means to be an equal partner; which is strongly influenced by feminist literature. Her perception is that if two individuals are equal, there is no place for submission in that relationship. At this point, she has not fully reconciled these seemingly incongruent concepts.

At no time did she discuss how race or class influenced or shaped her worldview. However, the story of her marriage indicated that she is maintaining an awareness of the difficulties of her childhood, a result of growing up below the poverty live. Because she was afraid of being without benefits and income, she and her fiance went ahead and secretly married before her EAS date. They then participated in the planned ceremony for their families three months later. Another indicator of this awareness is her concern of having only one income for the household. Although her husband's salary is enough to cover standard living expenses, she wants to be able to earn her own money and not rely on him for financial support. She has used this as a motivator to fast-pace herself through her graduate education and anticipates finishing the program in May 2013.

The unwanted sexual contact Lily experienced during her time in service serves as a motivator for her advocacy of other female veterans. In knowing the culture of the 
military, she believes that she can better relate to someone else who has gone through similar types of military experiences and wants to be a source of support for them. Instead of allowing the experience to continue to push her towards negative actions, she is now allowing the experience to push her towards more positive actions. This experience also indirectly led to her chosen career path of counseling. Initially, Lily expressed that she had processed her feelings and thoughts regarding the two incidents of unwanted sexual contact; however, during the second interview, she mentioned still feeling anger towards her husband for a comment he made about the alleged perpetrator of the last incident.

Based on her verbal and nonverbal cues, I would argue that although she has been able to move beyond her feelings associated with the first incident, she has not fully processed and dealt with her feelings regarding the second incident. She mentioned during our conversation an ability she has to suppress her emotions. I believe that she is still engaging in this form of coping, with regard to her feelings of her husband's response to the second incident. Although she did not acknowledge it, I could see the distress in her posture while she discussed her husband's reactions to the second incident. As she continues to progress through her mental health counseling program and engages in more contact with clients, I anticipate she will be forced to address these feelings in order to continue growing as a professional counselor. 


\section{CHAPTER FIVE: SHARED NARRATIVES AND STUDENT ENGAGEMENT}

In this chapter, I present the participants' shared narratives of identity, enculturation (i.e. military and higher education), and a discussion of their levels of engagement as students. My choice of what to emphasize is based on what I see as being the most significant aspects of the collected data. I acknowledge there may be other ways of understanding the texts, and I am sure that as I continue to revisit the narratives, while drafting articles for publication, I will be able to understand the data in different ways. The amount and degree of emphasis across the thirty-six transcripts is what led me to identify three topics as the primary themes of the female veteran participants' experiences: movement towards a renegotiation of identity, regaining control, and becoming advocates. Following a discussion of the themes, I discussed their levels of engagement are discussed in relation to the scholarly literature reviewed in Chapter Two. Engagement in this study is understood as their process of academically and socially integrating into the campus community (Kuh, 2003)

\section{Shared Identity Dialogue}

Most theories of identity development discuss a psychological progression of identity formation (Evans et al., 2010). However, no such theory has been written that discusses a renegotiation of identity after separation from a total institution such as the military. Therefore, narrative provides a framework for understanding how the female 
veteran participants make sense of their identity renegotiation and experiences. Through their narratives, the female veterans in this study were able to articulate an emotionality of growth, which allowed me to gain a better understanding of their identity.

The women in this study acknowledged that their choices and the way they view the world may be structured by gender. However, they do not see gender as being the only lens from which they are able to understand their experiences. Although aware of possessing a gendered identity, the gendered self was seen as an inherent part of their realities. They interacted and engaged the world around them based on their experiences as women and were willing to say as much; but only a few, when asked to discuss their identity, even mentioned the role of gender.

Because definitions of self often vary within social contexts, the cultural experiences an individual has establishes boundaries for how they perceive themselves within and outside of that context. Although divisions such as gender, race, ethnicity, and class are frequently used to discuss identity, central to the discussion is how the individual chooses to explain her difference and connection to others as she interfaces with various systems and structures (Zaytoun, 2006). Exploring how sense of self, context, and connection emerge and change over time is essential to understanding how the women in this study discuss their identity.

The majority of the female veteran participants described their identity as being in transition; therefore, I focused on discussing their movement towards a renegotiation of identity in this chapter. Through analysis of the narratives, I was able to identify three major components associated with how the women of this study engaged in the 
renegotiation of their identity: belonging and unsupported, movement towards authenticity, and meaning construction.

Belonging and unsupported. The women of this study were not recruited by the military; they intentionally sought out the military experience. Although their motivations for joining differed, all the women saw the military as an opportunity to fulfill a desire. In committing themselves to the institution, social bonding was a welcomed byproduct of the environment. Although the women interviewed acknowledged how the culture of the military creates a divide amongst women and exists as a gendered place, the majority credit the organization with propelling them towards adulthood and helping them to gain a sense of direction.

Belonging. After first learning the ways of military culture, they were able to learn more about themselves and their place within the system. Although their place did not always result in a positive view of self, the majority of the women interviewed felt like they belonged. This institutional bonding to their respective branches provided the female veteran participants with a greater sense of purpose and meaningfulness that connected their initial motivation for joining with the organization's mission (Siebold, 2007). The women in this study overwhelmingly responded to this institutional bonding by developing a militarized identity. In order to reach a certain level of maturity and success within their respective branch of service, some of the women adopted a persona that would allow them to have a stronger sense of congruence between themselves and the organization (Bailey, 2007). 
Sophia You need to look good in your uniform. I mean, a female that looks good in her uniform is little, very little, to no makeup. That your hair must make a pony and neat. Your uniform must be neat and pressed and just sharp. Your boots from head to toe. You have to know your job and know it well. When you show up to a fight, you show up based on your own merit, not on your back thinking that this ought to get you promoted because now you're just contributing to the male stereotypes of what they think a woman should be. So be able to performed based upon your own ability. Don't be overly feminine. If a guy scratches his private parts and spits while standing next to you, and snorts his nasal congestion and swallows it, don't you dare be grossed out.

MacKayla It's funny because when you put the uniform on, you are supposed to transform into this professional killing machine. Alright, it's extreme but you're supposed to be this professional, you're representing the Army, you're representing the military, you're representing your country.

Hermione It's a way of life. It really is. While you're in the military, you're married to the military, you are the military. There is that little bit of separation that you can divide yourself, but it's always there. I left the Navy, but I'm married to the Navy. I understand that. I recognize that. I think that's why a lot of times marriages fail, because the spouse cannot recognize that you are part of this bigger system, that this is your life. Even if it's your spouse's life, it's still your life. It's a way of life, it's not an aspect of life. You can't just cut it off. 
There were only three examples of women who did not develop a militarized identity, but instead remained in the inductee stage of development (Bailey, 2007); Dasha, Kate and Orpah.

Kate With the structure and people telling me what to do, yes, on the whole it didn't slow my rule; it didn't cramp my style or anything like that. I guess I just didn't pay much attention to it. I think this might be because I never fully incorporated the military into my identity. It was just something I was doing for the time being, even after 12 years.

Orpah I've never been on to be much of a conformist, which I guess going into the military, I worried about that being an issue for me. I don't like orders from other people. I don't really like being told what to do or that I have to conform to a particular idea or notion or standard. It ended up not really being a problem in the military. [Once] there was the whole issue of the way you treat the enlisted. There was a certain assumption that you had to speak to the men in a certain tone, barking orders, that kind of stuff. I never, ever did that. I didn't like it. The adoption of the militarized personas led to internal conflicts and experiences of tension as some of the women found themselves pushing against the structure of the military system. For those two that remained in the inductee stage, once the military no longer provided them with the opportunities they were looking for, they separated from the system.

Unsupported. The female veteran participants who adopted a militarized persona existed in the between space, not feeling supported as an individual, yet feeling like they 
belonged within the system. I am using the phrase "between space" to indicate the tension between who the women were and who they thought they were supposed to be in the military system. The feeling of fragmentation felt by the female veteran participants stems from the conflicting messages received within their respective branches.

As new service members, they received messages of empowerment and unity. However, those messages did not include an equal directive for all members of the organization. In actuality, the military organization dictated how the women were allowed to view their identity and pushed for a saliently expressed militarized, masculine identity.

Orpah I expected the military to let me embrace the notion that being female is not second to being male...unfortunately, that did not hold true.

Through their training, the women learned what parts of themselves were considered appropriate for the social context of the military; they also learned what parts of themselves to keep hidden. For most, the internalized social context conflicted with their understood identity. Consequently, they begin to act out a self that developed from their various military enculturation experiences and not from their own self-consciousness.

Once they were no longer able to live in the between space, they separated from the military. Leaving the military was decided by some and decided for others. All of those making the decision, with the exception of one (Dasha), felt overwhelmed during the transition out of the military and unsure of what direction their life would take in the future.

MacKayla I'm used to being the one in charge and now I'm the one on the receiving end, which is not a bad thing. In a way it's nice. So it's nice, but at the 
same time I struggled with that a lot when I got out, my level of self-importance. And right now it's not important at all. Where I was in the military, I had a lot of people who relied on me and who trusted me, even would just talk to me about personal things in their lives. I liked being somebody that people could depend on and could trust and I don't have that anymore.

Alina There were a couple of months where I was completely lost because I hadn't planned on getting out. I had gotten hurt and discharged medically. Going in I knew I was in for 20 years, four years later what am I going to do. I joined at 17 , so I had been on my own since I was 17 . The next thing I know I'm back at home with my parents and unemployed for the fist time since I graduated high school. Trying to pull all that back together took a little while.

Katniss Very much, I miss it. I miss it a lot. There was so much that could have been done, should have been done. I wish I could, and I think I blew it off for a long time. I'm not functional in regular society in civilian life. I exceled in the Navy, and I figured I would also be able to excel in the civilian world as well. However that wasn't the case. I was either walked on, or walked over. I sank into a depression that I wasn't sure if I would be able to get a hold of. Finally after almost 5 years of fighting it, I decided to see someone at the VA. I wasn't welcomed with open arms, but at the same time they were much more understanding and showed me that I was able to make something of myself. I was able to reestablish myself as a mother, a wife, as a care giver. While I still fight 
my daily battles I feel better about my identity, who I am. Being a student is just a stepping stone to where I will be.

Orpah It has been difficult for me adjusting even all these years later to the civilian world when it's not like that at all. That's how I learned my professional behavior and mannerisms. I've often been disappointed.

Those having the decision made for them shared the same feelings as the first group, but they also felt resentment towards the institution for making the decision for them.

Discussion. Outsider-within is a concept identified by Collins (as cited in Zaytoun, 2006) that demonstrates an individual's sense of belonging within a particular social context. The individual that falls into this category has knowledge of their role within that social context, but no real power. The female veterans in this study often expressed a sense of belonging to their respective military branches, but not feeling supported or validated (i.e. sense of powerlessness) in their experiences within the system. The militarized identity that arose from being in a social context of unequal power led to a fragmentation of experience.

When confronted with life outside of the military, each of the participants had to make a decision of where she would turn to regain her sense of belonging and support. Some chose higher education and some chose relationships. Through this choice, they began to move forward in learning about themselves and learning how to evaluate what aspects of their identity they wanted to maintain or discard. A sense of belonging allowed the women to regain focus and move towards gaining control of their lives. The concept of gaining control will be discussed in the next chapter. Lack of support and strategies to 
ease the tension experienced were the most influential elements of the transition process effecting the female's exit from the military.

Movement towards authenticity. In transitioning out of the military, the female veteran participants are forced to ask themselves who they are if no longer service members. For many of them, their identities are carefully crafted around the system of the military. As the world around them changes, they feel a need to change in order to survive and continue moving forward. The women are in the process of unfreezing their meaning perspectives and aligning their identity with their life mission and purpose. Unfreezing their meaning perspectives is the process by which these women are letting go of certain military experiences and holding on to those that are congruent with who they are becoming ( Jarvis, 1987, 1993; Mezirow, 1978). They are renegotiating their identities as a way to maintain continuity among their past, present, and future selves.

As part of letting go, the women had to decompress and come to terms with how they changed within the military structure. Only then were they able to begin rebuilding their lives. Those who experienced a loss of identity described experiencing an increasing awareness of how the military environment changed them and reshaped their understandings of themselves. Though they felt powerless to do anything about those changes while on active duty, they began to challenge the reshaping once they were free of the system.

Purpose and life mission. Critical reflection or introspection followed the disorienting dilemmas of the female veterans' lives (Mezirow, 1991). For most of the women in the study, various life transitions served as these dilemmas (e.g. leaving the 
military, getting married). Introspection was key to aligning purpose and mission with their renegotiated identity. They started with an understanding of identity rooted in other's perspectives and shifted to an understanding of their identity that flows from internal reflection. Through a series of life transitions or dilemmas, they have been able to move into more authentic versions of self expression and understanding. In moving towards an authentic identity, they learned how to include and exclude aspects of their lives that no longer fit who they understood themselves to be. The women discussed being guided by what they considered their life mission and purpose. Through choice, they gained the power needed to create and alter identity as their lives continue to change.

Movement away from roles. For some of the women interviewed, living out their missions and becoming authentic required a movement away from the limitations of understanding themselves through roles. With every new experience, they now seek meaning that helps them to understand themselves from a more complete or holistic perspective in relation to the experience. Although it may not be possible to completely extract oneself from the influence of external contexts, these women are now more aware of how the external contexts can shape them. They have developed a filtering system that evaluates how well the external fits with their renegotiated identity. If there is a good fit, then they are willing to allow it to shape and inform them. If there is not a good fit, they are learning how to remove it from their lives.

Jennifer I do feel like I am part of the student body, but not [really] a part of the student body. I seem to interact with my teachers because they are my age or a just a little bit older. I do have more personal relationships with my professors 
than I think most students do. I don't go to many student activities. It is not that I wouldn't feel welcome, but there is stuff going on at home. I don't want to live on campus. If I don't have classes, I don't want to be here. So maybe it's just an extension of me or maybe it's because I feel like where most people have their college bonds, I did that in military. So I feel like the social part I've already done and I did that in the military and now it's not that important.

I do not want to give the impression that this process of filtering is an easy one. Identity is messy and complex. The point I want to emphasize is that through their growth towards becoming a more authentic individual, they are also increasing in their awareness of outside influences. Through this awareness, they are better able to process and construct meaning from their experiences.

Towards roles. For other women in the study, their authentic selves are actualized through their roles. They are still moving towards a more complete understanding of themselves, but specific roles are critical to their understanding of who they are becoming. Instead of being open to how roles and relationships evolve as they grow in understanding their identity, they believe that certain roles will always remain a constant and have forever altered their lives and identity. This view was primarily held by the women who were mothers. Every other aspect of themselves flowed around their role of mother.

Sylvia Not seeing my family narrowed my identity, and they make me who I am. They pretty much governed the choices that I make in my life. I realized that wasn't what I wanted or completely who I was. So, bottom line is once you have 
children, everything about you changes. Your whole mindset changes, everything you thought was right or wrong, it changes. It's that deep. I felt like I reached who I was. I felt like I reached my, fulfilled my purpose and that was who I was.

Hermione That's kind of who I am. I don't go into the husband/wife relationship because that's an external. It's a connection but it's not the same as the connection to my daughter if that makes sense. He's part of my life. I could or can't imagine my life without him, either or. I'm not disillusioned. I know that life can change whereas if I lost my daughter, that would completely change me forever. I can't imagine life without her because I don't want to ever, ever have to deal with that. That's kind of who I am. She [has also given] me a new way of looking at the world, which is wonderful.

For the majority of the female veterans who fit into this category, the role of mother did not occur until after they separated from the military. They expressed an unwillingness to juggle this role while on active duty and did not feel comfortable moving into this area of life while serving.

Discussion. The life transitions of separating from the military and/or becoming a mother served as disorienting dilemmas for the female veterans involved in this study. Through these dilemmas, they have been able to engage in critical reflection and create a vision of their renegotiated identity as a more authentic expression of themselves. There is a conscious movement away from an external-oriented self to a self-defined individual. Even with those whose identity is firmly rooted in a specific role, they are choosing to center themselves in that role; it is not a result of external pressures to do so. The 
authentic self emerges from the separation and connectedness experienced; as they move away from the military (separation) and regain control (connectedness) through educational or relationship experiences. Through their authentic expressions of self, they are seeking "to encompass all the dimensions of life, both inner (e.g. mental, emotional, spiritual) and outer (social, political) (Zaytoun, 2006).

Meaning construction. The external constructs of military and higher education experiences have not only shaped the female veteran participants' narratives, these constructs have also effected their meaning-making strategies (Bem, 1993). The process of learning to manage and negotiate identities can be conceptualized by understanding the meaning attributed to the experiences of the women and how that meaning informs their current understanding of self.

Military enculturation experiences. Through participation in a military system that emphasizes gender polarization and androcentrism, the women found themselves as collaborators in their own oppression. On the one hand, they often felt fear and forced to remain silent to witnessed and experienced injustices. On the other hand, they acted as perpetrators in the oppression of other female service members; frequently passing judgement on those not perceived to exhibit enough masculinity to meet military standards. This led to an internal conflict being experienced by most of the participants and a fragmenting of their identity. Although they recognized the military as being a system in which they were able to grow and mature, they no longer liked how they were being forced to fit into a particular mold. The incongruence of self proved to be too much for most of them and they made the choice to leave. For most of the participants, the 
meaning attached to their military experience is one in which they were able to learn about their core self (i.e. personal characteristics, strengths/weaknesses, and capacity to handle the variance of life's circumstances).

Higher education enculturation experiences. The flexible expression of self permitted within higher education communities provided the women with an opportunity to choose how they want to relate to the system. Some chose to anchor themselves in the experience and freely explored new ways of being and relating to others. They took time to reflect on their life missions and how future career decisions would align, while others chose to focus on the outcome of their time in higher education, degree completion. Those focusing on degree completion still fully engaged in the academic community as a way to socialize themselves into their impending profession. A shared meaning between the groups regarding their time in higher education is that they have been able to shed portions of their military experiences and retain those that give strength to their new understanding of self.

Informing identity. The role of androcentrism is the central component of the female veteran participants' encultured lens. Because most of them entered the military at an early stage in the development of their identity, they embraced the militarized identity and made it their own. In moving within the system, they began to experience an incongruence with an identity emphasized by the military and thoughts of who they wanted to become. For most, the incongruence is rooted in the direct or witnessed experiences of injustices. Seemingly, the interpretation of actions or events being unjust was a part of who the women were prior to joining the military. Though none attributed 
this ability to having a gendered worldview, that seems to be the best way to describe how they were able to acknowledge something as being unfair regarding differences between the experiences of men and women.

Kegan's (1994) Constructivist-Developmental theory seemed to be the most appropriate when discussing the change in meaning-making that occurred between the meaning attached to the experiences in the military and experiences in higher education. While transformative learning helps orient the reader to the content of consciousness (understanding the disorienting dilemma or transition), Kegan's theory (1994) will help to emphasize the female veteran participants' structure of consciousness.

Although I did not formally assess the female veteran participants' meaningmaking capacity, I interpreted their narratives and speculated on which order best articulated their expressed idea of meaning-making. The process of meaning making emerging from the female veteran students' narratives indicate that while serving in the military, they primarily engaged in third order meaning making. In transitioning from the military and exiting from the role of active duty service member, the female veteran participants in this study are engaging in the process of moving from the third order of meaning making to the fourth order of meaning making. Noteworthy is that one of the women was operating out of the fourth order while on active duty. Being a member of the marginal discourse in the military seemed to serve as a catalyst for movement from thirdorder to fourth order. The process of meaning-making that emerged from the narratives moved from: (1) satisfaction with externally formed meaning construction; to (2) dissatisfaction with insufficient external definitions and perceptions; to 3) search for an 
internally defined meaning construction; to (4) tentative internal meaning construction and more authentic expression of self.

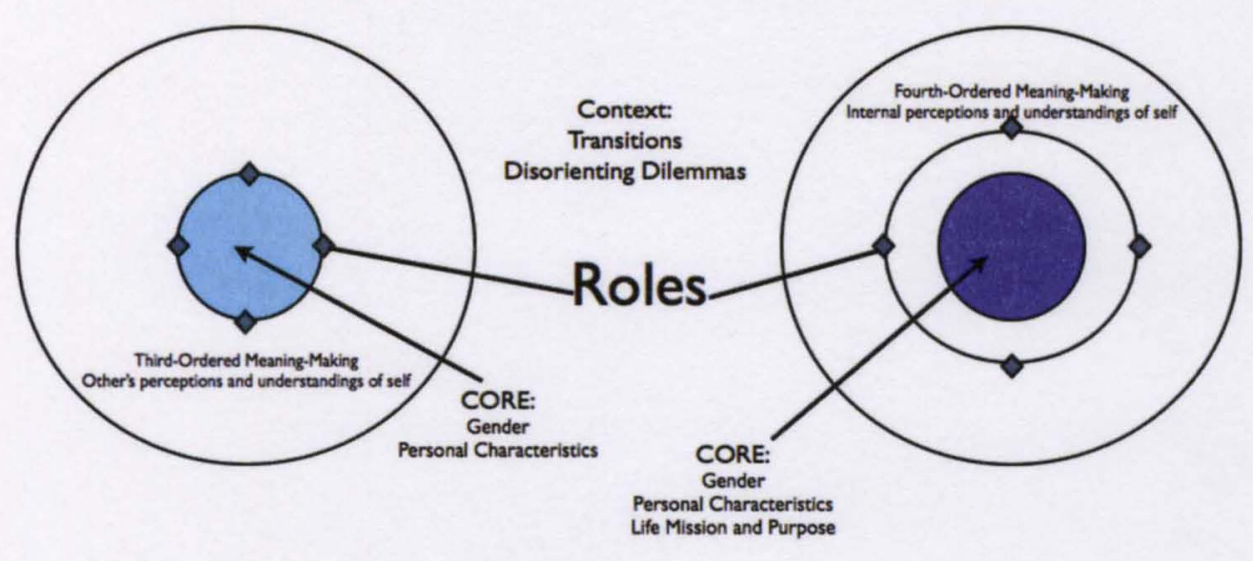

Figure I.I Movement Towards a Renegotiated Identity

Figure 1 is a diagram I constructed to display the participants' evolving approach to constructing meaning in the renegotiation of their identity. The majority started with a core identity that existed only in relation to their roles. They were completely open to external experiences shaping and altering their sense of self. As they began to experience fragmentation in their identity and notice injustices in the system, their ways of knowing evolved. There was a gradual movement towards understanding self and aligning that with an internally understood mission and purpose. From there, the women began to construct meaning from a more enclosed space. They still were aware of external context, 
but they have placed a filter in between their core identity and those external perceptions. The intent now is to operate from more authentic expressions of self.

Summary. This section presented excerpts from each of the women's narratives to illustrate the connection between the narratives and the first research question of this study: How do female veterans describe their understood identity (e.g. gender) after separating from the military? In analyzing collected data, I found that the majority of the women understand their identity as being in transition; therefore, the findings in this chapter discuss the transitional nature of creating identity and were organized into three sections: belonging and unsupported, renegotiating identity, and meaning construction. The majority of the women described significant identity challenges and their narratives suggest that the experience of transitioning out of the military acted as a catalyst in many ways for them to move towards introspection. For most, these identity challenges began while they were in the military and serving on active duty. They found themselves existing in the between space, at odds with the system and trying to be successful within the system; often times taking on a persona that did not feel authentic.

Transitioning out of the military and exiting from the role of service member allowed them to rediscover or discover their purpose and life missions. This led to a renegotiating of their identity and created opportunities for them to incorporate the meaningful aspects of their military experiences into who they wanted to become. Movement towards authenticity is the final step for these women in renegotiating their identity. Through acquiring an understanding of their purpose, they are able to selfvalidate instead of looking for only external forms of validation. The ability to engage in 
self-authorship or authentic expressions of self occurred as the women transformed their ways of knowing. No longer did they feel obligated to construct meaning around externally oriented perceptions; meaning construction for most shift from third order consciousness to fourth order consciousness. Although they may still encounter systems in which they feel like an outsider-within, they perceive the situations differently because they are living more authentically with self-created identities.

\section{Regaining Control}

The quest to find an environment in which the women felt a sense of belonging and support indicates a desire or need to exercise control. By choosing what direction to go in or who to involve in decisions being made, the women were able to express control in their lives and regain some of the power they felt they had lost in the military. Their primary means of expressing control came either through educational pursuits or engaging in relationships. Although all the women in the study are pursuing education, the meaning attributed to the experience is not the same for all.

For some, education is a vehicle to help them move towards a more rewarding and fulfilling career opportunity. These women are not looking for support from their academic experiences; it is simply a means to an end. They instead seek their support and connectedness from the relationships they have outside of the academic community. Although they value the importance of their education, they are seeking out relationships as a way to anchor themselves. The support from certain relationships has created a safe space for the women to enact transitions in their lives. Most of the women sought support 
from their spouses or significant others and not from other family units. They viewed these individuals as being more in touch with their evolving identity.

Katniss Pretty much [name of significant other] and I came to the conclusion, "Alright, we can get out. You come home, your family is here, we can make this work."

Alina I couldn't really decide what I wanted to do and then part of us moving from Florida, moving in together and everything was I made a promise [to myself] that I would go back to school and get my degree. Yes, he's actually already in [city, state]. So I've applied to grad school down there and I'll be moving down there to our house as soon as I'm done here.

For others, their educational experiences are a source of support and connectedness. The educational opportunities act as an anchoring force for the women and their growing understanding of identity. They view the higher education environment as a safe community that allows them to explore, discover, and reconcile aspects of their identity into a more holistic view of self.

Jennifer It's kind of open. I'm just enjoying the education part so much right now that I know if I start thinking about what am I going to do when I get out then I'll start freaking out and I'll not be doing anybody any good. I have vague ideas. My path is definitely going from... Every semester I'm narrowing it down a little bit more so, hopefully, by the time I graduate. I want to enjoy education for education's sake. While I do want a well-paying job, I don't want to be one of 
those people that just focus on that. I do want to enjoy education for education's sake. I want to take classes that I' $m$ interested in and explore multiple directions. Annie You know, I'm just very passionate about doing good in school, challenging - constantly challenging myself. [I feel more myself] in the higher ed setting. I'm a huge geek about what I do and I really enjoy doing the research and going the extra mile for it. I really enjoy my teachers - professors - they're all very passionate and they've all held amazing jobs. Stuff like, "I want to do that! I want to do that! I want to do that!" I'm really excited to be in my field and see what opportunities are available. It's very eye-opening. I love the fresh perspectives. The things that make you go, "Ooh!"

The majority of the female veterans interviewed received messages about education and relationships from their families and the military. These messages helped to inform how the women engage each system.

Messages about education. From their families they learned that education is costly, continual, and necessary. Although not the primary reason given for joining the military, these women were very aware of the educational benefits available to them if they served in the military. For some, they perceived this as being their only option for gaining access to higher education. Their families stressed the cost associated with pursuing a degree and usually left the responsibility of cost up to the individual child. Penelope My parents have six kids and I'm the fourth of six and they didn't set aside any money for any of us. So when I graduated high school I told my parents I'm ready to go to college. I'm smart. I made straight A's mostly. I think college is 
a good next step. They were like 'Oh, well, we didn't set aside any money because we didn't figure anybody would go to college.'

Others received a message that higher education should be a constant and continual part of their lives. They were encouraged to learn for the sake of knowledge and the power associated with knowing.

Dasha There has always been a very positive atmosphere and support group in our family about school, about education and training, and that it is valuable. It is worth the investment in time and money.

Still others received a message from families that higher education was a necessary part of life, neither good nor bad. This message often connected the importance of higher education to employability and mobility within the job force.

Isabella But being the oldest and growing up a little bit rough with my parents, they were like, "Go to college. Join the military. Do something."

Most of the women now view education as a way to gain access to certain opportunities and advance in society. They have an idea of how they want to fulfill their life missions in relation to a career, however, they believe they cannot gain access to that opportunity without proper training and a certain level of education.

The primary message received from the military was that education was necessary. To gain access to higher ranks and be promoted within the military structure required service members having a certain level of education. All commissioned officers have to possess a bachelor's degree and all enlisted service members have to continue to advance their education in order to move up in rank. However, not all branches 
administer promotion points for education in the same way. For some, the points are given based on degree attainment. For others, points are given for course completion. Either way, the message is clear. To be successful in the military requires the pursuit of education in some form.

Messages about relationship (connectedness). The messages the women received were not about how to be in a relationship with someone or build a connection. They were instead messages about how to express oneself in relation to someone else. Most of the women grew up witnessing traditional gendered expressions of identity. From their families, they learned that being a part of the family unit required them to meet certain female gender expectations. Movement towards the military was their first step towards resisting those expectations. Once part of the military system, they received two primary messages about relationships: interaction within the unit is expressed through an androgynous or masculine identity and interactions with others outside of the military is secondary. Both the family and military messages presented the women with a skewed vision of what it means to express oneself in relation to someone else.

Summary. Despite whichever method was selected as a point of control for the women, they were able to propel themselves forward beyond expressed and implied military and family messages to determine how they would like their identity to look. I view the choice to control their higher education or relationship experiences as being necessary to helping them achieve certain goals related to renegotiating their identity. Being in control of choosing their support system provided an opportunity to discover and explore identity in what they considered to be safe spaces. The meaning attached to 
the messages they received from their family and home life heavily influenced how they chose a supportive environment. Women that chose higher education as an expression of their control understood the messages to mean that one's identity is best understood in relation to a larger social context. Women that chose relationships as an expression of their control understood the messages to mean that one's identity is best understood through traditional gendered expressions. Whether through education or relationships, these women feel more empowered in their selected safe spaces. By using the control gained from the relationship and education experiences, they are ready to engage in other meaningful interactions as determined by their own standards.

\section{Becoming Warriors of Advocacy}

Although not expressly verbalized by all of the participants, their interests and actions indicate a desire to either become social justice advocates or continue evolving in their advocacy efforts. By using skills they learned while working in the male-dominated field of the military, these women are able to further an agenda of promoting the empowerment of other female veterans. For most of the women in the study, this notion of becoming an advocate began while they were on active duty.

Annie Once I joined the military and I saw all these unresolved social issues it made me very passionate about it. I'm in the Human Services program. Anything that has to do with helping female veterans is something I want to be a part of. I feel very strongly about the lack of recognition and even how sometimes the recognition may be negative. I feel there is a bigger story to be told which a lot of civilians do not take into consideration. 
A shared experience of witnessing injustices in the military created a bond and sense of togetherness between the female veterans I interviewed and other female veterans (i.e. social solidarity), even though there may not have been a direct interaction (Breton, 2011). These shared values are symbolic of a learned group identity and establish a boundary between female veterans and civilian women. The female veterans in this study were grafted into the cohesive community of the military and are therefore more concerned with advancing social justice issues related to female veterans than females in general (Breton, 2011).

Sylvia I believe as females in the military and as veterans we have an unspoken bond that no other career or profession will ever have!

The experiences of the women in this study are filled with tensions that exist between the positive and negative effects of solidarity. On the one hand, they experienced a negative effect of social solidarity with the military; a system that is highly cohesive yet inequitable ( Breton, 2011; Siebold, 2007). On the other hand, they now have social solidarity with other female veterans, a positive effect of solidarity. What makes the effect positive or negative is the sense of belonging and connectedness felt as a member of the group. For the majority of the women interviewed, the identity of advocate for other female veterans was preempted by their overall military experience of solidarity. From that negative tension, they have been able to learn the importance of social cohesion after experiencing incongruence with a system in power.

The female veteran participants took the positive aspects they learned from the military (i.e. group bonding) and paired it with how they wanted to be treated within any 
system to develop an approach for engaging in other displays of social cohesion. They have been able to use their understanding of an authentic experience of social cohesion to inform how they interact with other female veterans in developing social solidarity. Through the use of value introjection (other-oriented behavior) and bonded solidarity, they are moving from just the experience of solidarity to the action of social justice advocacy in an effort to create an improved social connectedness among all female veterans (Breton, 2011).

In analyzing the participants' transcripts, there are some recurring elements in their narratives that provide a framework for understanding what unites them in their quest for greater social cohesion through advocacy actions. The women frequently discussed issues of fairness, sense of belonging, appreciation for the military experiences, and a feeling of obligation to help other female veterans. These recurring elements are the foundation for the solidarity among female veterans. Fairness was perceived by them as being equitable treatment. They were not necessarily concerned with being treated differently than their male counterparts; they were concerned with being treated unfairly or not being provided with a fair chance. For instance, the women did not mind having different physical fitness standards, but they did mind being excluded from certain military responsibilities simply because they were women.

The disjointed nature of their experience of faimess and belonging generated a fragmentation of their identity. They were able to retain a sense of loyalty to parts of the military system, while also attempting to distance themselves from other aspects of that system. Sense of belonging is perceived as being recognition and authentic membership 
within the military community. For the majority of the women interviewed, they struggled with not feeling accepted or appreciated within the military system. For some, the feelings were there during their entire time of service. For others, the feelings did not arise until after a particular disorienting dilemma, such as sexual harassment. The sense of obligation to other female veterans is interpreted as being related to the participants' greater sense of loyalty to the military system, likely a result of the perceived advantages of being a part of their respective branches.

Even after sharing some of their most negative military experiences, the women were quick to show appreciation for their time on active duty.

Penelope The funny thing is that when I was in the military, I found it hard to say good things about it. But now that I am out of the military, I see lots of good things about [my experiences].

They recognized their individual growth depended in part on their interactions within the military system. What they were able to learn about themselves seemed to overshadow many of the negative experiences that occurred. Their gravitation towards social justice issues that will work to empower other female veterans emphasizes their need to connect with others who share their experiences and appreciation.

Although not all women who served in the military will become social justice advocates, I would argue that all who possess these themes in their narrative of military experience will. For example, there is only one female veteran, out of the eighteen, whose narrative does not align with becoming an advocate. In her narrative she does not include 
a discussion of the concept of fairness nor does she experience a sense of obligation to other female veterans.

Lala In my experience women tend to be gossipy and snippy and mean and I just don't have time for that. I have a strong personality, and I don't have a lot of patience and women try my patience. Like, "Oh my God, I hate women! Her viewpoint about social advocacy differed from all other participants. After hearing her responses, I asked about her motivation for participating in the study. Her motivation for participating was out of a desire to contribute in hopes that the favor will be returned to her if she ever decides to conduct research. She experienced no kinship or solidarity with other female veterans and did not ask about their responses or narratives.

Summary. The concept of "coming to voice, coming to power" is an illustration of identity that is connected to a raised feminist consciousness. Becoming aware of social injustices regarding gender relations can encourage women to actively seek out opportunities to make change in their lives. Existing in between the cultures of military and civilian, forces the female veteran participants "to realize they cannot be isolated within a particular description of identity" (Zaytoun, 2006). Caught in the between space helps the female veteran to understand that her identity has connections to others who have similar experiences. Although these women initially entered into a male-dominated area, the majority have moved back into female dominated disciplines. Within these female dominated disciplines, they are taking what they have learned from their foray into the other and they are using it to build up other women. They are becoming advocates for the cause of feminism, without even being fully aware of their actions. 


\section{Engagement in Higher Education}

The average woman in this study is enrolled full-time, married, and pursuing an undergraduate degree with immediate plans to pursue a graduate degree. Technically, there is an even split between those participants who have children and those who do not have children. However, three of the women I spoke with that currently have no children are in their first trimester of pregnancy. There are some similarities when comparing the average identifiable characteristics of the participants in my study with the data collected in the NSSE 2010 survey: older and married. However, there were far more differences between the average characteristics of my participants and that of the student veteran portrayed by the NSSE survey results: enrolled full-time, not first generation students, and not distance learners. It is important to note that there were several women who identified they would participate in distance education programs because that type of learning environment provides the most flexibility for childcare. However, they prefer the traditional classroom environment.

Unlike the results from the veteran students surveyed by the 2010 NSSE, the female veterans in this study are engaged in the college community and are satisfied overall with their educational experiences. These women did not indicate a need to engage in the traditional experience of higher education (i.e. social and academic integration). However, they expressed a need to engage the meaning of the higher education experience and connect it with their renegotiated identity. In reflecting on their purpose and identity, the women identified second career options that became a part of their renegotiated identity; they began to envision themselves in these new careers. Through 
the process of engaging the meaning of their higher education experiences, they were able to build connections between their future selves and their current degree pursuits. Their enculturation experiences are focused on extrapolating meaning from the higher education environment that will help them to become competent professionals in their next career; capitalizing on the socialization process that occurs within one's academic discipline.

Gender specific literature. When considering the gender specific literature that discusses how life roles and commitments can play a part in preventing women from being engaged in their education (Santovec, 2007), I did not find that to be true for my participants. Although they did not express traditional engagement with the institution, they expressed an engagement with their chosen career path; recognizing that their education will help them to achieve their goals. Considerations of work and family responsibilities moved in tandem with their academic performance and intent.

Sylvia I try to include my children in things that go on at school, especially -there was a dedication ceremony a year or two ago, and I brought my kids with me so they could be a part of that. I actually like taking them to [name of institution], because it's nice to walk around and they have little stores and places to go to, so I like taking them there.

Although some of the participants worked part-time, they indicated that their job responsibilities were further down on their priority lists and did not interfere with school or home obligations. The majority of the women were able to sustain themselves financially because of assistance provided by the Post $9 / 11$ GI Bill. For those that were 
married, their husband's income sustained the household. External commitments, such as family responsibilities, helped the women to remain focused on their educational pursuits (Chartrand, Camp, \& McFadden, 1992; Dill \& Henley, 1998; Sciarra \& Whitson, 2007). The women saw themselves as role models for their families and pursuing a degree helped them to portray what they envisioned when thinking of a good role model.

Academic and social engagement. Lundberg (2003) identifies the importance of adult students engaging in educationally related peer discussions, regardless of the environmental context (on campus with student peers or off-campus with community peers). Their level of engagement in these discussions is identified as a strong predictor of learning and commitment to education. This has proved true for my participants. They frequently shared stories of how they were incorporating their classroom knowledge into different aspects of their everyday lives, often detailing how they shared the information with their husbands, significant others, and family in order to improve a specific action or situation.

Compliance with the widely held concept of academic engagement by interacting with faculty members or instructors was split between the viewpoint of engaging out of necessity and engaging out of an individual motivation for an improved learning experience (Lundberg, 2003; Merriam et al., 2007). Additionally, the women expressed no desire to have their military experiences or perspectives addressed more in the college curricula. They were content with having the opportunity to disclose certain experiences only if they deemed them significant to the conversations in the classroom. 
Hermione I'm not just going to bring it up if it doesn't have something specifically to do with what we're talking about. I'm not definitely not hesitant, but I don't go out of my way to do it either.

In their narratives, the women frequently stated they would like to be more socially engaged on campus, however, it seemed to be more of the "right thing to say" instead of a legitimate feeling. They would use words like "should be" or "need to be" to discuss participation in activities with peers and faculty. When pressed about how they plan to increase their level of social engagement, I was often told that "I really just don't have time." Part of the reason for the lag in social engagement was the result of scheduling restraints and other community commitments. Another reason primarily given was that they found it difficult to connect with the college community because they did not believe programs, services, or organizations were meant for them. The majority expressed no desire to increase their levels of social engagement.

MacKayla I don't talk much to people these days. That's something else. I don't have the interaction that I had. I go to class. I don't talk to anybody there just because I'm not there to make friends. I'm there to learn. Then I come home and do homework with the kids and talk to my husband. I don't have friends here. I don't go out and do things.

Alina The lack of accountability and general attitude that I encountered, particularly among the first or second year students, made it very difficult to communicate and relate to others. To be honest, I found myself dismissing those students that didn't share my drive to succeed. Not to mention the age difference. 
Being a decade older than people who are considered your academic equals (if that is the right word) is something that I still have issues overcoming in my senior year.

Still others were able to identify meaningful social engagement activities that allowed them to connect with other students on campus outside of the classroom.

Kate I went to the initiation ceremony of Golden Key. That is really the only thing they have had. With Secular Students, we are going to the Reason Rally next month up in D.C. There is Darwin Day which I think was today. Last semester we had an Ask-An-Atheist Day, so I was at the table talking with people.

When asked about their level of engagement with veteran services, only a few stated that they were interested in participating in activities for veterans. The female veteran participants appear to be content with how their educational journeys are unfolding and show no signs of wanting to stop out regardless of their levels of social or academic engagement.

Persistence. By viewing the women's experiences through the lens of Bean and Metzner's (1985) model of attrition, I have been able to determine that the women's narratives place less emphasis on integration into a system and more on the integration of their academic, environmental, and psychological variables in relation to the system. The integration of the female veteran participants' variables in relation to their respective higher education campus emphasizes a commitment to education and a commitment to completing degree requirements. 
Four variables are used to discuss the integration in relation to the system: academic performance, intent to leave/commitment to the institution, background and defining variables, and environment. When considering academic performance, the majority of the women placed emphasis on their GPAs. They were eager to share how well they were doing and used a discussion of their grades to inform me of their success in the classroom.

Kate I'm still going to get an A in that class, so don't you worry. That is the thing. Somewhere along the line, if I get an A-, it would be the end of the world. I would not be able to handle it. [Getting an A means] I win. I'm smart enough to do this. It is all for myself. It is meeting my own personal goal of proving to myself that I can do it. I guess this is part of everything I have ever done if I care enough about it.

Katniss I have a 4.0 GPA. I'm very strong. My overall GPA is a 3.88 , which for being a mom at 32 , it's pretty decent.

Lala I like getting good grades. I get really mad if I get less than an A. The participants expressed an intent to continue the pursuit of their degree. However, they were open to receiving their degree from a different institution than the one in which they were currently enrolled. Although they expressed a desire to finish up at whatever program they started, they recognized that military life is unpredictable and that they may have to transfer if their spouse or significant other is relocated to another military assignment. For those that were married to a non-military spouse, they also did not express a commitment to the institution, nor did they express an intent to leave the 
institution. This commitment to degree attainment and not the institution itself aligns with what I learned from my previous research on female veteran student engagement (Author, under review). Key background and defining variables for the female veterans was their time in service and the identification of a career goal that aligned with their understood life mission. An important environmental variable related to their commitment was the financial assistance they received from Post 9/11 GI Bill benefits, retirement pay, and disability pay. The financial assistance provided the women with an opportunity to focus on their academic pursuits without being overly concerned about their current financial situations. This was true for both the married and single women who participated in this study.

Summary. From the data, I was able to conclude that the experience of engaging in higher education had little differentiation between the experiences of female veterans and those typically discussed when referring to adult learners. The distinguishing factors of their experiences were the commitment to an educational goal, not the institution, and their contentment with allowing their military experiences and perspectives to go unaddressed in the classroom environment. Because of their military background, the women appear to have an easier time accepting that their needs can be met at different campuses. For them the important aspect of their education is the degree and not the institution from which they receive it. Within the culture of the military, individuals learn to recognize that no assignment is permanent and that being a service member extends beyond a duty assignment or unit placement. Loyalty is directed towards the military. 
Similarly, the women of this study are loyal to their degree attainment goals, not the institution.

Unlike other underrepresented groups on campus, female veterans did not express a desire to have their military experiences called out or incorporated into classroom discussion (Harper \& Hurtado, 2007). The women I interviewed identified themselves as being very private individuals. They expressed feeling hesitant to bring up their military experiences because of how others would perceive them or because it was something that they only wanted to share with other veterans. They expressed no resistance to bringing up specific military related experiences if they were deemed relevant to classroom discussion. With most aspects of their life, they wanted the opportunity to choose disclosure instead of being forced into disclosing or discussing personal experiences. 


\section{CHAPTER SIX: IMPLICATIONS AND FUTURE RESEARCH}

In this final chapter of my dissertation, I discuss implications for practice within the higher education and military communities. Though the women in this study are full-time students and separated from military service, limiting dialogue to one community over another does not speak to their overall experiences. Therefore, I will discuss implications of the findings from this study in regards to both. Additionally, I will discuss the theoretical implications of the findings as well as how research can be continued in the area of female veterans and female veteran students.

\section{Military Enculturation Implications}

Some of the women experienced feelings of helplessness, silence, distrust, or fear while serving in the military. These feelings acted as psychological barriers that prevented them from taking action (Moane, 2010).

Kate No, whenever I tried to complain it was just taken out on me even worse. I had no supervisory allies whatsoever. Again, I felt helpless.

Jennifer You are told in boot camp that there are certain things you can do if your chain of command is mistreating you. You can go to so-and-so or so-and-so but in reality you don't really know who you can talk to. You don't know who is safe. My first couple of years on the boat were pretty bad. 
Penelope At the time, I think I was an E3. So of course everything I said was null and void, right? Because I'm not important and I don't know how to read or understand anything. The part about the military that really confuses me is that they send you to school and they want you to be smart in order to do your job, but they don't want you to be smart enough to ask any questions.

Because they experienced these psychological barriers within a total system like the military, it is not feasible to ask them to take on the sole responsibility of enacting change. This is often what is expected of those feeling oppressed. They are responsible for reporting and initiating investigations only after an incident has already occurred.

Adopting a more proactive approach to instituting change will likely improve the organizational climate and structure. Implementing change from the top down can send a clear message of intent and highlight the leadership's support of the initiative. Similar to the actions taken when repealing the Don't Ask, Don't Tell policy, the culture of the military can be sent a message from its leadership that it is not okay to create oppressive environments within the five branches of service. In sharing in the narratives with the female veteran participants, it is apparent that identifying women as formal members of the military organization is no longer enough. We want to feel like authentic members of the military.

Political (i.e. power relations) and cultural (i.e. masculine focus) oppression in the military promotes the concentration of power in a largely male minority. This type of system reinforces an attitude of male privilege, where gender difference contributes to the presence of unwanted sexual conduct and harassment. Although the majority of the 
women in this study did not experience or witness what they defined as unwanted sexual conduct or harassment, it is only because they were frequently making excuses for or failing to report some of the behavior that occurs within the military system.

MacKayla People joke around. I can tolerate that. It's the company, whatever. It was never malicious. Just sexual joking around. Everybody does it. I read the articles and everybody is up in arms over stuff.

Lala I was at a party, got really drunk. Woke up, like, my pants around my knees. I didn't even want to do anything about it. I woke up my friend, "Can we go? This sucks. I don't even want to be here." She's like, "No, we have to go to the hospital! This is going to come back and haunt you!" I'm like, "No, it wouldn't. I don't care." Have you ever heard the saying, "To be a woman in the military, you have to be either a bitch or a slut." Have you heard that saying? You can be both. I was both. Had the dude asked, I probably would have done it anyway. Because military ideology justifies the status quo, it plays an important role in maintaining the cultural oppression experienced by the female veteran participants of this study. To move beyond these oppressive situations, there needs to be a movement towards a feminist consciousness of military ideology. This consciousness requires changes in philosophies of practice among military leadership that considers the experiences of and analyzes the group feeling oppressed (e.g. females) (Moane, 2010). Participatory methods are effective approaches to raising consciousness and facilitating transformative action (Moane, 2010). Such approaches may include action research that links structural inequalities to limiting situations, acknowledges both strengths and 
vulnerabilities of changes to the system structure, and creates spaces that allow dialogue between different groups within the system (Moane, 2010).

\section{Higher Education Enculturation Implications}

Instead of only providing a discussion of possible implications for the higher education community, I want to invite the reader to also explore the following questions to determine the implications for practice on their respective campuses:

1. What opportunities are being provided that allow female veteran students to contribute to the campus community as a collective unit? How are their contributions recognized? How can institutions assist female veteran students in enacting their advocacy efforts towards other female veterans?

2. How do higher education institutions assist female veterans in learning to appreciate what they have received from the military environment?

Relating to a desire for social activism. Higher education communities should acknowledge the need for some adult learners, specifically female veteran students, to engage in activities that not only promote individual growth, but also assist the individual in learning how to empower others through advocacy actions. I recognize that this dual focus presents challenges to the higher education community. After all, institutions may already have programs in existence that meet either one or the other of those needs. Developing a program specifically for female veterans, when considering their average enrollment numbers, may not seem practical.

I would argue that the appeal of a program, such as this, likely extends beyond female veterans. Many young women today are trying to understand themselves and their 
role in pushing forward social justice concerns related to feminist ideology. Although some may struggle with identifying themselves as feminist, they are committed to principles of equality and justice (Harris, 2010). The practice of feminism for many has taken on the form of narratives of choice that create opportunities for them to push a social justice agenda through individual activism (Harris, 2010). Higher education institutions can facilitate opportunities for women to come together, engage in selfdiscovery, and find their voice for activism. By understanding the experiences that led to social activism for the female veteran participants in this study, educators can become more thoroughly involved in meeting the needs of other female veterans and women pursuing higher education.

An example of a social justice program focused on individual and collective development can be found at Kalamazoo College (Smith, 2012). They have developed a formalized program of social justice advocacy that is loosely coupled with the academic mission of the institution. This program is housed under the Arcus Center for Social Justice Leadership and was designed to give all students a better idea of how to enact change in the world based on their respective passions regarding advocacy. By providing opportunities for students to engage in thoughtful reflections and focused awareness, students are able to "turn their passion into a viable social justice enterprise through classes and financial support" (Smith, 2012, para. 6). The center also provides opportunities for students to attend annual lectures and participate in relevant internships.

Relating to the individual. As the individual narratives illustrate, female veteran students articulate varied enculturation experiences and understandings of their identity. 
As educators (i.e. practitioners and faculty), it is important to allow and respond to that variation. When the experiences of veteran students remain undifferentiated, the opportunities to engage the individual student is decreased through projections of the general onto the individual. Although it is important to understand general background variables that may be contributing to the experiences of female veteran students, an allowance should be made for educators to step outside the norm of theorized standards of engaging students. As educators, a great service can be done for female veteran students by allowing them the opportunity to attach value and meaning to their experiences instead of telling them what meaning they should draw from their experiences.

One way would be to rethink the timing associated with engaging these students. In consideration of the psychological transition that these women may be going through after transitioning out of the military, more emphasis should be placed on their second semester instead of their first semester with regard to targeted programming. However, I would still advocate for orientation and academic service programming during the early part of their first semesters. Providing them with a semester to acclimate and adjust will allow an opportunity for them to begin the process of attaching meaning to their experience of higher education. Once the meaning has been created, educators can facilitate dialogue that helps female veteran students to develop their own plans of action. The students can then be invited to co-create programs and identify learning outcomes for those programs with the assistance of administrators. 


\section{Recommendations for Continued Research}

Based on the data collected from the participants, I would suggest the continued exploration of the following areas:

1. Discourse analysis of official military language and terminology (e.g. Airman, Seaman/Sailor, Soldier, Marine): The military uses gendered language when identifying and describing service members, which may serve to reinforce the masculine culture; further analysis of the language and terminology would provide additional insight into the organizational culture of the military.

2. Narrative or poetic inquiry of the lived experiences of externally identified veteran students who struggle with the label of veteran: During this research project, I heard several of the women discuss their hesitance to label themselves as "veteran"; an exploration of the meaning individuals attach to this word may provide important implications regarding the development of services for the military and veteran student community.

3. Narrative or poetic inquiry of the lived experiences of female veterans who experience tension in moving from service member to spouse: Many of the women described a tension that arose in their lives as they transitioned from active service member to military spouse; increased understanding of this particular tension may help to better inform the academic community's understanding of female veterans` identity.

4. Cross case comparative analysis of a female veteran who adopted a persona of a more masculine militarized identity compared to a female veteran who fully 
internalized the military masculine identity: This type of analysis can provide a clearer understanding of the variance between experiences of female veterans.

5. Comparative analysis of female veteran students' completion rates with male veteran students' rates: In considering the differences observed between the characteristics identified in the 2010 NSSE and the participants in my study, it may be helpful, when designing retention programs, to see if there are significant differences between the completion rates of male and female veteran students.

6. Intrinsic motivation and meaning making approaches leading to self-efficacy among female veteran students: The women in this study appear to possess high levels of self-efficacy; understanding what led to this development in their lives may prove helpful when designing outreach services for this population and other similar student populations.

7. Exploration of why women want to serve again after experiencing the negative tensions in the military: The majority of the women expressed a desire to serve in the military again, despite their negative experiences; understanding loyalty and commitment to an institution or organization, even in the face of adversity, may prove beneficial to college and university campuses as they recruit students and try to maintain contact with alumni.

I took this approach to presenting areas for future research because of the number of ideas floating in my mind as I engaged this research process. Along each stage of this journey, I saw opportunities to veer off on tangents leading away from my established research questions. The list comprises the ideas that are the most complete; there are others. Although I am inclined to pursue more qualitative approaches to research, I would argue 
in favor of increased quantitative and qualitative research in the area of female veterans. Therefore, I included areas of continued research that will allow the reader to pull from both research traditions. In moving back and forth between the general and specific, I believe a more holistic articulation of the experiences of female veteran students can be provided and understood. 


\section{EPILOGUE}

My hope is that this study offered new insight into the experiences of female veterans undergoing identity renegotiation and transition into higher education. By acknowledging and remaining wakeful to my own experiences, I have been able to orient myself to the narratives, thereby creating what I hope is a more human experience of the data. Through participation in this study, the female veteran participants learned they are not alone in their struggle to define themselves and adjust to life outside of the military. Our experiences, though distinct, are reflections of each others' experiences.

All participants expressed interest in the findings and were excited to be a part of the process. Most found the interview conversations to be therapeutic and felt freed from the weight of their military experiences. As they begin to feel lighter, I found myself feeling weighed down with the knowledge of their experiences. I unashamedly admit feeling inundated with data at the conclusion of all the interviews and briefly considered running away to the wilderness of Alaska in retreat. I repeatedly asked myself during data analysis, "What possessed you to conduct so many interviews?" I have thirty-six transcripts from eighteen participants, data everywhere. The longest transcript is 57 pages and the shortest is 25 pages. During the interviews I was not concerned with page numbers or how long we sat in conversation. I just enjoyed the moments of getting to know the women. It was not until the first few transcripts started rolling in that I started 
to feel overwhelmed. Even though I say this, I would not change a thing. I was allowed access into the lives of these women and that above anything else makes everything worthwhile.

The nature of this study weighed heavily on me from the very beginning. I struggled to find the best research methodology to study the identity of female veterans and I struggled to present the findings in a way that honored their experiences. I found myself, at times, almost unable to leave out portions of narrative because everything they shared meant something and was a testament to who they were. If there was a way I could present the entirety of the interview recordings to the academic community, I would; no editing, no structuring, just raw information.

I have come to realize that the fullness of the experience I shared with each female veteran interviewed cannot be captured and reproduced. Those were isolated moments in time that I can only hope to share fragments of with others through the retellings of narrative included in my dissertation. No one else will ever experience what I shared with my participants, and I find myself saddened by that fact. These women are remarkable and I feel privileged to have shared in a segment of their journey with them.

"Shared Moments"

I have been changed by this process

Because others are able to see themselves in me

Reminding them of who they were, who we are

As female veterans

I listen to their stories of healing

Of becoming and transformation

And I recognize the process as my own

Recounting mischievous moments, we share laughter

Discussing moments of loss, we share tears 
Though some have loss more than others, we all grieve United through our lived military experiences

Through this process we found our voices Silenced by

The same organization that gave us power

To experience more...to become authentic 


\section{REFERENCES}

Ackerman, R., DiRamio, D., \& Garza-Mitchell, R. (2009). Transitions: Combat veterans as college students. New Directions for Student Services, 126, 5-14.

Astin, A. W. (1977). Four critical years: Effects of college on beliefs, attitudes, and knowledge. San Francisco, CA: Jossey-Bass.

Astin, A. W. (1985). Involvement: The cornerstone of excellence. Change, 17, 35-39.

Bach, H. (2007). Composing a visual narrative inquiry. In D. J. Clandinin (Ed.), Handbook of narrative inquiry: Mapping a methodology (pp. 280-307). Thousand Oaks, CA: Sage Publications.

Baechtold, M., \& De Sawal, D.M. (2009). Meeting the needs of women veterans. New Directions for Student Services, 126, 35-45.

Bailey, D. (2007). Invisible warriors: In search of better counseling services for women who serve in the military. (Doctoral dissertation). Retrieved from ProQuest. (Document ID: 3329212).

Baker, H. (2006). Women in combat: A culture issue. U.S. Army War College Strategy Research Project, Carlisle Barracks: U.S. Army War College.

Banks, J. (2010). Female nontraditional students in higher education. (Doctoral dissertation). Retrieved from Dissertations \& Theses. (Publication No. AAT 3432098). 
Bauman, M. (2009). The mobilization and return of undergraduate students serving in the National Guard and Reserves. New Directions for Student Services, 126, 15-23.

Baxter Magolda, M. B. (1990). Gender differences in epistemological development. Journal of College Student Development, 31(6), 555-561.

Baxter Magolda, M. B. (1999). Constructing adult identities. Journal of College Student Development, 40(6), 629-644.

Bean, J. P., \& Metzner, B. S. (1985). A conceptual model of nontraditional undergraduate student attrition. Review of Educational Review, 55, 485-540.

Belenky, M. F., \& Stanton, A. V. (2000). Inequality, development, and connected knowing. In J. Mezirow \& Associates (Eds.), Learning as transformation (pp. 334). San Francisco, CA: Jossey-Bass.

Bruner, J. (2004). Life as narrative. Social Research, 71(3), 691-710.

Belenky, M. F., Clinchy, B. M., Goldberger, N. R., \& Tarule, J. M. (1986). Women's ways of knowing: The development of self, voice, and mind. New York, NY: Basic Books.

Bem, S. L. (1993). The lenses of gender: Transforming the debate on sexual inequality. New Haven, CT: Yale University Press.

Berger, P. L., \& Luckmann, T. (1967). The social construction of reality. Garden City, NY: Doubleday and Company.

Blickenstaff, J. C. (2005). Women and science careers: Leaky pipeline or gender filter? Gender and Education, 17(4), 369-386. 
Bloom, L. R. (1998). Under the sign of hope: Feminist methodology and narrative interpretation. Albany, NY: State University of New York Press.

Boshier, R. (1973). Educational participation and dropout: A theoretical model. Adult Education, 23, 255-282.

Bradley, J. S., \& Graham, S. W. (2000). The effect of educational ethos and campus involvement on self-reported college outcomes. Journal of College Student Development, 4l(5), 488-502.

Brady, I. (2009). Foreword. In M. Prendergast, C. Leggo, \& P. Sameshima (Eds.), Poetic inquiry: Vibrant voices in the social sciences (pp. xi- xvii). Rotterdam, Netherlands: Sense Publishers.

Branker, C. (2009). Deserving design: The new generation of student veterans. Journal of Postsecondary Education and Disability, 22(1), 59-66.

Breese, J. R., \& O'Toole, R. (1995). Role exit theory: Applications to adult women college students. Career Development Quarterly, 44(1), 12-25.

Breton, M. (2011). Citizenship consciousness, nonbounded solidarity, and social justice. Social Work With Groups, 34(1), 35-50. doi: 10.1080/01609513.2010.520103

Bridges, W. (1980). Transitions: Making sense of life's changes. Addison-Wesley, Reading, MA.

Business and Professional Women's Foundation. (2007). Women veterans in transition. Washington, D.C.: Business and Professional Women's Foundation.

Cahnmann, M. (2003). The craft, practice, and possibility of poetry in educational research. Educational Researcher, 32(3), 29-36. 
Carr, D. (1986). Time, narrative, and history. Bloomington, IN: Indiana University Press.

Carrington, P., Scott, J., \& Wasserman, S. (2004). Models and methods for social network analysis. New York, NY: Cambridge University Press.

Castells, M. (1997). The power of identity: The information age - economy, society, and culture. London: Blackwell.

Castro, C. (2005). Battlemind training: Transitioning from combat to home. Washington, DC: Walter Reed Army Institute of Research.

Chartrand, J. M., Camp, C. C., \& McFadden, K. L. (1992). Predicting academic adjustment and career indecision: A comparison of self-efficacy, interest congruence, and commitment. Journal of College Student Development, 33, 293-300.

Chase, S. E. (2005). Narrative inquiry: Multiple lenses, approaches, voices. In N. K. Denzin \& Y. Lincoln (Eds.), Handbook of Qualitative Research. (3rd ed.) (pp. 651-679). San Francisco, CA: Jossey-Bass.

Clandinin, D. J., \& Connelly, F. M. (2000). Narrative inquiry: Experience and story in qualitative research. San Francisco, CA: Jossey-Bass.

Clandinin, D. J. \& Murphy, S. (2007). Looking ahead: Conversations with Elliot Mishler, Don Polkinghorne, and Amia Lieblich. In Clandinin, D. J. (Ed.), Handbook of narrative inquiry: Mapping a methodology (pp. 632-650). Thousand Oaks, CA: Sage Publications.

Cohn, C. (2000). How can she claim equal rights when she doesn't have to do as many push-ups as I do? The framing of men's opposition to women's equality in the 
military. Men and Masculinities, 3(2), 131-51.

Cook, B. J., \& Kim, Y. (2009). From soldier to student: Easing the transition of service members on campus. Washington, DC: American Council on Education.

Cooney, R. T., Wechsler-Segal, M., Segal, D. R., \& Falk, W. (2003). Racial differences in the impact of military service on the socioeconomic status of women veterans. Armed Forces and Society, 30, 53-86.

Cote, J., \& Levine, C. (2002). Identity formation, agency, and culture. Hillsdale, NJ: Lawrence Erlbaum Associates.

Cornum, R. (1996). Soldiering: The enemy doesn't care if you're female. In J. H. Stiehm (Ed.), It's our military too! Women and the US military (pp. 3-23). Philadelphia, PA: Temple University Press.

Craig, C., \& Huber, J. (2007). Relational reverberations: Shaping and reshaping narrative inquiries in the midst of storied lives and contexts. In D. J. Clandinin (Ed.), Handbook of narrative inquiry: Mapping a methodology (pp. 251-279). Thousand Oaks, CA: Sage Publications.

Creamer, E., Duggan, M., \& Kidd, R. (1999). STD 105: Process groups as instructional medium for re-entry women at Paul D. Camp Community College. Inquiry: The Journal of the Virginia Community Colleges, 4(2), 19-25.

Daloz, L. A. (1986). Effective teaching and mentoring: Realizing the transformational power of adult learning experiences. San Francisco, CA: Jossey-Bass.

Davies, C. (1996). The sociology of professions and the profession of gender. Sociology, $30(4), 661-678$. 
Davis, K. D., \& McKee, B. (2004). Women in the military: Facing the warrior framework. In F. C. Pinch, A. T. MacIntyre, P. Browne, \& A. C. Okros (Eds.), Challenge and change in the military: Gender and diversity issues (pp. 52-75). Winnipeg, Manitoba: Canadian Forces Leadership Institute, Canadian Defense Academy.

Deaux, K. (1995). How basic can you be? The evolution of research on gender stereotypes. Journal of Social Issues, 51, 11-20.

Deal, T. E., \& Kennedy, A. A. (2000). Corporate cultures: The rites and rituals of corporate life. Perseus Publishing, Cambridge, MA, USA.

Denzin, N. K., \& Lincoln, Y. S. (2000). The discipline and practice of qualitative research. In N. K. Denzin \& Y. S. Lincoln (Eds.), Handbook of qualitative research (2nd ed.) (pp. 1-28). Thousand Oaks, CA: Sage.

Dill, P. L., \& Henley, T. B. (1998). Stressors of college: A comparison of traditional and nontraditional students. The Journal of Psychology, 132(1), 25-33.

DiRamio, D., Ackerman, R., \& Mitchell, R. L. (2008). From combat to campus: Voices of student-veterans. Journal of Student Affairs Research and Practice, 45(1), 73-102.

Dixson, A. D., Chapman, T. K., \& Hill, D. A. (2005). Research as an aesthetic process: Extending the portraiture methodology. Qualitative Inquiry, 11, 16-26.

Dunivin, K. O. (2008). Military culture: A paradigm shift. Air War College Maxwell Paper, 10, 1-37.

Ebaugh, H. R. (1988). Becoming an ex: The process of role exit. Chicago: University of Chicago Press. 
Elder, G., Johnson, M., \& Crosnoe, R. (2003). The emergence and development of life course theory. In J. Mortimer \& M. Shanahan (Eds.), Handbook of the life course (pp. 3-19). New York: Kluwer Academic.

Enloe, C. (2000). Manuevers: The international politics of militarizing women's lives. Berkeley and Los Angeles, California: University of California Press.

Evans, N. J., Forney, D. S., Guido-DiBrito, F. M., Patton, L. D., \& Renn, K. A. (2010). Student development in college: Theory, research, and practice ( $4^{\text {th }}$ ed.). San Francisco, CA: Jossey-Bass.

Faulkner, S. L. (2007). Concern with craft: Using arts poetica as criteria for reading research poetry. Qualitative Inquiry, 13, 218-234.

Frantz, S., \& Asher, G. (2009). Supporting veterans in the classroom. Minnesota state colleges and universities. Little Falls, MN: PaperClip Communications.

Freeman, M. (2007). Autobiographical understanding and narrative inquiry. In D. J. Clandinin (Ed.) Handbook of narrative inquiry: Mapping a methodology (pp. 120-145). Thousand Oaks, CA: Sage Publications.

Gannon, S. (2001). (Re)presenting the collective girl: A poetic approach to a methodological dilemma. Qualitative Inquiry, 7, 787-800.

Garrick, J., \& Solomon, N. (2001). Technologies of learning at work: Disciplining the self. In V. Sheared \& P. A. Sissel (Eds.), Making space: Merging theory and practice in adult education (pp. 301-313). New York: Bergin \& Garvey.

Gilbert, J. (2001) Science and it's 'other': Looking underneath 'woman' and 'science for new directions in research on gender and science education, Gender and 
Education, 13(3), 291-305.

Gilligan, C. (1982). In a different voice. Cambridge, MA: Harvard University Press.

Glazer-Raymo, J., Townsend, B., \& Ropers-Huilman, B. (Eds.). (2000). Women in American higher education: A feminist perspective (Vol. 2). Needham Heights, MA: Ginn.

Glesne, C. (1997). That rare feeling: Re-presenting research through poetic transcription. Qualitative Inquiry, 3, 202-222.

Glesne, C. (1999). Becoming qualitative researchers: An introduction. White Plains, NY: Longman.

Goodman, J., Schlossberg, N. K., \& Anderson, M. L. (2006). Counseling adults in transition: Linking practice with theory (3rd ed.). New York, NY: Springer.

Gouliquer, L. (2011). Soldiering in the Canadian forces: How and why gender counts. Unpublished doctoral dissertation, McGill University, Canada (NR74385).

Harris, A. (2010). Mind the gap. Australian Feminist Studies, 25(66), 475-484. doi: $10.1080 / 08164649.2010 .520684$

Hayes, E., \& Smith, L. (1994). Women and adult education: An analysis of perspectives in major journals. Adult Education Quarterly, 44(4), 201-221.

Heilbrun, C. (1988). Writing a woman's life. New York: Ballantine.

Heinz, W., \& Kruger, H. (2001). Life course: innovations and challenges for social research. Current Sociology, 49(2), 29-45.

Herbert, M. S. (1998). Camouflage isn't only for combat: Gender, sexuality, and women in the military. New York: New York University Press. 
Hersh, S. (2003). Chain of command: The road from 9/11 to Abu Ghraib. New York: HarperCollins, 2004

Hicks, M. (2011). Making my narrative mine: Unconventional articulations of a female soldier. Qualitative Inquiry, 17(5), 461-465.

hooks, b. (1997). Wounds of passion: A writing life. New York: Henry Holt and Company.

Huber, M., Clandinin, D. J., \& Huber, J. (2006). Relational responsibilities as narrative inquirers. Curriculum and Teaching Dialogue, 8(2), 209-223.

Hugo, J. M. (1990). Adult education history and the issue of gender: Toward a different history of adult education in America. Adult Education Quarterly, 41(1), 1-16.

Harper, S. R., \& Hurtado, S. (2007). Nine themes in campus racial climates and implications for institutional transformation. In S. R. Harper \& L. D. Patton (Eds.) Responding to the realities of race on campus, New Directions for Student Services, Vol. 120 (pp. 7-24). San Francisco: Jossey-Bass.

Ivie, R. Czujko, R., \& Stowe, K. (2002). Women physicists speak: the 2001 international study of women in physics. Washington, DC, American Institute of Physics.

Jackson, S., \& Jones, J. (1998). Thinking for ourselves: An introduction to feminist theorizing. In S. Jackson \& J. Jones (Eds.), Contemporary feminist theories (pp. 1-11). New York: New York University Press.

Jackson, S., \& Scott, S. (2002). Gender: A sociological reader (Eds.). New York: Routledge.

Jarvis, P. (1987). Adult learning in social context. New York: Croom Helm. Jarvis, P. (1993). Learning as a religious phenomenon. In P. Jarvis \& N. Walters (Eds.), 
Adult education and theological interpretations (pp. 3-16). Malabar, FL: Krieger. Johnson-Bailey, J. (1999). The ties that bind and the shackles that separate: Race, gender, class, and color in a research process, International Journal Of Qualitative Studies In Education (QSE), 12(6), 660.

Jones, S. (1997). Voices of identity and difference: A qualitative exploration of the multiple dimensions of identity development in women college students. Journal of College Student Development, 38(4), 376-385.

Josselson, R. (1987). Finding herself: Pathways to identity development in women. San Francisco: Jossey-Bass.

Josselson, R. \& Lieblich, A. (2003) The narrative study of life. London: Sage.

Jun, J. (2005). Understanding dropout of adult learners in e-learning. (Unpublished doctoral dissertation). University of Georgia, Athens, Georgia.

Kanter, R. M. (1977). Men and women of the corporation. New York: Basic Books.

Kasworm, C. (2003). Adult meaning making in the undergraduate classroom. Adult Education Quarterly, 53(2), 81-98.

Kegan, R. (1994). In over our heads: The mental demands of modern life. Cambridge, MA: Harvard University Press.

Kinzie, J., Hayek, J., Palmer, M., Hossler, D., Jacob, S., \& Cummings, H. (2004). 50 years of college choice: Social, political and institutional influences on decisionmaking process. Indianapolis, IN: Lumina Foundation.

Kirsch, G. E, Maor, F. S, Massey, L, Nickoson-Massey, L., \& Sheridan-Rabideau, M. P. 
(2003). Feminism and composition: A critical sourcebook. Boston: Bedford/St.

Martin's Press.

Knefelkamp, L. L., Golec, R. R., \& Wells, E. A. (1985). The practice-to-theory-topractice model. Unpublished manuscript, University of Maryland, College Park.

Kovitz, M. (2000). The enemy within: Female soldiers in the Canadian forces. Canadian Woman Studies, 19(4), 36-40.

Kovitz, M. (2003). The roots of military masculinity. In P. R. Higate (Ed.) Military masculinities: Identity and the state (pp. 1-14). Westport, CT.: Praeger Publishers.

Kroth, M., \& Boverie, P. (2000). Live mission and adult learning. Adult Education Quarterly, 50, 134-150.

Kuh, G. D. (2003). What we're learning about student engagement from NSSE. Change 35(2): 24-32.

Lazarus, R., \& Folkman, S. (1984). Stress, appraisal, and coping. New York: Springer Publishing Company.

Liao, T. F., \& Cai, Y. (1995). Socialization, life situations, and gender-role attitudes regarding the family among white American women. Sociological Perspectives, $38(2), 241-260$.

Lincoln, Y. S., \& Guba, E. G. (1990). Judging the quality of case study reports. Qualitative Studies in Education, 3(1), 53-59.

Lorber, J. (1998). Gender inequality: Feminist theories and politics. Los Angeles: Roxbury. 
Lundberg, C. A. (2003). The influence of time-limitations, faculty, and peer relationships on adult learning: A causal model. Journal of Higher Education, 74(6), 665-688.

MacKinnon-Slaney, F. (1994). The adult persistence in learning model. Journal of Counseling and Development, 72(3), 268-275.

Madden, M. E. (2007). Strategic planning: Gender, collaborative leadership, and organizational change. In J. Chin, B. Lott, J. Rice, and J. Sanchez-Hucles, Women and leadership: Feminist visions and diverse voices (pp. 192-208). Somerset, NJ: Blackwell Press.

Martin, J. R. (2000). Coming of age in academe: Rekindling women's hopes and reforming the academy. New York and London: Routledge.

Meilinger, P. S. (2007). American military culture and strategy. Joint Force Quarterly, 46 (3), 80-86.

Meloy, J. (2001). Writing the qualitative dissertation: Understanding by doing. Hillsdale, NJ: Lawrence Erlbaum.

Merriam, S. B., Caffarella, R. S., \& Baumgartner, L. M. (2007). Learning in adulthood: A comprehensive guide ( $3^{\text {rd }}$ ed.). San Francisco, CA: Jossey-Bass Wiley.

Merriam, S. B., \& Grace, A. P. (2011). The Jossey-Bass reader on contemporary issues in adult education. San Francisco: Jossey-Bass.

Mezirow, J. (1978). Perspective transformation. Adult Education, 28(2), 100-110.

Mezirow, J. (1990). How critical reflection triggers transformative learning. In J. Mezirow \& Associates (Eds.), Fostering critical reflection in adulthood (pp. 1-20). San Francisco, CA: Jossey-Bass. 
Mezirow, J. (2000). Learning to think like an adult: Core concepts of transformation theory. In J. Mezirow \& Associates (Ed.), Learning as transformation (pp. 3- 34). San Francisco, CA: Jossey-Bass.

Miles, M., \& Huberman, M. (1994). Qualitative data analysis: A source book for new methods ( $2^{\text {nd }}$ ed.). Thousand Oaks, CA: Sage Publications.

Military Friendly Academic Advisory Board (2011). Military friendly schools. G. I. Jobs. Retrieved from http://www.militaryfriendlyschools.com/article/about-us

Miller, H. L. (1967). Participation of adults in education: A forcefield analysis. Boston: Center for the Study of Liberal Education for Adults, Boston University.

Moane, G. (2010). Sociopolitical development and political activism: Synergies between feminist and libertion psychology. Psychology of Women Quarterly, 34(4), 521-529. doi:10.1111/j.1471-6402.2010.01601.x

Moradi, B. (2005). Advancing womanist identity development: Where we are and where we need to go. The Counseling Psychologist, 33(2), 225-253.

Morgan, M. J. (2003). The reconstruction of culture, citizenship, and military service. Armed Forces \& Society, 29(3), 373-391.

Motulsky, S. L. (2005). Snails, gazelles, and elephants: A qualitative examination of identity and relational processes of midlife women in career transition. (Doctoral dissertation). Retrieved from Dissertations \& Theses. (AAT 3161643). Nanton, C. R. (2009). Ties that bind: Cultural referent groups and coping strategies of adult women as learners. New Directions for Adult and Continuing Education, 122, $13-22$. 
National Survey of Student Engagement. (2010). Major differences: Examining student engagement by field of study—annual results 2010. Bloomington, IN: Indiana University Center for Postsecondary Research.

Park, J., \& Choi, H. (2007). Differences in personal characteristics, family and organizational supports, and learner satisfaction between dropouts and persistent learners of online programs. In G. Richards (Ed.), Proceedings of world conference on e-learning in corporate, government, healthcare, and higher education (pp. 6444-6450). Chesapeake, VA: AACE.

Pascarella, E., \& Terenzini, P. (1991). How college affects students: Findings and insights from twenty years of research. San Francisco, CA: Jossey-Bass.

Patton, M. Q. (2002). Qualitative research and evaluation methods (3rd ed.). Thousand Oaks, CA: Sage.

Perry, W. G. (1998). Forms of intellectual and ethical development in the college years. Austin, TX: Holt, Rinehart, \& Winston.

Pierce, G. (1998). An inclusive paradigm for education-valuing the different voice. Initiatives, 58(3), 57-66.

Piirto, J. (2002). The question of quality and qualifications:Writing inferior poems as qualitative research. Qualitative Inquiry, 15(4), 431-446.

Poindexter, C. C. (2002). Research as poetry: A couple experiences HIV. Qualitative Inquiry, 8, 707-714.

Polkinghorne, D. (2004). Practice and the human sciences: The case for a judgmentbased practice of care. Albany, N.Y.: State University of New York Press 
Prendergast, M. (2009). "Poem is what?" Poetic inquiry in qualitative social science research. International Review of Qualitative Research, 1(4), 541-568.

Radford, A. W. (2009). Military service-members and veterans in higher education: What the new GI Bill may mean for postsecondary institutions. Washington, DC: American Council on Education.

Richardson, L. (1992). The consequences of poetic representation: Writing the other, rewriting the self. In C. Ellis \& M. G. Flaherty (Eds.), Investigating subjectivity: Research on lived experience (pp. 125-140). Newbury Park, CA: Sage.

Richardson, L. (1993). Poetics, dramatics, and transgressive validity: The case of the skipped line. Sociological Quarterly, 34, 695-710.

Richardson, M. (1998). Poetics in the field and on the page. Qualitative Inquiry, 4, 451462.

Richardson, L. (2002). Poetic representations of interviews. In J. F. Gubrium \& J. A. Holstein (Eds.), Handbook of interview research: Context and method (pp. 877891). Thousand Oaks, CA: Sage.

Riessman, C. K. (1993). Narrative analysis. Newbury Park, CA: Sage.

Riessman, C. K. (2002). Analysis of personal narratives. In J. F. Gubrium \& J. A. Holstein (Eds.), Handbook of interview research (pp. 695-710). Thousand Oaks, CA: Sage. 
Reissman, C. K. (2008). Narrative methods for the human sciences. Thousand Oaks, CA: Sage.

Rossman, G. B., \& Rallis, S. F. (2003). Learning in the field: An introduction to qualitative research ( $2^{\text {nd }}$ ed.). Thousand Oaks, CA: Sage.

Rubenson, K. (1977). Participation in recurrent education: A research review. Paper presented at meeting of National Delegate on Developments in Recurrent Education, Paris, March 1977. In K. P. Cross (Ed.) Adults as learners: Increasing participation and facilitating learning. San Francisco, CA: Jossey-Bass.

Rubin, H. J., \& Rubin, I. S. (2005). Qualitative interviewing: The art of hearing data (2nd ed.). Thousand Oaks: Sage.

Rumann, C.B., \& Hamrick, F.A. (2009). Supporting student veterans in transition. New Directions for Student Services, 126, 25-34.

Santovec, M. L. (2007). Campus work/life policies: Moving from policy to practice. ADVANCE Library Collection. Paper 136. Retrieved from http:// digitalcommons.usa.edu/advance/136.

Schlossberg, N. K. (1981). A model for analyzing human adaptation to transition. Counseling Psychologist, 9(2), 2-18.

Schlossberg, N. K., Waters, E. B., \& Goodman, J. (1995). Counseling adults in transition: Linking practice with theory, (2nd ed.). New York: Springer Publishing Company.

Schwandt, T. A. (2000). Three epistemological stances for qualitative inquiry: 
Interpretivism, hermeneutics and social constructionism. In N. K. Denzin \& Y. S. Lincoln (Eds.) Handbook of qualitative research (pp. 189-214). Thousand Oaks, CA: Sage Publications.

Sciarra, D. T., \& Whitson, M. L. (2007). Predictive factors in post-secondary educational attainment among Latinos. Professional School Counseling, 10(3), 307-316.

Siebold, G. L. (2007) The essence of military group cohesion. Armed Forces \& Society, $33,286-295$.

Silva, J. (2008). A new generation of women: How female ROTC cadets negotiate the tension between masculine military culture and traditional femininity. Social Forces, 87 (2), 937-958.

Skinner, K. M., Kressin, N., Frayne, S., Tripp, T. J., Hankin, C. S., \& Miller, D. R. (2000). The prevalence of military sexual assault among female veterans' administration out-patients. Journal of Interpersonal Violence, 15, 291-310.

Smith, M. (2012). Social justice revival: Colleges embrace social justice curriculum. Inside Higher Ed. Retrieved from http://www.insidehighered.com/news/ 2012/01/31/colleges-embrace-social-justice-curriculum

Smith, N. L. (under review). Experiencing the journey: An exploration of the shared narratives of female veteran students' college integration experiences. Journal About Women in Higher Education.

Smith, S. (1987). A poetics of women's autobiography: Marginality and the fictions of self-representation. Bloomington: Indiana University Press. 
Soeters, J. L., Poponete, C. R., \& Page, J. T. (2006). Culture's consequences in the military. In T. W. Britt, A. B. Adler, \& C. A. Castro (Eds.), Military life: The psychology of serving in peace and combat (pp. 13-34). Westport, CT: Praeger Security International.

Sorsoli, L., \& Tolman, D. (2008). Hearing voice: Listening for multiplicity and movement in interview data. In S. N. Hesse-Biber \& P. Leavy (Eds.), Handbook of emergent methods (pp. 495-515). New York: Guilford.

Spady, W. G. (1971). Dropout from higher education: Toward an empirical model. Interchange, 2(3), 38-63.

Spanard, J. A. (1990). Beyond intent: Reentering college to complete the degree. Review of Educational Research, 60(3), 309-344.

Spencer, B. (2006). The purposes of adult education: A short introduction. Toronto: Thompson Educational Publishing.

Stahl, V., \& Pavel, M. (1992). Assessing the Bean and Metzner model with community college student data. Dissertation presented at the annual meeting of the American educational research association (ERIC No. ED 344 639).

Stalker, J. (1996). Women and adult education: Rethinking androcentric research. Adult Education Quarterly, 46(2), 98-113.

Stalker, J. (1998). Women in the history of adult education: Misogynist responses to our participation. In B. Trilling \& C. Fadel (Eds.) Learning for life in our times (pp. 238-249). Toronto: Thompson Educational Publishing.

Stets, J. E., \& Burke, P. J. (2000). Identity theory and social identity theory. Social 
Psychology Quarterly, 63, 224-237.

Strickley, V. L. (2009). Veterans on campus. Little Falls, MN: PaperClip Communications.

Stryker, S., \& Serpe, R. (1982). Commitment, identity salience, and role behavior: Theory and research example. In W. Ickes \& E.S. Knowles (Eds.) Personality, roles, and social behavior (pp. 199-218). New York: Springer-Verlag.

Tai, R. H., \& Sadler, P. M. (2001). Gender differences in introductory undergraduate physics performance: University physics versus college physics in the USA, International Journal of Science Education, 23(10), 1017-1037.

Thompson, M. (1997). Toward a balanced adult education historiagraphy: The case of women in the histories and literature. PAACE Journal of Lifelong Learning, 6, $41-58$.

Tinto, V. (1975). Dropout from higher education: A theoretical synthesis of recent research. Review of Educational Research, 45(1), 89-125.

Tisdell, E. J. (2000). Feminist pedagogies. In E. Hayes \& D. Flannery (Eds.), Women as learners: The significance of gender in adult learning. San Francisco, CA: JosseyBass.

Tisdell, E. J. (2001). Feminist perspectives on adult education: Constantly shifting identities in constantly changing times. In V. Sheared \& P.A. Sissel (Eds.) Making spaces: Merging theory and practice in adult education (pp. 271-285). Westport, CT: Bergen \& Garvey.

U.S. Department of Veterans Affairs. (2007). Women veterans: Past, present, and future. 
Washington D.C.: U.S. Department of Veterans Affairs.

van Manen, M. (2003). Researching Lived Experience: Human science for an action sensitive pedagogy. Toronto, Ontario: Transcontinental Printing, Inc.

Van Rooy, D., Van Overwalle, F., Vanhoomissen, T., Labiouse, C., \& French, R. (2003). A recurrent connectionist model of group biases. Psychological Review, 110, $536-563$.

Ward, A. (2011). Bringing the message forward: Using poetic re-presentation to solve research dilemmas. Qualitative Inquiry 17, 355.

Wolf, M. A. (2009). Older adult women learners in transition. New Directions for Adult and Continuing Education, 122, 53-62.

Woodring, P. (1981). Writing about education. The Phi Delta Kappan, 62(7), 500-501.

Yin, R. K. (2011). Qualitative research from start to finish. New York, NY: Guilford Press.

Zaytoun, K. (2006). Theorizing at the borders: Considering social location in rethinking self and psychological development. NWSA Journal, 18(2), 52-72.

Zhou, M., \& Xiong, Y. S. (2007). The multifaceted American experiences of the children of Asian immigrants: Lessons from segmented assimilation. Ethnic and Racial Studies, 28(6), 1119-1152. doi: 10.1080/01419870500224455 


\section{APPENDIX A: Participant Invitation Letter}

Requestor: Natesha L. Smith, doctoral candidate (University of Louisville)

Population: Female Veteran Students (currently enrolled; expected enrollment for spring of 2012)

Communication Date: December 1, 2011

Purpose: To identify participants for dissertation research

Sender: nlsmit07@louisville.edu

Subject Header: Female Veteran Students

Message: My name is Natesha Smith and I am a doctoral candidate in the Counseling and Personnel Services program at the University of Louisville. As a female veteran, I am interested in how other female veteran students experience the transition from military to college. Specifically, I am concerned with exploring how the enculturation experiences of each of these environments (military and college) informs the identity of female veterans. I am seeking participants who have completely separated from the military (excluding Inactive Ready Reserve), who have completed at least one year of coursework post military to college transition, and whose military experience was on active duty. Participants of the study will be asked to engage in two interviews and to keep a reflective journal of the interviewing experience. At the conclusion of the study, each participant will receive a $\$ 30$ gift card to a place of their choosing from the provided list (i.e. Amazon.com, Target, Barnes \& Noble).

For more information, or to participate in this project, please contact Natesha L. Smith at (443) 307-7202, or nlsmit07@louisville.edu. 


\section{APPENDIX B: Informed Consent}

IRB assigned number: 11.0634

Investigator(s) name $\&$ address:

Natesha L. Smith, Co-Investigator

P.O. Box 17765

Louisville, KY 40217

Michael Cuyjet, Principal Investigator

Education and Counseling Psychology

University of Louisville

Louisville, KY 40292

Site(s) where study is being conducted: Old Dominion University, University of Louisville, University of Central Florida

\section{Introduction and Background Information}

This study, which focuses on better understanding the transition experiences of female veteran students, is being conducted under the direction of Dr. Michael Cuyjet (Professor, Principal Investigator) and Natesha L. Smith (Doctoral Student, Co-Investigator). You are invited to take part in this study because of your ability to contribute to the discussion of military to college transition as a female veteran student. Your participation in this study will last for approximately two months. Approximately 12 subjects will be invited to participate in this study.

\section{Purpose}

The purpose of this study is to explore the understood identity and enculturation experiences of female veterans transitioning from military to college.

\section{Procedures}

If you agree to participate in this study, you will be contacted to schedule two interviews. Prior to the start of the first interview you will be given time to complete the demographic questionnaire, approximately 15 minutes. Each interview should last between 1.5 to 2 hours. In addition, you will be asked to keep a reflective journal starting on the day of the first interview and ending one week after the second interview.

\section{Potential Risks}

There are no known risks to you for participating in this study.

\section{Benefits}

The information collected may or may not benefit you directly; however, the information learned in this study may help to inform the practices of student affairs professionals as they develop programs and services for female veteran students.

\section{Compensation}

You will be given a $\$ 30$ gift card (i.e. Amazon.com, Target, Wal-Mart, barnes \& Noble) at the conclusion of this study, for your time, inconvenience, or expenses while participating 
in this study. Inability to complete all components of the study will result in you receiving compensation at a prorated amount: $\$ 15$ gift card for completion of the demographic questionnaire and first interview; $\$ 25$ gift card for completion of the questionnaire and both interviews.

Because you will be paid to be in this study the University of Louisville must collect your name, address, social security number, ask you to sign a $\mathrm{W}-9$ form, and keep records of how much you are paid. We are required by the Internal Revenue Service (IRS) to collect this information. This information will be protected and kept secure in the same way that we protect your other private information. If you do not agree to give us this information, we cannot pay you for being in this study.

\section{Voluntary Participation}

Agreeing to participate in this study is completely voluntary. If you decide not to be in the study or if you decide to stop taking part at any time, you will not be penalized or lose any benefits for which you qualify as a student or a veteran.

\section{Confidentiality}

Your privacy will be protected to the extent permitted. If the results from this study are published, your name will not be made public nor will any digital image with clear identifying markers be made available to the public.

\section{Security}

The consent form with your signature will be stored separately from other identifying data and will maintained in a locked cabinet that is only accessible by the co-investigator. If permission is given, the audio recordings from the interview sessions will only contain the content of your narrative and not the explicit details of your identity. Permitted digital images containing identifiable markers will only be reviewed by the co-investigator. Permitted digital images without identifiable markers will be included in the published research project. After the interview recordings have been downloaded to the coinvestigator's personal computer, the file will be wiped from the recording device. All digital images will be deleted from the camera after being transferred to the coinvestigator's personal computer. Each transcription, audio recording, and digital image from the interviews will be kept on the password protected computer that is only accessible by the co-investigator.

\section{Contact Persons}

If you have any questions, concerns, or complaints about the follow up, please email or call Natesha L. Smith (Co-Investigator), nlsmit07@louisville.edu or 443-307-7202. You may also contact Dr. Michael Cuyjet (Principal Investigator), cuyjet@louisville.edu or 502-852-0628.

\section{Research Subject's Rights}


If you have any questions about your rights as a research subject, you may call the Human Subjects Protection Program Office at (502) 852-5188. You may discuss any questions about your rights as a research subject, in private, with a member of the Institutional Review Board (IRB). You may also call this number if you have other questions about the research, and you cannot reach the investigators, or want to talk to someone else. The IRB is an independent committee made up of people from the University community, staff of the institutions, as well as people from the community not connected with these institutions. The IRB has been reviewed this research study.

\section{Concerns and Complaints}

If you have concerns or complaints about the research or research staff and you do not wish to give your name, you may call 1-877-852-1167. This is a 24 hour hot line answered by people who do not work at the University of Louisville.

\section{Acknowledgment and Signatures}

Your signature below means that you agree to participate in this study and agree to have the co-investigator contact you to discuss your experiences as a female veteran. This information will be compiled and presented to the co-investigator's dissertation committee. You are not giving up any legal rights by signing this informed consent document. You will be given a signed copy of this consent form to keep for your records.

//SIGNATURES//

\section{LIST OF INVESTIGATORS}

Natesha L. Smith, Co-Investigator

Michael J. Cuyjet, Primary Investigator
PHONE NUMBERS

443-307-7202

502-852-0628 


\section{APPENDIX C: Proposed Interview Protocol}

\section{Narrative Interviewing}

I have identified seven areas of discussion within the four main stages (i.e. moving within the military, moving out of the military, moving into college, moving within college) of the participant's life story surrounding her transition to college. Those areas are the focus of the developed protocol and were developed from my personal experience of transition, discussions with three other female veterans, and the current literature on female veterans. Each of the listed seven areas will be discussed at some point during the two interview sessions. I have also included a list of possible journal discussion points I will provide to each participant.

Interviewer: Natesha Smith

\section{Interview Protocol}

Interviewee:

Interview time planned: Approximately 1.5 hours

Interview place: Interviewee's Choice

Recording: Digital voice recorder

Opening Comments (1st Interview): As previously indicated in our email/telephone communications, I am conducting a research study with female veterans who have transitioned from the military to college. I would like to thank you for your participation. Content from the time we spend together will be included in my doctoral dissertation. However, your name will not be used and your narrative will remain confidential. Although you have signed the consent form to participate in this study, you may choose to withdraw your consent at any time. Do you have any concerns or questions before we begin?

\section{Interview Discussion Areas:}

1. Transition: Discuss the life transition that led to your decision to enter college. Length of time since the transition, type of experiences/responses encountered during and after the transition, other relevant information or reflections of the transition experience

2. Family: Describe your family's involvement in your life choices.

Messages from family (education, military, identity/role, expectations)

3. Military Environment: What was your life like in the military? Activities engaged in (social and training related); interactions with other servicemembers of equal or lesser rank; interactions with superiors, expectations (self and institution); motivation for pursuit; meaning of the experience; understood place within the organization; experience of being female in the military; achievements of areas of discouragement

4. Higher Education Environment: What has your life been like as a student? 
Activities engaged in (social and academic related); interactions with peers; interactions with staff/faculty; expectations (self and institution); motivation for pursuit; meaning of the experience; understood place within the organization; experience of being female in higher education; achievements or areas of discouragement

5. Purpose/Life Mission: How would you describe your life's purpose?

Understood life mission; congruence between understood mission and the military; congruence/incongruence between understood mission and new career choice; higher education's connection to life mission

6. Personal: Describe your primary identity before college and after enrollment. Sense of belonging (in the military and higher education settings); noticeable identity or behavioral changes (self-reflection, family, friends); describe roles (as student and as a service-member); restrictions felt or experienced in expressing yourself; discuss sources of support

7. Decision Making: What is your process of decision-making?

Biggest influences in major life decisions and choices (e.g. circumstances, mentors, family); reflection on choices made (regrets or celebrations)

\section{Possible Journal Prompts}

Feelings and thoughts raised after the interview

Describe the experience of sharing your story. What did it feel like?

Process of transition and acclimation

Reactions of others to your life choices (e.g. leaving the military, pursuing your degree) 


\section{APPENDIX D: Example of Poetic Representation in Research}

The following poetic representation was taken from an article describing the experience of being a female soldier and was formed in response to the author's research question (Hicks, 2011):

\section{So, Research Question 1. What is it like to be a female soldier?}

Being a female soldier is being treated like an 18 -year- old boy by nostalgic elders. They see me in uniform and ask how my folks are doing and if I miss home or if I've got a sweetheart and I look down at my 27 -year-old educated, mature, female body and look back up at them in disbelief.

Being a female soldier is always being trouble.

Being a female soldier is making sure not to cause trouble; to be the girl that ruins everything.

Being a female soldier is a built in assumption of many that you could not have done what a man has done and you could not possibly have given the same that a man gave. Being a female soldier is reveling in a different world where merit matters and you can become a leader.

Being a female soldier is a lot like being a soldier, most of the time, but sometimes, it isn't.

Being a female soldier is being called a cunt in basic training and a dumb slut after you are promoted to noncommissioned officer.

Being a female soldier is listening to the Colonel that works in the same room chortle about sexual harassment allegations involving Arnold Schwarzenegger, crowing "That ugly bitch is lucky he touched her!"

Being a female soldier is having the same Colonel notice your reaction, and say

"Don't you ever glare at me like that again, do you understand?"

Being a female soldier is having to tell that Colonel "Yes sir."

Being a female soldier is learning that there is nothing you can't do, only things you don't want to do, and things that people won't let you do. Being a female soldier is being in charge of men.

Being a female soldier is having people of color in charge of you.

Being a female soldier is performing a type of drag. And liking it.

Being a female soldier is competing and winning.

Being a female soldier is handing flowers to the incoming Commander's spouse -regardless of the gender of either of you.

Being a female soldier is the same as being a male soldier. 


\begin{tabular}{|c|c|c|c|c|c|c|c|c|c|}
\hline Shared Narrative & Orpah & Lily & Sophia & Tanumen & Annie & Lala & Alyese & Jennifer & है. \\
\hline $\begin{array}{l}\text { Belonging and } \\
\text { Unsupported }\end{array}$ & $x$ & $x$ & $x$ & $x$ & $x$ & $\begin{array}{l}\text { belonging, but } \\
\text { felt supported }\end{array}$ & $x$ & $x$ & $\vec{\Phi} \underset{8}{*}$ \\
\hline Discovering Mission & post military & post military & military & pre-military & post-military & post-military & post-military & post-military & है \\
\hline \multicolumn{9}{|l|}{ Authenticity } & \\
\hline $\begin{array}{l}\text { Third to Fourth order } \\
\text { Meaning-Making }\end{array}$ & $\mathrm{x}$ & & & 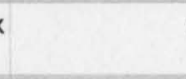 & & third order & & $x$ & 官产. \\
\hline \multicolumn{9}{|l|}{ Regaining Control } & ᄋే \\
\hline thru Relationships & & $\mathrm{x}$ & $\mathrm{x}$ & & & & $\mathrm{x}$ & & ఠ \\
\hline \multicolumn{2}{|l|}{ thru Education $x$} & & & $x$ & $x$ & $x$ & & $\mathrm{x}$ & $\vec{\Omega}$ \\
\hline Advocacy & $\begin{array}{l}\text { underrepresented } \\
\text { groups }\end{array}$ & $\begin{array}{l}\text { female } \\
\text { veterans }\end{array}$ & $\begin{array}{l}\text { female } \\
\text { veterans }\end{array}$ & $\begin{array}{l}\text { women in } \\
\text { modern day } \\
\text { slavery }\end{array}$ & $\begin{array}{l}\text { female } \\
\text { veterans }\end{array}$ & $n / a$ & $\begin{array}{l}\text { women and } \\
\text { children }\end{array}$ & veterans & 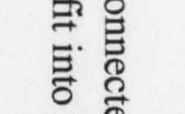 \\
\hline \multicolumn{9}{|l|}{ Engagement } & 2 \\
\hline Academically & & $\mathrm{x}$ & $\mathrm{x}$ & $\mathrm{x}$ & $\mathrm{x}$ & $\mathrm{x}$ & $\mathrm{x}$ & $\mathrm{x}$ & $0 \leq$. \\
\hline Socially & & $x$ & & & $x$ & & & $\mathrm{x}$ & 焉 \\
\hline & & & & & & & & & 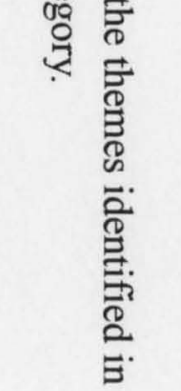 \\
\hline
\end{tabular}




\begin{tabular}{|c|c|c|c|c|c|c|c|c|c|c|}
\hline Shared Narrative & Alina & MacKayla & Penelope & Isabella & Kate & Abriana & Dasha & Hermione & Katniss & Sylvia \\
\hline $\begin{array}{l}\text { Belonging and } \\
\text { Unsupported }\end{array}$ & $\begin{array}{l}\text { belonging, but } \\
\text { felt supported }\end{array}$ & $x$ & $x$ & $x$ & $x$ & $x$ & $\begin{array}{l}\text { belonging; } \\
\text { didn't really } \\
\text { see a need for } \\
\text { the support }\end{array}$ & $x$ & $x$ & $\begin{array}{l}\text { belonging; but } \\
\text { felt supported }\end{array}$ \\
\hline Discovering Mission & post-military & post-military & post-military & military & military & $\begin{array}{l}\text { military and } \\
\text { post-military }\end{array}$ & military & post-military & post-military & military and pos \\
\hline \multicolumn{11}{|l|}{ Authenticity } \\
\hline $\begin{array}{l}\text { Third to Fourth order } \\
\text { Meaning-Making }\end{array}$ & 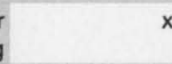 & 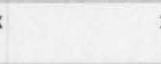 & $x$ & & fourth order & r & fourth order & $x$ & $\mathrm{x}$ & $x$ \\
\hline \multicolumn{11}{|l|}{ Regaining Control } \\
\hline thru Relationships & $x$ & $x$ & $x$ & $x$ & & & $x$ & & $x$ & $x$ \\
\hline thru Education & & & & & $x$ & $x$ & & $\mathrm{x}$ & & \\
\hline Advocacy & veterans & $\begin{array}{l}\text { female } \\
\text { veterans }\end{array}$ & $\begin{array}{l}\text { female } \\
\text { veterans }\end{array}$ & $\begin{array}{l}\text { women and } \\
\text { children }\end{array}$ & $\begin{array}{l}\text { underrepresented } \\
\text { groups }\end{array}$ & $\begin{array}{l}\text { female } \\
\text { veterans }\end{array}$ & $\begin{array}{l}\text { empowerment } \\
\text { of women }\end{array}$ & $\begin{array}{l}\text { female } \\
\text { veterans }\end{array}$ & $\begin{array}{l}\text { female } \\
\text { veterans }\end{array}$ & $\begin{array}{l}\text { veterans and } \\
\text { children }\end{array}$ \\
\hline \multicolumn{11}{|l|}{ Engagement } \\
\hline Academically & $x$ & $x$ & $x$ & $x$ & $x$ & $x$ & $\mathrm{x}$ & $x$ & $\mathrm{x}$ & $x$ \\
\hline Socially & & & & & $x$ & & $x$ & & & \\
\hline
\end{tabular}




\section{APPENDIX F: Snapshot of Remaining Narratives}

A brief portraiture of each participant, not included in Chapter Four, is presented here to provide additional background information for understanding the experiences of the female veteran participants.

Orpah

Unlike the other participants, Orpah served in two branches of service, Air Force and Navy. She initially joined the Air Force as a way to advance in her career as a nurse and separated when she no longer had an effective childcare plan if there was a deployment. After spending some time away from active duty service, she made a decision to join the Navy Reserve because she missed the camaraderie and unit support. However, she did not adjust well to the differences between the two organizations and separated after one year. As a Caucasian female, with a background in Pan-African Studies and Nursing, Orpah maintains a high degree of sensitivity to the power relationships that exist in organizational systems. Her narrative emphasized the power relationships at work in the military, higher education, and healthcare systems.

MacKayla

As the only Active Guard-Reserve (AGR) member of the study, MacKayla experienced the military as someone who existed between the worlds of active duty service member and the world of military reservist. Although not subjected to some of those experiences associated with active duty members, routine change of duty assignment, she still immersed herself in the culture of the active duty military member. She initially started her military career as an Army Reservist and then switched to AGR status. Her current role of student has served as an anchor for further exploration and renegotiation of her identity.

Isabella

Having been medically retired from the Air Force at the age of 23, Isabella is still trying to recover from the separation and understand her identity a part from the military. She is married to an active duty service member, but refuses to attach the label of military spouse to any aspect of her identity. The eldest of five, Isabella routinely referred to herself as the responsible and sensible one of her siblings and acknowledges a strong desire to serve as a role model for them. However, her narrative is marred by grief over the loss of a child and then a miscarriage a year later. I make the distinction because of the amount of grief she expressed during the interview. To achieve some sense of closure, Isabella and her husband created small cards to acknowledge the loss (Image 1.2)

Her thoughts are consumed with becoming a mother and during the course of both interviews she articulated the many ways she is still attempting to move beyond her previous experiences. During our interviews, Isabella informed me she was pregnant; which shifts her from one between space to another. Instead of grappling with who she wants to become compared to who the military wants her to become, she is now 
grappling with wanting to solely focus on motherhood or determining if all of her focus should go towards pursuing a career as a Marine Biologist.

Image 1.2

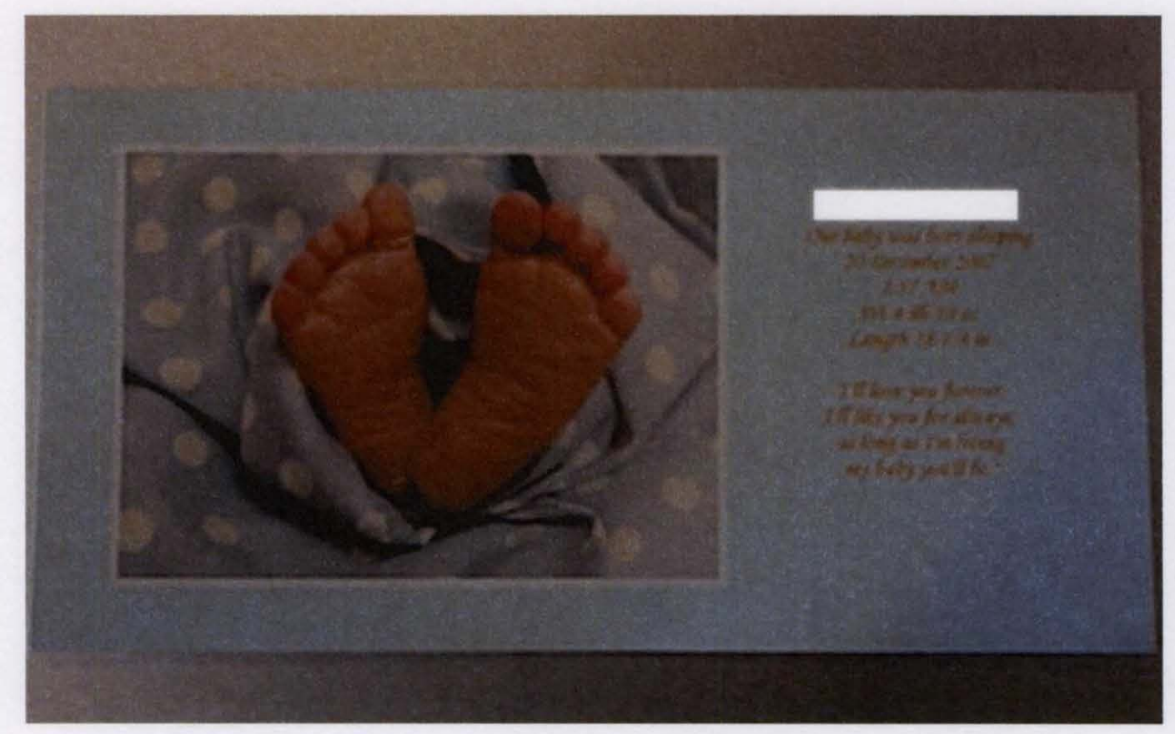

\section{Hermione}

Hermione is currently working on her undergraduate degree in English. In her early 30 s, a military spouse and mom with one young daughter, she served in the Navy for eight years prior to pursuing her undergraduate education. With an identity firmly situated in her role as mother, she chose to wait until separating from the military to have a child. Since her separation from the Navy, she has experienced difficulty in determining what her role is in context to the civilian world. After reflecting on what she considers to be her life mission, she has began the process of identifying herself in relation to her intended career of Secondary Education teacher. She has been inspired by opportunities to explore her understanding of self while in the higher education environment.

\section{Kate}

Kate's narrative highlights her struggle with the perceptions of others and the labels placed on individuals. She spends a great deal of time discussing her identity as being holistic and relational; not a fragmented self understood through roles or other socially constructed factors. Her understanding of self is constant and according to her has remained unchanged by her military and higher education experiences. Although she believes that her identity has been shaped by her close relationships, she expressed that mostly her understanding of self stems from moments of introspection.

Annie

Annie's narrative is one of healing and recovery. From day one of active-duty service in the Navy, she struggled against military culture. Not one to leave her obligations unfulfilled, she attempted to learn how to successfully navigate the 
organization. She chose to silence her voice and keep her head down until the end of her service contract. After separating, she has chosen to use her negative experience of the military as motivation to assist other female veterans in the experience of transition from active to civilian. As part of moving beyond her experiences, she chose to turn her military uniforms into a tangible expression of transformation, combat paper (Image 1.3). Combat paper is paper made from various military uniforms. Her experiences in higher education have served as foundation for her journey of healing and have empowered her to explore ways of being and becoming within the educational community.

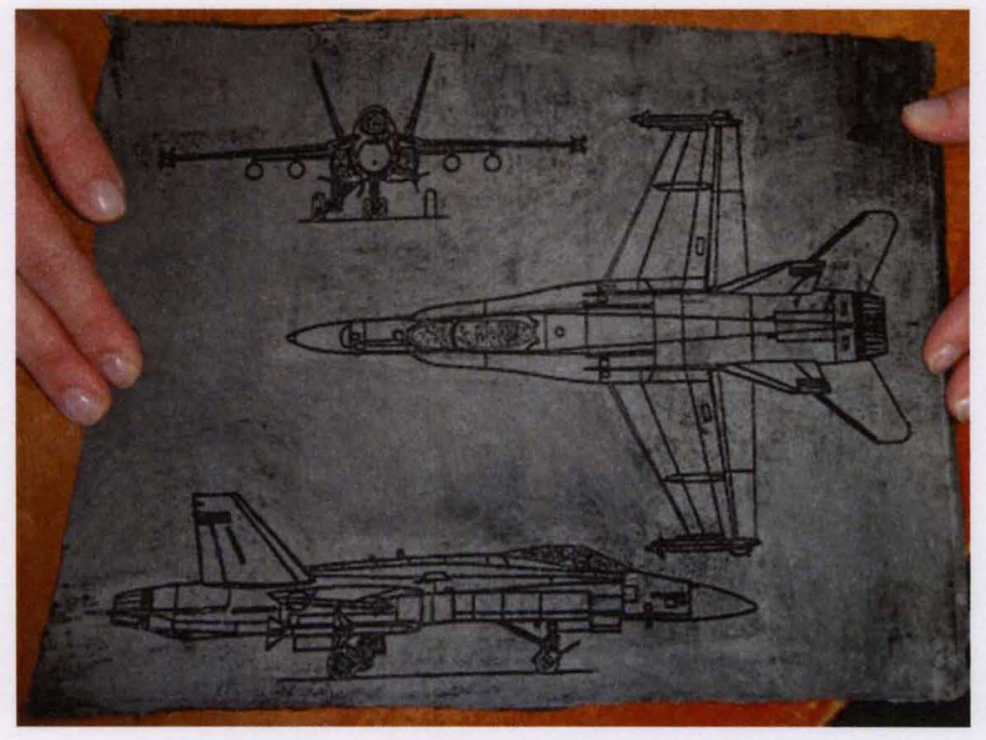

Image 1.3

Sophia

Sophia turned to the military in pursuit of a career. She entered knowing that she wanted to serve at least twenty years and fulfilled her intended goal in 2011. Although education was a strong part of military experience, Sophia did not complete her undergraduate degree while on active duty; a decision that she now regrets. She is currently in her final semester of college and is looking forward to continued employment in the federal government sector. As a wife and mother of two, Sophia has taken comfort in her family relationships and credits those relationships as helping her to move beyond her time in the military and grow in her understanding of self. She is woman of faith and is working to align her understood life mission with her new career pursuits and understood identity.

Sylvia

As the mother of three young children, Sylvia wanted to focus on the responsibilities of motherhood and decided to separate from the Air Force after six years of service. She initially joined as a way to fulfilling a purpose in my life, fulfilling the need to help others. With a strong commitment to service, Sylvia felt prepared for active duty life and welcomed the culture. An interest in assisting female veterans and stay-at- 
home parents increase their self-efficacy efforts regarding higher education, led to her pursuit of an Applied Learning and Education graduate degree. Through her higher education experiences she has been able to explore her identity beyond the roles that exist in her life.

Lala

Although Lala has been separated from the Navy for approximately seven years, she more than any other participant, is struggling with understanding herself a part from the military organization. She does not identify with the identity of female veteran and feels more comfortable with being identified as a sailor or seaman. She is pursuing an undergraduate degree as a way to make herself marketable for government positions. She sees her roles of wife and mother as being barriers to reentering military service and would consider rejoining once her children are older; there are currently 2 and 6 years of age. Her identity is rooted in her political values (i.e. Democrat) and religious beliefs (i.e. Buddhist). She strongly denies the influence of her gender as being an important factor in how she understands herself and her connection to the world around her.

Jennifer

Jennifer initially joined the military as a way to earn money towards her education. While serving on active duty she was able to complete the requirement for an associate's degree. After being medically discharged from the Navy, she decided to continue her educational pursuits by focusing on obtaining an English Linguistics degree. Jennifer pursued a degree similar to her job function in the military as a way to build on her experience and move into government contract work at the completion of her undergraduate education.

Unable to fulfill her duty requirements in the military, Jennifer has felt unsure and lost about how to renegotiate her identity. She grew up in a military family and expected it to be a part of her life for longer than 8 years. Her turn to higher education was an attempt to gain additional perspective, however, she believes that she is only placing her life on pause by attending. Jennifer's only solace is her relationship with her husband. She credits the relationship with providing an opportunity to explore new ways of making meaning and of understanding herself in relation to others.

Penelope

Penelope identified the Navy as a way out of what she considered to be a mediocre life in a small town; she also wanted to travel and earn money for college. With no intentions of becoming a career service member, she separated at the end of her contract. After separating, Jennifer was unsure of what direction to take next in life. She turned her focus towards creating a strong bond with her new husband and begin to explore ways of being that would help her to understand her role outside of the military. About a year after her separation, she decided to pursue a degree in dental hygiene. 


\section{Katniss}

Wanting to see the world, Katniss decided to pursue a twenty-year career in the Navy. However, after serving for only seven years, she felt forced to separate in order to care for her two children and move forward with a relationship with someone who was not affiliated with the military. Although Katniss made this decision seven years ago, she still feels some regret and wishes to one day reenter military service. She has spent her time in higher education exploring her identity outside of the military and improving her understanding of self in relation to greater social contexts.

Alina

Now attending her fourth institution since being medically discharged from the Navy in 2005, Alina is in her final semester of study. She is eagerly awaiting graduation so that she can move closer to her fiance, who currently lives in a different state. She credits her relationship with him as being a great source of support in encouraging her to complete her educational goals. Although excited about receiving her degree in biology, she is more focused on what the completion of her degree program represents; that she can now reunite with her significant other.

The source of Alina's difficulty in identifying a plan that she could commit to regarding her education was the effect of her separation from the military on her understood identity. She had no intentions of separating from the military; she wanted to retire and plans of serving beyond even the twenty year requirement. One of the artifacts shared during our interviews was of a coin (Image 1.4) she received that inspired her to make a commitment to serving until retirement.
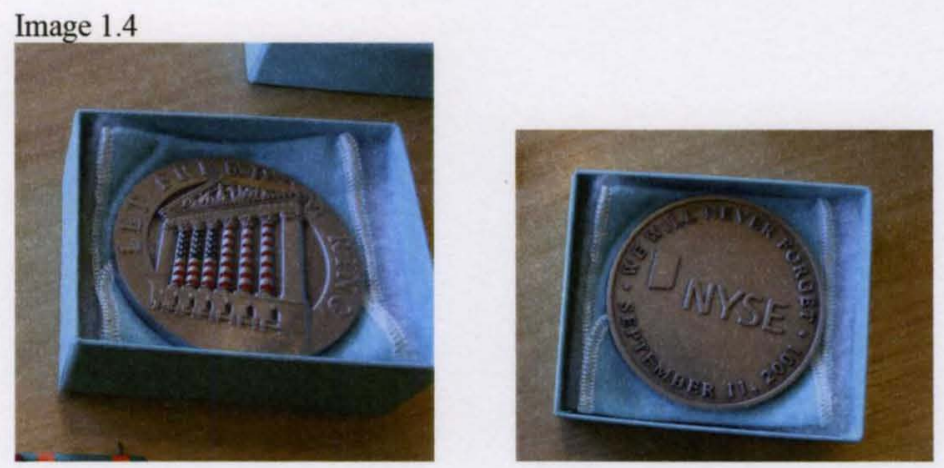


\section{CURRICULUM VITAE}

P.O. Box 17765

Phone: 443-307-7202

\section{Education}

Expected May 2012

Doctor of Philosophy

May 2008

Master of Arts

May 2003

Bachelor of Arts

\section{Natesha L. Smith}

Louisville, KY 40217

Email: nlsmit07@louisville.edu

University of Louisville, Louisville, KY Counseling and Personnel Services

Specialization: College Student Personnel

Asbury Theological Seminary, Wilmore, KY

Counseling

University of Southern Mississippi, Hattiesburg, MS

Criminal Justice

\section{Research Interests}

- Career development of transitioning military personnel and ethnic minorities

- Socialization of female graduate students of color, emphasis on mentoring programs

- Interpretations of nonverbal communication cross culturally

\section{Professional History}

University of Louisville, Louisville, KY

January 2011 - December 2011

College Student Personnel, Educational and Counseling Psychology

Teaching Assistant

Responsible for assisting in teaching class sessions and uploading/managing course content in Blackboard system. Assisted in developing syllabi and instruction materials for graduate level courses (i.e. Student Subcultures, Student Affairs Programs, Policies and Practices, and Topical Seminar: Minority Serving Institutions). Provided grades and feedback on classroom assignments to enrolled students.

University of Louisville, Louisville, KY

September 2009 - July 2011

Office of Military and Veteran Student Services

Graduate Assistant/Intern

Responsibilities included assisting in the enhancement of transition services for military and veteran students, to include reviewing military transcripts, providing academic advising/counseling, and discussing eligibility and application process for VA benefits. 
Developed and implemented outreach services to monitor students' academic progress each semester. Conducted evaluations of office programs and services. Assessed the needs of the veteran and military student population through various measures (i.e. focus groups, interviews, surveys). Served as a mentor to the University Veterans Organization (UVO) and assisted in the creation of programs that encouraged student integration into the campus community (i.e. Career Transition Series, female veteran student luncheon).

University of Louisville, Louisville, KY

May 2010 - August 2010

Workforce Leadership, ELFH

Teaching Assistant

Assisted in teaching undergraduate workforce development course. Researched various issues related to adult learning strategies and online teaching formats. Developed digital and audio course content presentations for weekly upload into Blackboard Tegrity system. Facilitated class discussions through online Blackboard system. Constructed and graded mid-term and final exams; designed tracking system for all graded assignments.

University of Louisville, Louisville, KY

August 2009 - July 2010

Dean of Students Office

Graduate Assistant

Assisted both the Dean of Students and the Assistant Dean of Students in supporting initiatives, programs, and services for students and the campus community. Planned, developed, and provided training for the Student Conduct Hearing Council, using methods such as classroom training, demonstrations, and workshops. Researched and developed reports on current best practices for student conduct services. Developed educational outreach programs for student conduct process in collaboration with multiple campus offices. Served as a conduct officer by providing assistance with non-academic conduct violations. Served on the University's Student Care Team and provided followup assistance to students interacting with other team members.

Centre College, Danville, KY

July 2008 - July 2009

Career Counselor

Offered culturally sensitive counsel to individuals in order to assist them in determining and reaching career goals. Instructed students individually and in groups, using various teaching methods such as lectures, discussions, and demonstrations. Adapted teaching methods and instructional materials to meet students' varying needs, abilities, and interests. Initiated contact and maintained communication with employers and organizations interested in hiring students for internships and full-time employment. Conducted on-site performance evaluations of students in various internship placements.

Georgetown College, Georgetown, KY

August 2007 - May 2008

Career Counselor

Primary responsibilities included teaching and organizing individual/group sessions on job readiness strategies. Facilitated the development of a career action plan for current 
students and alumni. Coordinated and organized a Graduate School Fair and Leadership Seminar for students on campus. Fostered relationships with the local employer community to provide students with opportunities to develop professional skills and integrate academic learning into their work environments.

Department of Defense (Army)

June 2003 - April 2006

Military Officer

Appointed to positions responsible for training, leadership, management, and supervision of over 200 personnel and 15 million dollars worth of equipment. Conducted

performance counseling that identified ways to improve and sustain professional behaviors, skills, and knowledge. Assessed section leaders' abilities and designed training to further increase skills and develop leadership knowledge. Analyzed training needs to develop new training programs. Conducted or arranged for ongoing technical training and personal development classes for soldiers. Planned, developed, and provided training and staff development programs, using methods such as field training and exercises, demonstrations, on-the-job training, and meetings.

\section{Publications}

Cuyjet, M. \& Smith, N. (submitted). Collaborative program development: A report on a U.S./Barbados cooperative program creation and implementation. GleaningsCaribbean Tertiary Level Personnel Association Publication.

Smith, N. L. (in progress). Career transition series: A model for transitioning veterans. Kentucky Journal for Higher Education Policy and Practice.

Smith, N. L. (revise and resubmit). Experiencing the journey: A narrative inquiry of the integration experiences of female veteran students. Journal About Women in Higher Education.

Smith, N. L. (2009). Policy that moves beyond employment toward worker resiliency. Career Convergence.

Smith, N. L. (2008). Military to civilian: Assisting transitioning Army personnel in navigating the civilian job market. Career Convergence.

Wilson, K., Smith, N., \& Berry, M. (in progress). 'I was able to complete my associate's degree on my first deployment':The espoused storylines about college attendance in Army materials. Journal of Higher Education

Wilson, K. B., Smith, N., Lee, A. L., \& Stevenson, M. (accepted, 2013). When the Army post is the campus: Understanding the social and academic integration of soldiers attending college. Journal of College Student Development.

Wilson, K. B. \& Smith, N. L. (accepted, 2012). Civilian educational practices with soldiers. New Directions for Adults and Continuing Education.

\section{Presentations}

Wilson, K., Smith, N., \& Berry, M. (2011). 'I Was Able to Complete My Associate's Degree on My First Deployment':The Espoused Storylines About College 
Attendance in Army Materials. Accepted research paper presentation for the Association for the Study of Higher Education.

Wilson, K. B. \& Smith, N. L. (2011). When the Army Post is the Campus: Understanding the Social and Academic Integration of Soldiers Attending College. Accepted presentation for the University of Louisville's Veteran Symposium, Louisville, $\mathrm{KY}$.

Carr, T. \& Smith, N. (2011). So, We Have Veteran Services. Now What? Accepted presentation for the American College Personnel Association, Baltimore, MD.

Smith, N. L. (2010). Complexities of Culture: Impact of Transition from Military to College on the Gender Identity of Female Veterans. Accepted poster presentation for the Association for the Study of Higher Education, Indianapolis, IN.

Smith, N. L. (2010). Career Development: An Exchange of Ideas. Invited presentation for Barbados Community College, St. Michael, Barbados.

Smith, N. L. \& Carr, T. (2010). Enhancing Your Veteran Student Organization. Invited presentation for the University of Louisville's Veteran Symposium, Louisville, $\mathrm{KY}$.

Smith, N. L. \& Carr, T. (2010). Career Transition Series: A Model for Transitioning Veterans. Accepted presentation for the College Personnel Association for Kentucky (CPAK), Louisville, KY.

Johnson, J., Dolan, D., \& Smith, N. (2010). Student Conduct: A Means to Enhancing Critical Thinking. Accepted presentation for the College Personnel Association for Kentucky (CPAK), Louisville, KY.

Smith, N. L. (2008). Networking Strategies for Career Success. Invited presentation for Kentucky Phi Beta Lambda Conference, Louisville, KY.

Funded Research, Fellowships, and Awards

Dissertation Completion Award, School of Interdisciplinary and Graduate Studies, 2012 Grant funded by the College of Education and Human Development's Research and Faculty Development Committee, \$3000. 2011-2012.

Grant funded by the National Association of Student Personnel Administrator's Research Foundation, \$6000. 2011-2012.

Southern Regional Education Board (SREB) Doctoral Scholar, Awarded 2009

Career Convergence Recognition Award (2009) for published article, National

Association of Career Development (NCDA)

Golden Key International Honour Society Member (2009)

\section{Professional Affiliations and University Activities}

Graduate Student Representative, NASPA Kentucky Advisory Board 2010-present ACPA, American College Personnel Association 2010-present

AFS, Armed Forces \& Society 2010-present

ASHE, Association for the Study of Higher Education

2010-present

NASPA, National Association of Student Personnel Administrators

2008-present

NCDA, National Career Development Association, Government Relations 2007-present 